Universidad de Lima

Facultad de Ingeniería y Arquitectura

Carrera de Ingeniería Industrial

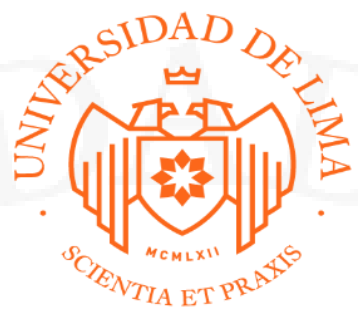

\title{
ESTUDIO DE PREFACTIBILIDAD PARA LA INSTALACIÓN DE UNA PLANTA DE FABRICACIÓN DE PRENDAS MÉDICAS DESECHABLES
}

Trabajo de investigación para optar el título profesional de Ingeniero Industrial

\section{Cinthia Veronica Cabrera Guerrero Código 20110198}

\section{Andrea Gabriela Talavera Delgado \\ Código 20111229}

\author{
Asesor \\ José Francisco Espinoza Matos \\ Lima - Perú
}

Noviembre del 2018 


\section{PRE-FEASIBILITY STUDY FOR THE INSTALLATION OF A DISPOSABLE MEDICAL MANUFACTURING PLANT}




\section{TABLA DE CONTENIDO}

RESUMEN EJECUTIVO ...........................................................................................1

ABSTRACT...................................................................................... ;Error! Marcador no definido.

CAPÍTULO I: ASPECTOS GENERALES............................................................... 3

1.1 Problemática de la investigación .............................................................................. 3

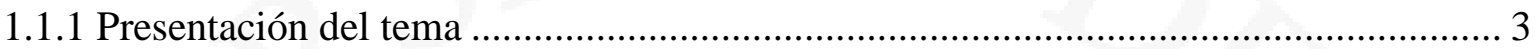

1.1.2 Descripción del producto o servicio propuesto........................................................... 3

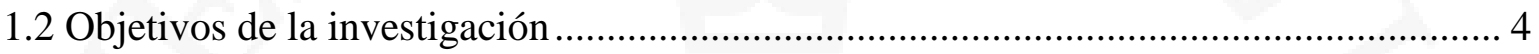

1.2.1 Objetivo general........................................................................................ 4

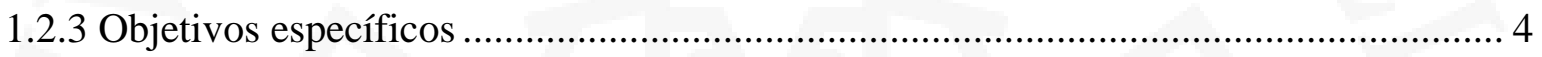

1.3 Alcances y limitaciones de la investigación .............................................................. 5

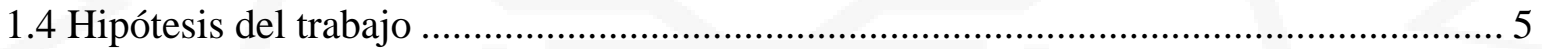

1.5 Justificación de la investigación ........................................................................... 6

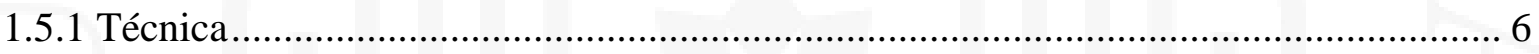

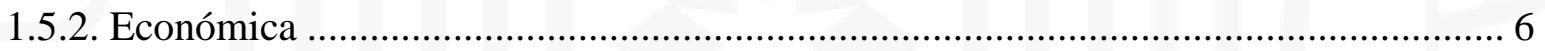

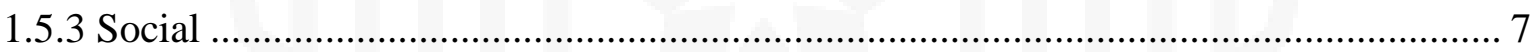

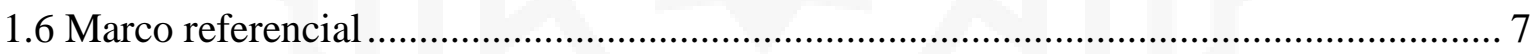

CAPÍTULO II: ESTUDIO DE MERCADO ...................................................................... 10

2.1 Aspectos generales del estudio de mercado ............................................................. 10

2.1.1 Definición comercial del producto ........................................................................ 10

2.1.2 Principales características del producto .............................................................. 11

2.1.3 Determinación del área geográfica que abarcará el estudio ....................................... 12

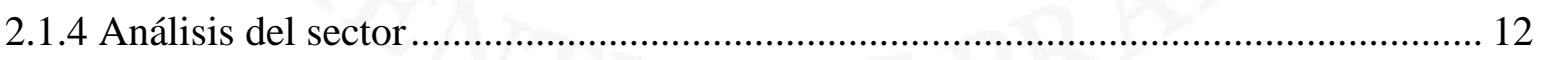

2.2 Determinación de la metodología que se empleará en la investigación de mercado..... 15

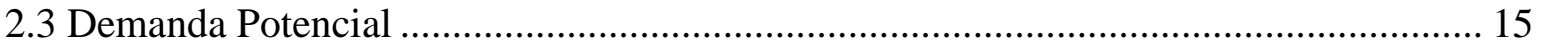

2.3.1 Patrones de consumo: incremento poblacional, consumo per cápita.......................... 15

2.3.2 Determinación de la demanda potencial ................................................................... 24

2.4 Determinación de la demanda en base a fuentes secundarias o primarias...................... 26

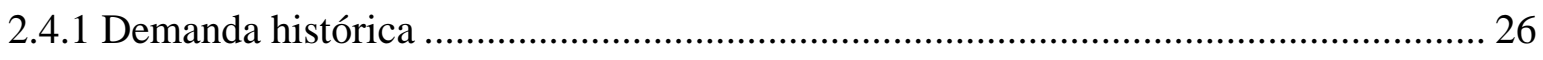


2.4.2 Demanda mediante fuentes primarias..................................................................... 26

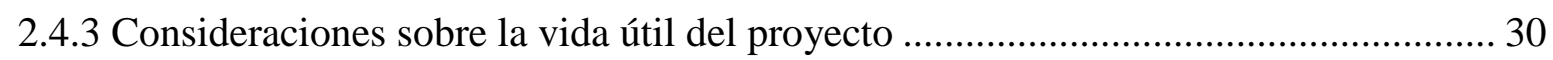

2.5.1 Empresas productoras, importadoras y comercializadoras .......................................... 30

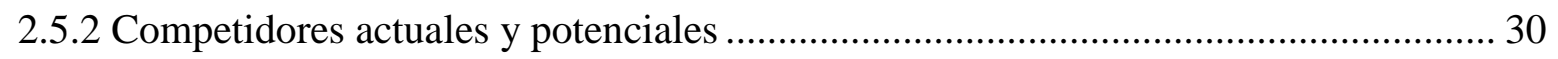

2.6 Definición de la Estrategia de Comercialización................................................................. 31

2.6.1 Políticas de comercialización y distribución ............................................................. 31

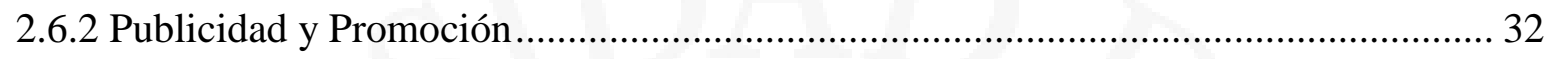

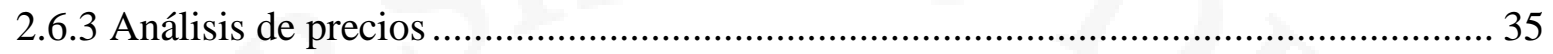

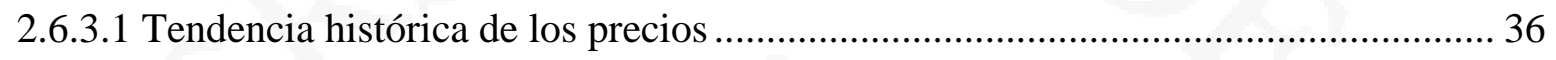

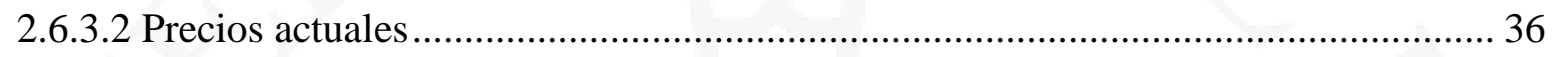

2.7 Disponibilidad de Materias Primas........................................................................... 37

2.7.1 Características de la Materia Prima ……………………............................................... 37

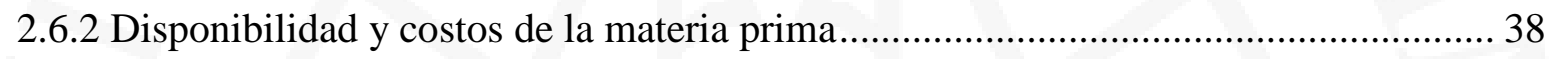

CAPÍTULO III: LOCALIZACIÓN DE PLANTA............................................................ 40

3.1 Identificación y análisis detallado de los factores de localización ................................... 40

3.2 Identificación y descripción de las alternativas de localización ...................................... 40

3.3 Determinación del modelo de evaluación a emplear ........................................................ 44

3.4 Evaluación y selección de la localización...................................................................... 44

3.4.1 Evaluación y selección de la macro localización........................................................ 44

3.3.2 Evaluación y selección de la micro localización ........................................................... 45

CAPÍTULO IV: TAMAÑO DE PLANTA ..................................................................... 48

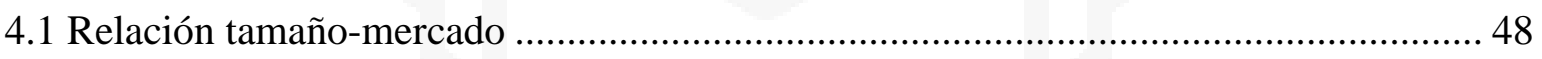

4.2 Relación tamaño-recursos productivos .................................................................. 48

4.3 Relación tamaño- tecnología ………………………………………………………. 50

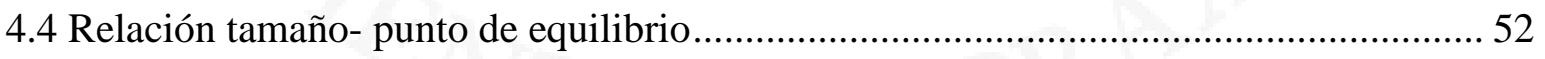

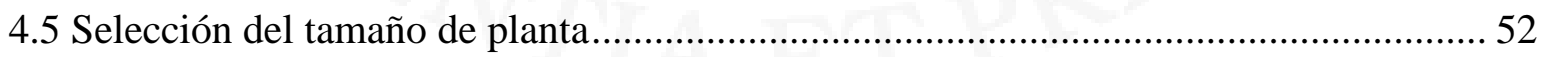

CAPÍTULO V: INGENIERÍA DEL PROYECTO.......................................................5 54

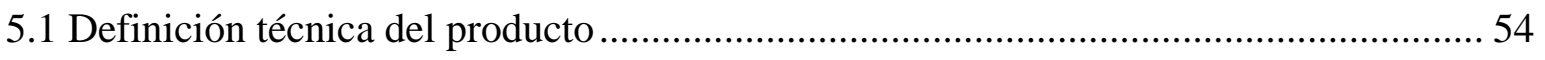

5.1.1 Especificaciones técnicas, composición y diseño del producto.................................... 54

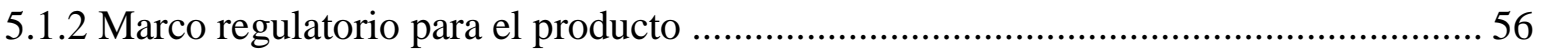

5.2 Tecnologías existentes y procesos de producción …………………………………....... 56 
5.2.1 Naturaleza de la tecnología requerida............................................................... 56

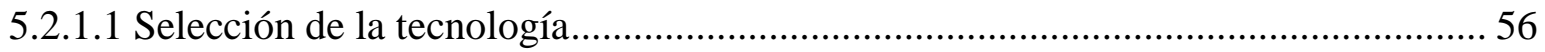

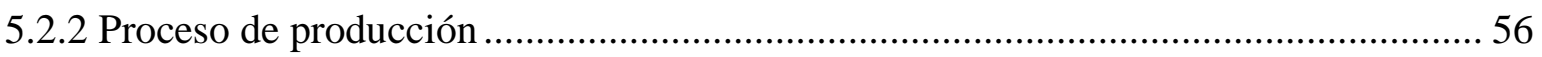

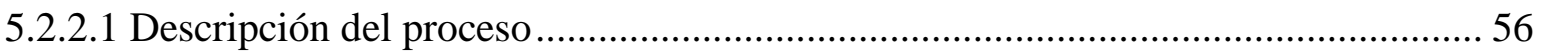

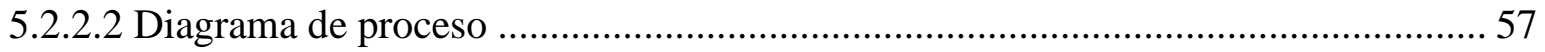

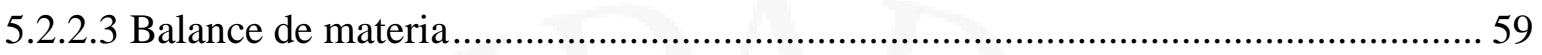

5.3 Características de las instalaciones y equipos...................................................... 59

5.3.1 Selección de la maquinaria y equipos ................................................................... 59

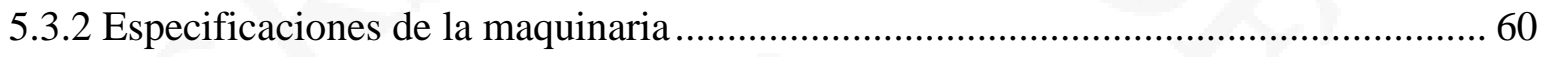

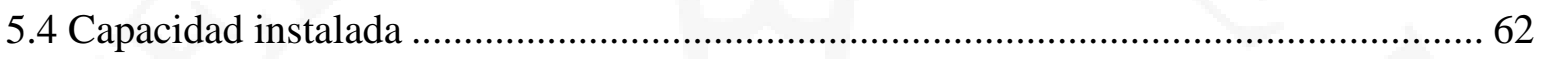

5.4.1 Cálculo detallado del número de máquinas y operarios requeridos ......................... 62

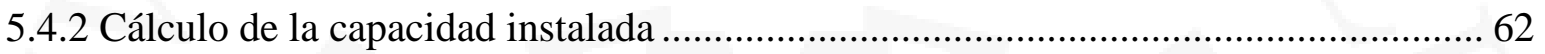

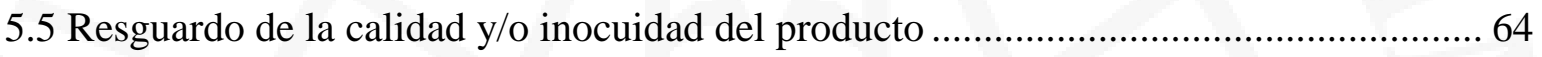

5.5.1 Calidad de la materia prima, de los insumos, del proceso y del producto................. 64

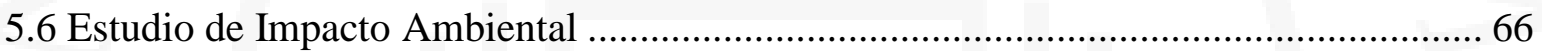

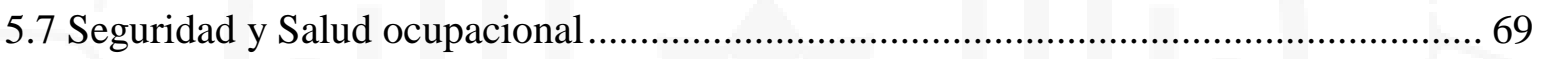

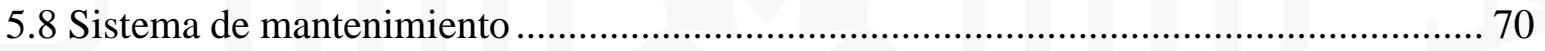

5.9 Diseño de la Cadena de Suministro ..................................................................... 71

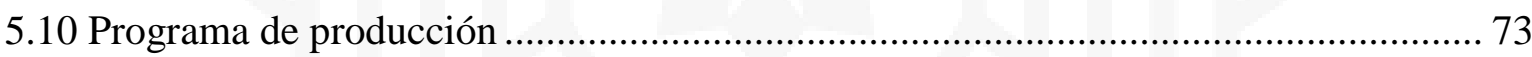

5.11 Requerimiento de insumos, servicios y personal indirecto.................................... 74

5.11.1 Materia prima, insumos y otros materiales ..................................................... 74

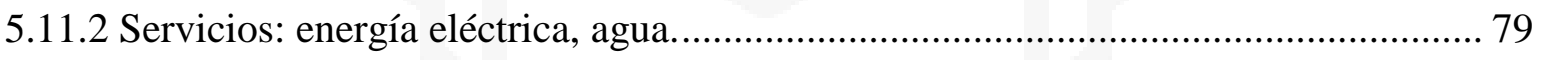

5.11.3 Determinación del número de trabajadores indirectos ........................................ 79

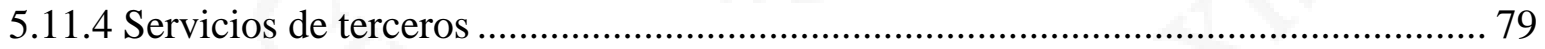

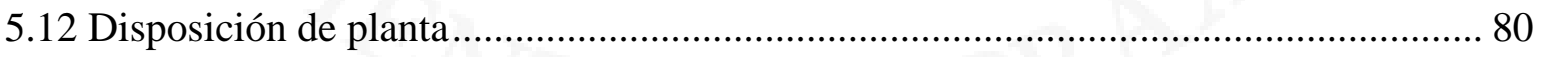

5.12.1 Características físicas del proyecto............................................................... 80

5.12.2 Determinación de las zonas físicas requeridas ................................................. 86

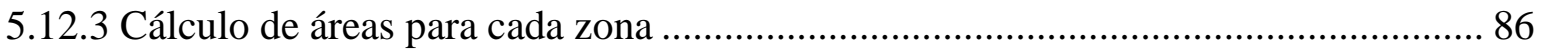

5.13.4 Dispositivos de seguridad industrial y señalización .......................................... 95

5.13.5 Disposición de detalle de la zona productiva..................................................... 95

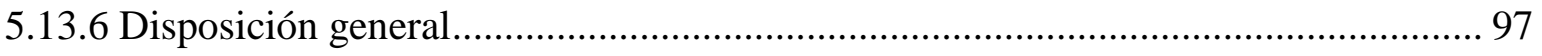


5.14 Cronograma de implementación del proyecto ................................................... 99

CAPÍTULO VI: ORGANIZACIÓN Y ADMINISTRACIÓN......................................... 100

6.1. Formación de la organización empresarial ......................................................... 100

6.2 Requerimientos de personal directivo, administrativo y de servicios ...................... 101

6.3 Esquema de la estructura organizacional ............................................................. 104

CAPÍTULO VII: PRESUPUESTOS Y EVALUACIÓN DEL PROYECTO.............. 105

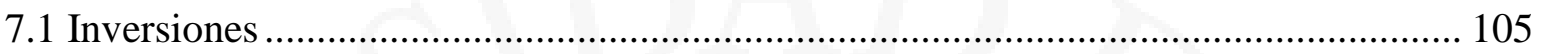

7.1.1 Estimación de las inversiones de largo plazo (tangibles e intangibles) ................... 107

7.1.2 Estimación de las inversiones de corto plazo (Capital de trabajo) .......................... 107

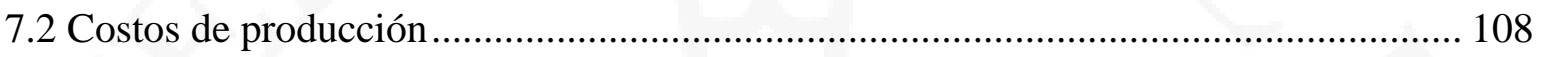

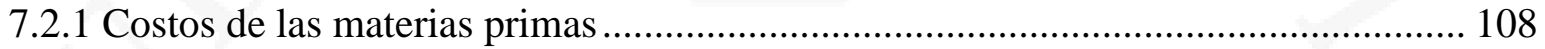

7.2.2 Costos de la mano de obra directa .................................................................. 112

7.2.3 Costo Indirecto de Fabricación .......................................................................... 112

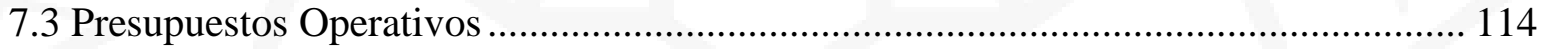

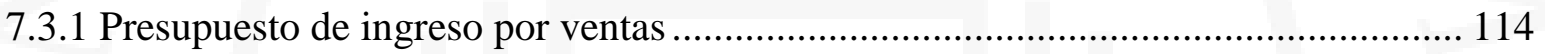

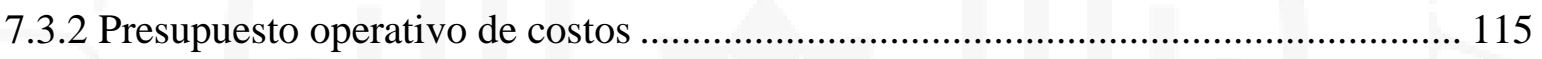

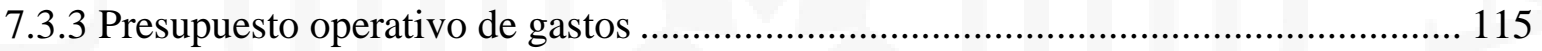

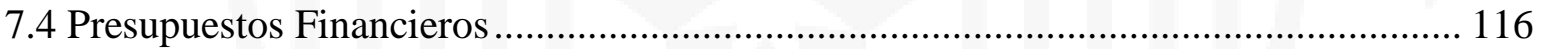

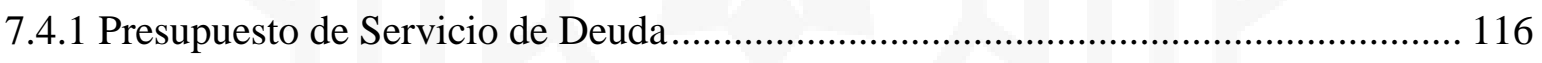

7.4.2 Presupuesto de Estado de Resultados .............................................................. 116

7.4.3 Presupuesto de Estado de Situación Financiera (apertura) .................................... 117

7.4.4.1 Flujo de fondos económicos ...................................................................... 118

CAPÍTULO VIII: EVALUACIÓN ECONÓMICA Y FINANCIERA ........................ 119

8.5 Evaluación Económica y Financiera..................................................................... 119

8.5.1 Evaluación económica: VAN, TIR, B/C, PR ..................................................... 119

8.5.2 Evaluación financiera: VAN, TIR, B/C, PR .................................................... 119

8.5.3 Análisis de ratios y indicadores económicos y financieros del proyecto ................. 120

8.5.4 Análisis de sensibilidad del proyecto...................................................... 121

CAPÍTULO IX. EVALUACIÓN SOCIAL DEL PROYECTO .................................. 125

9.1 Identificación de las zonas y comunidades de influencia del proyecto ..................... 125

9.2 Análisis de indicadores sociales ................................................................... 126 


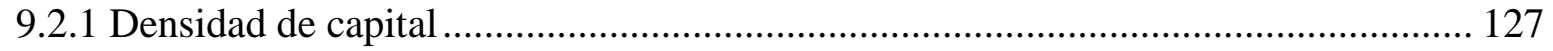

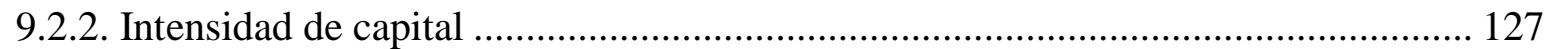

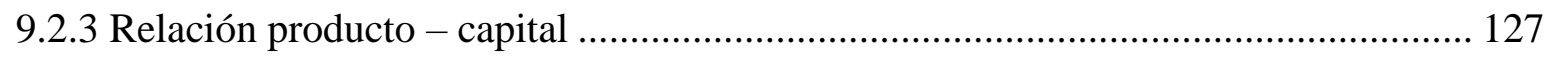

9.2.4. Productividad de la mano de obra................................................................. 127

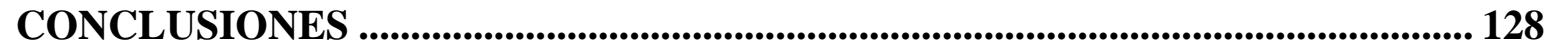

RECOMENDACIONES .................................................................................... 130

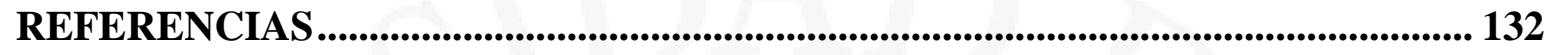

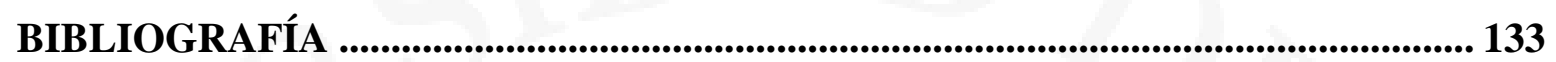




\section{ÍNDICE DE TABLAS}

Tabla 2.1 Nacimientos por tipo de procedimiento y por trimestre ................................. 16

Tabla 2.2 Nacimientos anuales por tipo de procedimiento.......................................... 17

Tabla 2.3 Necesidad anual para nacimientos por prenda y por procedimiento ................. 17

Tabla 2.4 Hospitalizaciones por trimestre ................................................................... 18

Tabla 2.5 Días de estancia promedio en EsSauld ........................................................... 19

Tabla 2.6 Necesidad trimestral de batas para hospitalizaciones ..................................... 19

Tabla 2.7 Necesidad anual de batas para hospitalizaciones........................................... 19

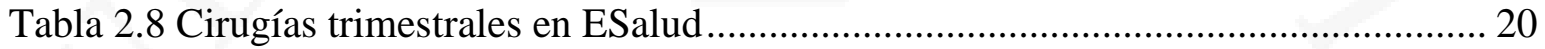

Tabla 2.9 Nacimientos en EsSalud .......................................................................... 21

Tabla 2.10 Ratio de conversión de EsSalud ................................................................. 22

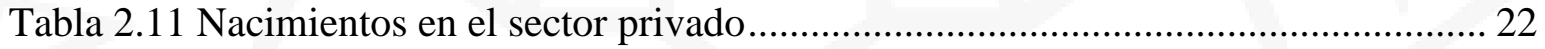

Tabla 2.12 Cirugías trimestrales en el sector privado................................................. 22

Tabla 2.13 Cirugías anuales en el sector privado ...................................................... 23

Tabla 2.14 Necesidad de batas anuales para intervenciones quirúrgicas ......................... 23

Tabla 2.15 Consultas médicas por trimestre .............................................................. 23

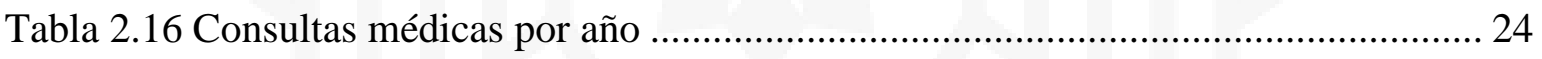

Tabla 2.17 Indicadores de radiodiagnóstico e imágenes ................................................ 24

Tabla 2.18 Necesidad anual de batas para consultas médicas ........................................ 24

Tabla 2.19 Dimensiones de una bata ....................................................................... 25

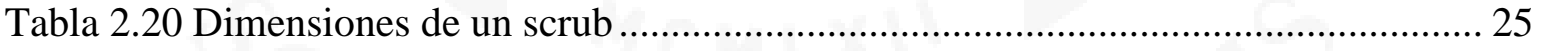

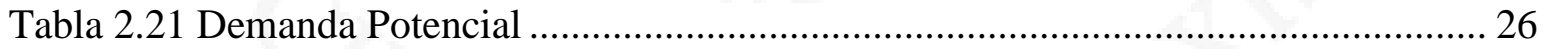

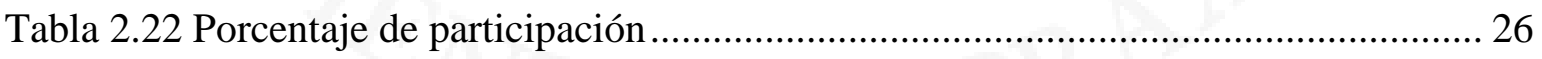

Tabla 2.23 Demanda del proyecto ......................................................................... 28

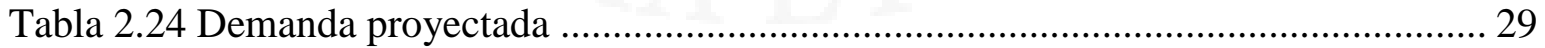

Tabla 2.25 Listado de proveedores de tela no tejida de polipropileno ............................. 39

Tabla 3.1 Puntuación de factores ................................................................................ 44

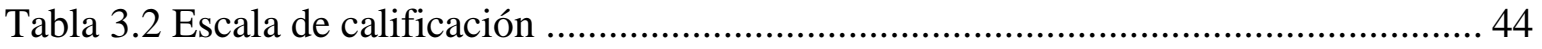

Tabla 3.3 Tabla de enfrentamiento y Tabla de Ranking de Factores .............................. 45 
Tabla 3.4 Tabla de enfrentamiento y Tabla de Ranking de Factores 47

Tabla 4.1 Demanda agregada proyectada ............................................................... 48

Tabla 4.2 Oferta de Materia Prima para Perú ................................................................. 49

Tabla 4.3 Cálculo de Tamaño- tecnología .................................................................. 51

Tabla 4.4 Cálculo Punto de Equilibrio....................................................................... 52

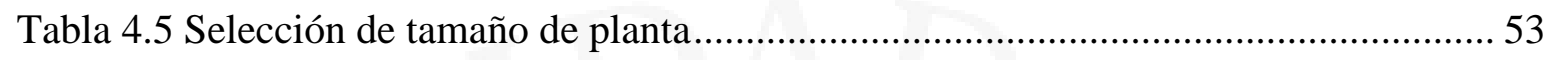

Tabla 5.1 Especificaciones técnicas de calidad del producto ......................................... 55

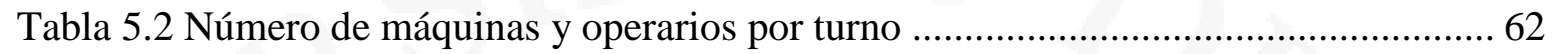

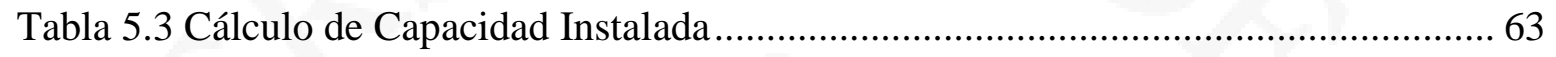

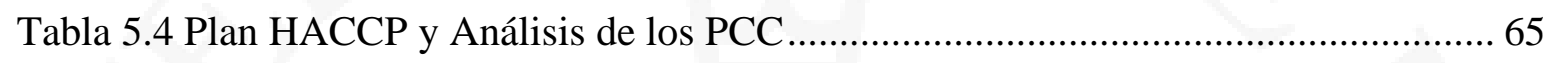

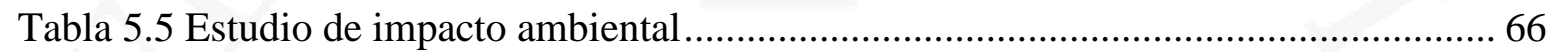

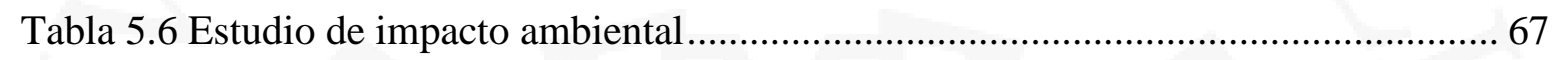

Tabla 5.7 Programa semestral de mantenimiento de máquinas y equipos ........................ 71

Tabla 5.8 Programa maestro de producción ................................................................ 73

Tabla 5.9 Programa maestro de producción semanal ................................................. 73

Tabla 5.10 MRP semanal de Batas ........................................................................ 75

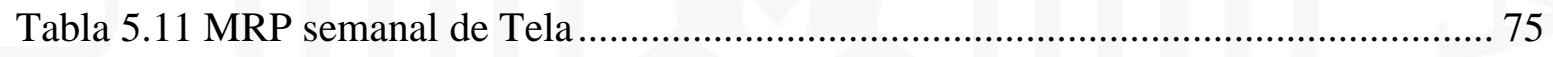

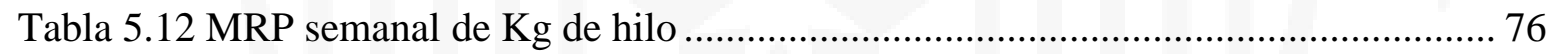

Tabla 5.13 MRP semanal de Unidades de Bolsas ........................................................ 77

Tabla 5.14 MRP semanal de elásticos .................................................................. 77

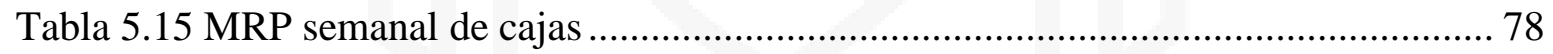

Tabla 5.16 MRP semanal de cajas ......................................................................... 78

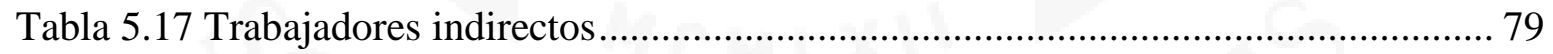

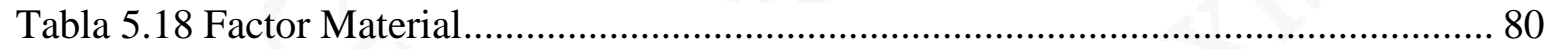

Tabla 5.19 Factor Movimiento ............................................................................. 81

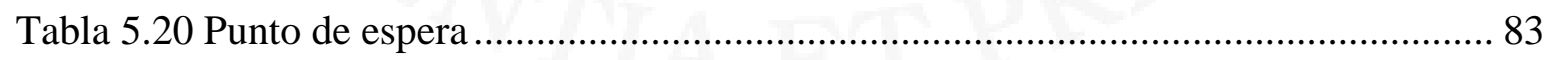

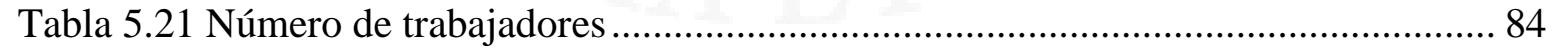

Tabla 5.22 Número mínimo de W.C.................................................................... 85

Tabla 5.23 Ingreso de fibras y salida de tela.......................................................... 87

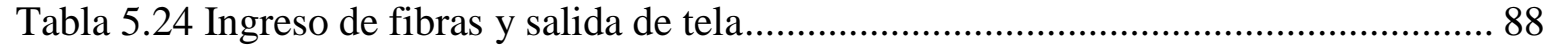

Tabla 5.25 Ingreso de fibras y salida de tela........................................................ 88 


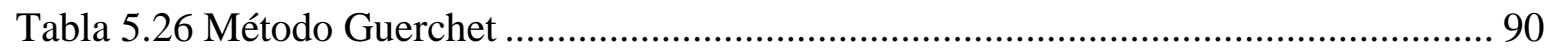

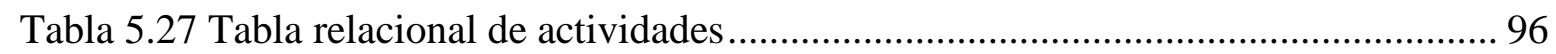

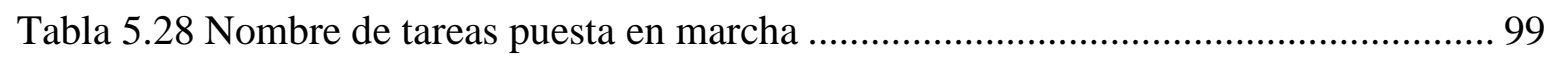

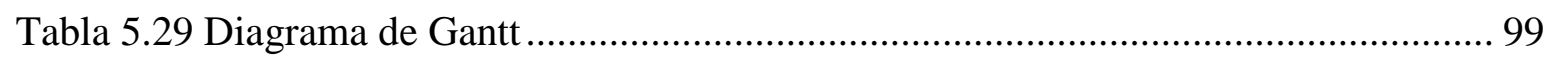

Tabla 6.1 Manual de Funciones Gerente General....................................................... 102

Tabla 6.2 Manual de Funciones de Jefes ....................................................................... 103

Tabla 6.3 Manual de Funciones de Supervisor............................................................... 103

Tabla 6.4 Manual de Funciones de Operarios ............................................................... 104

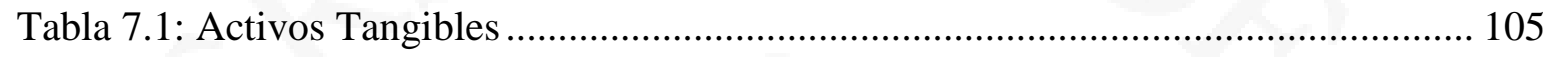

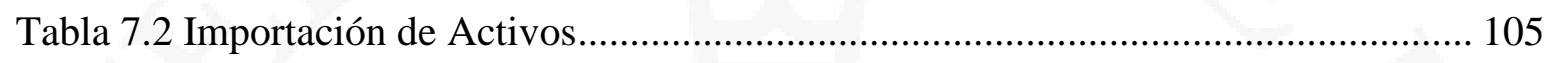

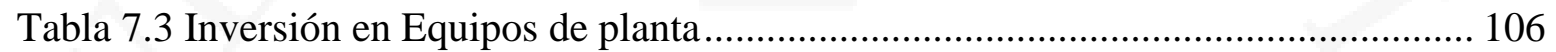

Tabla 7.4 Inversión en Muebles y enseres de oficina ......................................................... 106

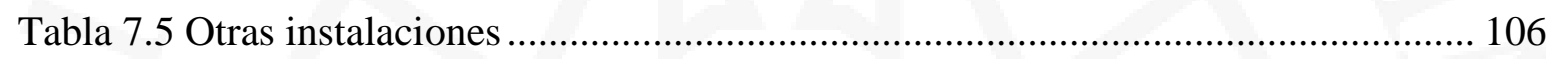

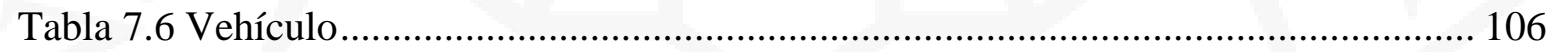

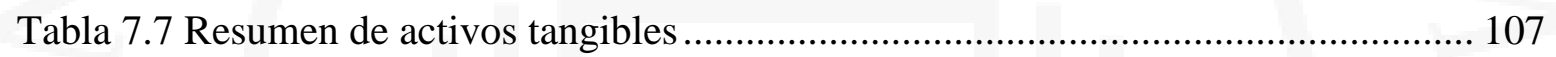

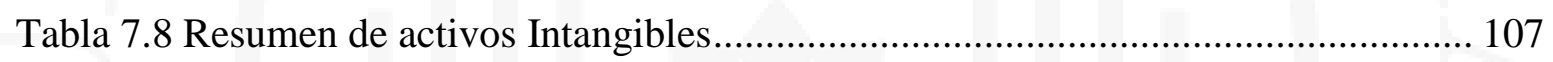

Tabla 7.9 Inversión según el uso y según dónde proviene .............................................. 107

Tabla 7.10 Inversión total según de donde proviene ....................................................... 108

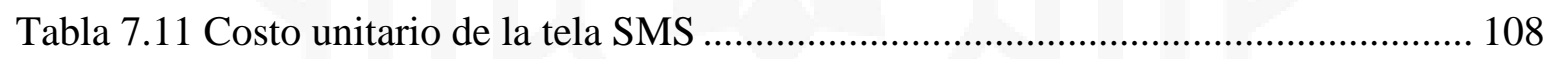

Tabla 7.12 Costo de importar la materia prima ……………............................................... 109

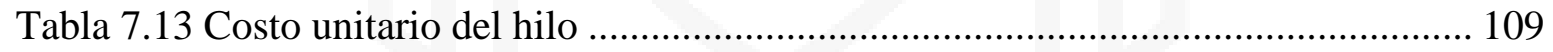

Tabla 7.14 Costo de importar la materia prima ……………............................................. 110

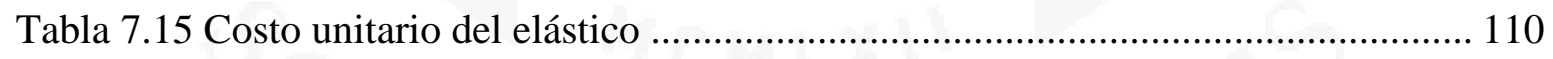

Tabla 7.16 Costo de importar la materia prima ………………........................................... 111

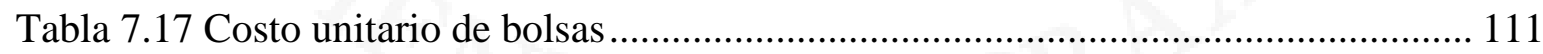

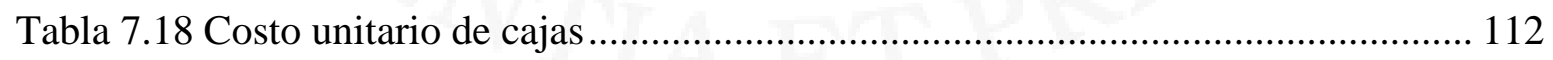

Tabla 7.20 Costo de mano de obra directa.................................................................... 112

Tabla 7.21 Costo de mano de obra indirecta ........................................................................ 113

Tabla 7.22 Costos indirectos de fabricación .................................................................... 113

Tabla 7.23 Gastos Administrativos y de Ventas................................................................ 113

Tabla 7.24 Costos Variables Unitario ............................................................................... 114 


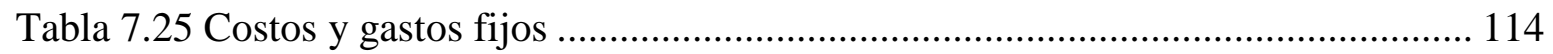

Tabla 7.26 Presupuesto de ingreso por ventas ......................................................... 114

Tabla 7.27 Cálculo de la amortización y depreciación................................................... 115

Tabla 7.28 Cálculo de costo de producción y venta. .................................................. 115

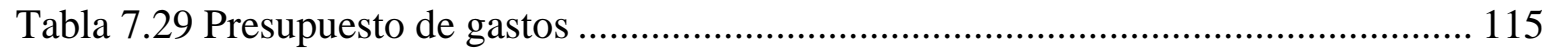

Tabla 7.30 Presupuesto de Servicios de Deuda .......................................................... 116

Tabla 7.31 Presupuesto de Estado de Resultados ........................................................ 116

Tabla 7.32 Presupuesto de Balance de Apertura ......................................................... 117

Tabla 7.33 Flujo de fondos económico................................................................. 118

Tabla 7.34 Flujo de fondos financieros ................................................................. 118

Tabla 8.1 Balance General del Primer Año ................................................................. 120

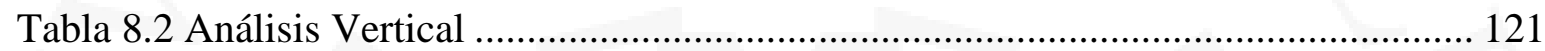

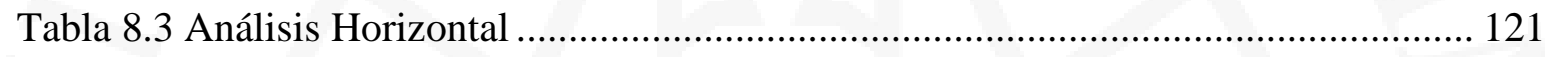

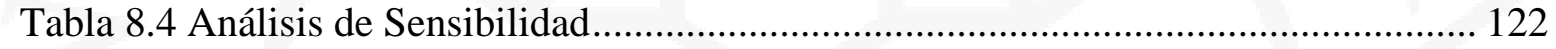

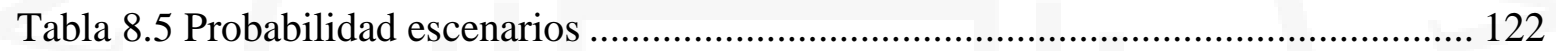

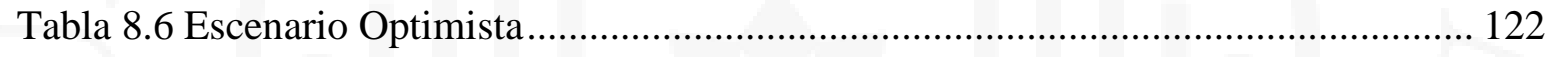

Tabla 8.7 Flujo Financiero Optimista .................................................................... 123

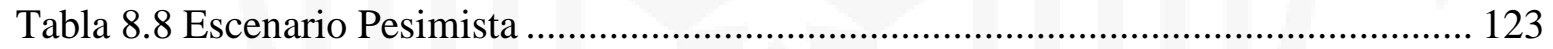

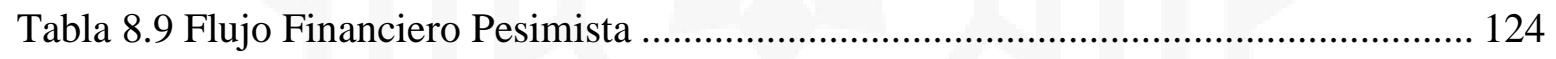

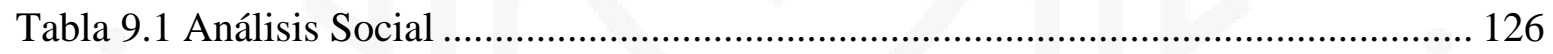




\section{ÍNDICE DE FIGURAS}

Figura 2.1 Regresión Exponencial de la tendencia del total de nacimientos..................... 16

Figura 2.2 Regresión Exponencial de la tendencia del porcentaje de cesáreas .................. 17

Figura 2.3 Regresión Lineal de la tendencia de hospitalizaciones ................................. 18

Figura 2.4 Regresión Polinómica de la tendencia de cirugías mayores............................. 20

Figura 2.5 Regresión Lineal de la tendencia de cirugías menores................................... 21

Figura 2.6 Regresión Exponencial de la tendencia de nacimientos en EsSalud................. 21

Figura 2.7 Regresión Lineal de la tendencia de batas...................................................... 29

Figura 2.8 Regresión Lineal de la tendencia de scrubs................................................... 29

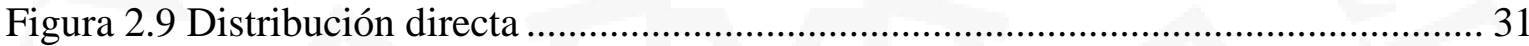

Figura 2.10 Importancia relativa de los instrumentos de promoción ................................ 33

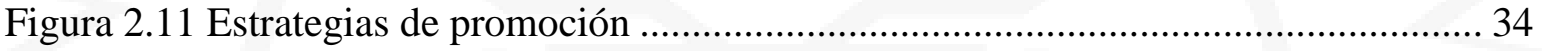

Figura 2.12 Determinación de Estratégicas de Precios costo versus valor ........................ 35

Figura 2.13 Partes de la tela de Polipropileno SMS ..................................................... 37

Figura 4.1 Regresión para proyección de oferta ........................................................ 50

Figura 5.1 Modelo de uniformes tipo batas y tipo scrubs ............................................ 54

Figura 5.2 Diagrama de Operaciones del Proceso para la Fabricación .............................. 58

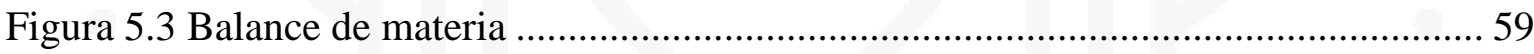

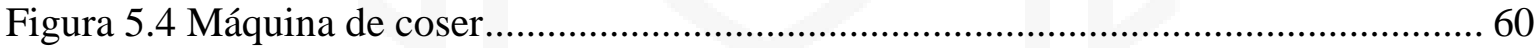

Figura 5.5 Empaquetadora al vacío .................................................................... 61

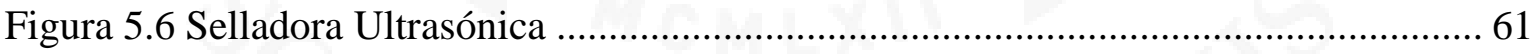

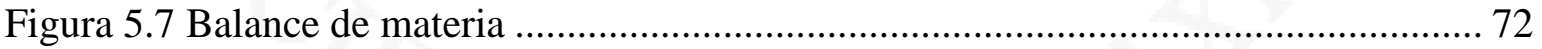

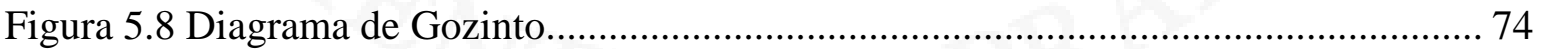

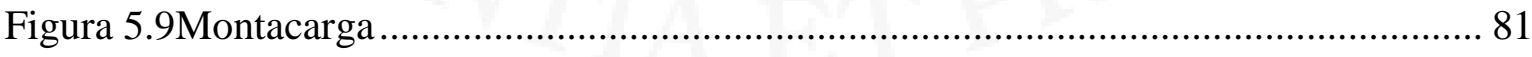

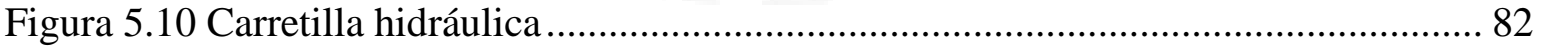

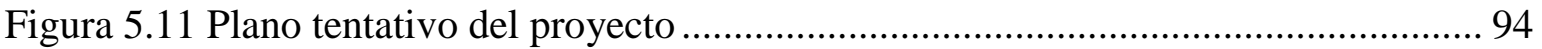

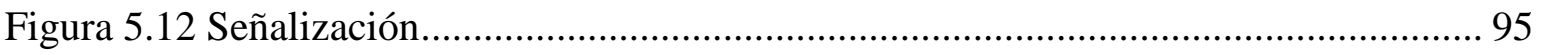

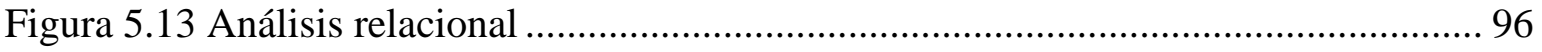

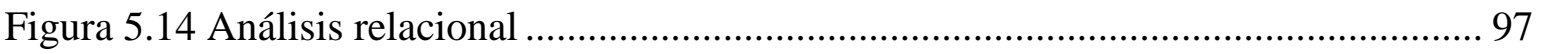


Figura 5.15 Plano tentativo del proyecto ............................................................. 98

Figura 5.16 Membrete del Plano tentativo del proyecto............................................. 98

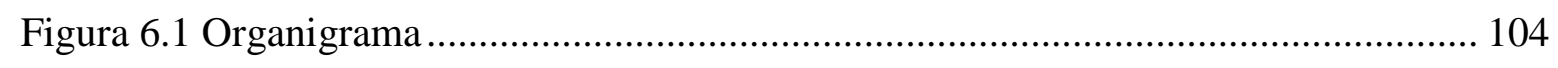

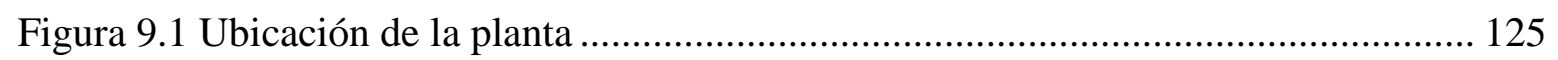




\section{ÍNDICE DE ANEXOS}

ANEXO 1: Listado de clínicas a nivel nacional ........................................................ 135

ANEXO 2: Porcentaje de participación de cada Nivel Socio Económico en Lima .......... 136

ANEXO 3: Cuadro de población de 12 y más años de edad, por afiliación a seguros...... 137

ANEXO 4: Información aduanera de las telas no tejidas de polipropileno...................... 139 


\section{RESUMEN EJECUTIVO}

El presente trabajo tiene como objetivo evaluar la factibilidad de la puesta en marcha de una fábrica productora de uniformes descartables para el sector salud.

En la actualidad, existe una gran cantidad de procedimientos y servicios del sector salud que requieren el uso de vestimenta protectora contra el riesgo biológico, para pacientes y personas de atención. Frente a esta necesidad, se analizó una mejor opción de vestimenta adicional a las ya existentes en el sector salud, con ello surgió la iniciativa de evaluar la factibilidad de implementar en nuestro país una fábrica de producción de uniformes descartables, que representan una idea innovadora para ofrecer un producto con características diferenciadas.

En primer lugar, se determinaron los objetivos, alcances y limitaciones de esta investigación, y se definió todo el proceso involucrado en producir los mencionados uniformes innovadores. En segundo lugar, se realizó el cálculo de la demanda objetivo, con información extraída de fuentes confiables, concentrándose en el consumo per cápita (CPC) de uniformes para médicos, enfermeros, estudiantes de medicina y enfermería. En tercer lugar, se definió la disposición de planta, los requerimientos necesarios para la puesta en marcha y se analizaron todos los elementos financieros y sociales para hacer posible este proyecto.

Al finalizar este estudio podemos concluir que este proyecto beneficia al sector textil nacional y a la comunidad, debido a que es una gran oportunidad de negocio, reduce las importaciones y apuesta por el crecimiento de la industria nacional. Gracias al uso de todos los conocimientos aprendidos y utilizados durante la carrera de Ingeniería Industrial, es posible afirmar la factibilidad de este proyecto.

Palabras claves: uniformes descartables para el sector salud; demanda objetivo; puesta en marcha; elementos financieros y sociales; es posible afirmar la factibilidad de este proyecto. 


\begin{abstract}
The present work aims to evaluate the feasibility of setting up a factory to produce disposable uniforms for the health sector.

At present, there is a great amount of procedures and services of the health sector that require the use of protective clothing against the biological risk, for patients and people of attention. Faced with this need, a better option of clothing was analyzed in addition to those already existing in the health sector. This led to the initiative to evaluate the feasibility of implementing a factory to produce disposable uniforms, which represent an innovative idea to offer a product with differentiated characteristics.
\end{abstract}

First, the objectives, scope and limitations of this research were determined, and all the processes involved in producing the mentioned innovative uniforms were defined. Second, the objective demand was calculated, with information extracted from reliable sources, focusing on per capita consumption of uniforms for physicians, nurses, medical and nursing students. Thirdly, the layout of the plant, the necessary requirements for the start-up, and all the financial and social elements were analyzed to make this project possible.

At the end of this study we can conclude that this project benefits the national textile sector and the community, because it is a great business opportunity, reduces imports and bets on the growth of the national industry. Thanks to the use of all the knowledge learned and used during the Industrial Engineering career, it is possible to affirm the feasibility of this project.

Key words: uniforms for the health sector; the objective demand; for the start-up; financial and social elements; it is possible to affirm the feasibility of this project. 


\section{CAPÍTULO I: ASPECTOS GENERALES}

\subsection{Problemática de la investigación}

\subsubsection{Presentación del tema}

El sector textil en el Perú ha ido evolucionando con el paso del tiempo, convirtiéndose en la actualidad en uno de los sectores con mayor crecimiento no solo en ganancias, sino también en tecnologías y en número de trabajadores y empresas.

El siguiente proyecto busca utilizar dichas tecnologías y los conocimientos aprendidos a lo largo de la carrera para hacer un estudio acerca de la viabilidad de una planta fabricadora de uniformes médicos desechables de Polipropileno SMS, que en conjunto forman un producto de calidad.

\subsubsection{Descripción del producto o servicio propuesto}

Los uniformes médicos desechables están hechos de tela no tejida de fibra de polipropileno SMS, el cual está compuesto por tres capas; Spunbond, que no se despeluza y es antiestática, Meltblown, que es un filtro de barrera viral y antibacterial y Spunbond nuevamente, características que permiten un producto de alta calidad y bajos costos. A diferencia de otros productos similares el tipo de tela permite que el uniforme sea antitraspirante, antiarrugas, anti-encogimiento y que se amolde mejor al cuerpo permitiendo comodidad y movilidad más eficaz, y vienen en presentaciones de diferentes colores según las necesidades de cada cliente.

La fábrica producirá dos tipos de uniformes, los cuales serán batas y scrubs con las siguientes características; totalmente esterilizado, de muy baja inflamabilidad, con una impermeabilidad mayor del 98\%, posee resistencia a sustancias y líquidos hospitalarios, con una eficiencia de protección bacterial mayor al 98\% y con una baja carga electrostática. Los puntos mencionados anteriormente fueron probados en el ensayo de calidad al que se sometió el producto. 
Respecto a las batas médicas, estas serán de color personalizable, de tamaño S-3XL, genero unisex, con un gramaje de 16 gramos por m2. Además, contará con muñequeras que permitirán mantener la esterilidad de los brazos. Para permitir el cerrado posterior de la bata se tendrá dos cintas para anudar.

Respecto a los scrubs, estos están conformados por un pantalón y un polo manga corta, el cual puede ser cuello redondo o V según lo prefiera el cliente. Los scrubs serán de color personalizable, de tamaño S-3XL, con un gramaje de 25 gramos por m2.

Ambos productos serán envueltos en bolsas de plástico y serán empacados 30 por caja.

\subsection{Objetivos de la investigación}

\subsubsection{Objetivo general}

Demostrar mediante un estudio la viabilidad económica, tecnológica, social y de mercado de implementar una planta que fabrique uniformes médicos desechables en base a Polipropileno SMS; a través de un análisis de demanda y disponibilidad de recursos productivos y tecnológicos.

\subsubsection{Objetivos específicos}

- Estimar la demanda de uniformes médicos del sector privado de Lima y Callao.

- Analizar la demanda no cubierta de uniformes médicos.

- Investigar la disponibilidad de materias primas y recursos tecnológicos apropiados para el proceso productivo.

- Calcular la inversión necesaria para implementar los recursos tecnológicos en una planta en el país.

- Determinar la viabilidad económica, social, de mercado y financiera del proyecto.

- Elaborar estudios preliminares de ingeniería. 


\subsection{Alcances y limitaciones de la investigación}

Los alcances de esta investigación son explorar el mercado del sector textil, específicamente de la producción de prendas hechas de polipropileno SMS en el Perú. Este estudio abarca la utilización de estas prendas en los centros de salud del país.

Entre las limitaciones se encuentran la poca de información disponible acerca del mercado actual de este producto debido a que recién se encuentra ingresando en el país.

\subsection{Hipótesis del trabajo}

La instalación de una planta fabricadora de uniformes médicos desechables de Polipropileno SMS es viable para el mercado peruano debido a que existe una demanda potencial con alta aceptación del producto, y el sector textil actual permite la instalación de la tecnología necesaria. 


\subsection{Justificación de la investigación}

\subsubsection{Técnica}

Los beneficios técnicos de este proyecto son:

- Se cuenta con las materias primas, insumos y equipos necesarios para llevar a cabo el proyecto en el país algunos que se importaran desde China.

- La disponibilidad de profesionales capacitados en la industria textil es alta, además la Biotecnología cada vez se va implementando más en los sectores productivos.

- El Ministerio de la Producción y otras entidades gubernamentales actualmente se encuentran invirtiendo importantes sumas de dinero en Biotecnología e Innovación como se puede observar en la noticia del Diario Gestión en el Anexo 1.

- Existe alta disponibilidad de terrenos para la localización de la empresa.

- Se implementará la ISO 3758:2006 para establecer los estándares de calidad que satisfagan los requerimientos de los clientes.

\subsubsection{Económica}

Los beneficios económicos que se esperan alcanzar son los siguientes:

- Reducción en los costos de producción y costo final del producto, gracias a la eficacia y eficiencia del proceso productivo mediante el uso de tecnologías limpias.

- Debido a que el producto no necesita ser lavado después de su uso, se reducirán los gastos de limpieza y almacenamiento comparado con los de los productos sustitutos.

- Existe una alta demanda potencial que permitirá que el negocio tenga liquidez y rentabilidad, gracias a los altos volúmenes de venta que se esperan debido a la practicidad del producto y sus precios accesibles. 


\subsubsection{Social}

Los beneficios no económicos de implementar este proyecto son los siguientes:

- Incremento en los puestos de trabajo debido a la necesidad de mano de obra directa e indirecta para en el área de producción y las áreas administrativas y de servicios.

- Aumento del nivel de conocimiento y perfil profesional propiciando por iniciativas de capacitación que tendrán un impacto en la mejora del nivel de ingresos.

- Distribución masiva y precios accesibles que permitirán la disponibilidad del producto a nivel nacional beneficiando incluso a las zonas más pobres del país.

- Disminución de la contaminación gracias a las buenas prácticas en los procesos productivos. Con ello la sociedad habitará en armonía con su entorno y disminuirá la probabilidad de contraer enfermedades producidas por la huella ambiental.

- Promoción de la implementación de un Plan de manejo de residuos sólidos en las instituciones que utilicen nuestros productos.

\subsection{Marco referencial}

A continuación, se presentan investigaciones previas sobre el tema.

- Indecopi. (2009). Compendio de normas técnicas peruanas y guías para su implementación. Textil - Confecciones. Lima, Lima, Peru: Universidad de Lima: La NTP establece los requisitos requeridos en el etiquetado de la vestimenta.

- Indecopi. (2010). Norma técnica Nº96-MINSA/DIGESA V.01 .- Norma Técnica de Salud de Gestión y Manejo de Residuos Sólidos en Establecimientos de Salud y Servicios Médicos de Apoyo.Lima, Lima, Peru

- Martínez Aguirre, Guillermo. (2012). La ingeniería en la industria de la confección. México DF, México: Universidad de Lima: La investigación se basa en la producción y tecnología de telas tejidas que sirve como base para los conocimientos de la industria textil y algunos procesos de manufactura, mas no para el proceso productivo de la tela no tejida debido a que poseen diferencias en las tecnologías aplicadas.

- Laos Cuneo, Jorge Eduardo. (1988). Análisis tecnológico para la fabricación de geotextiles no tejidos de polipropileno. Lima, Lima, Perú: Universidad de Lima: Tiene contenido relacionado con la fabricación de telas no tejidas. Se utilizará como 
base para determinar los procesos involucrados en la producción, tomando en cuenta insumos diferentes y la fecha del estudio.

- Costa, Mirko R. (). Geovelos o No-Tejidos Partes I y II. Revista Mundo Textil. Lima, Lima, Perú: Universidad de Lima: Ambos artículos explican sobre los tipos, características y propiedades de los geovelos, geotextiles o no-tejidos; contiene datos actualizados de la materia prima necesaria.

- Silvia Katherine Castillo López, Jethro Atoche Pilco. (2014). Estudio de prefactibilidad para la instalación de un taller textil que elabora prendas para niños con discapacidad motriz. Lima, Lima, Perú: Universidad de Lima: Tiene contenido sobre la viabilidad de la implementación de un taller textil. Se utilizará como base para definir procesos, máquinas, materiales, etc.

- Juan Carlos Quiroz Flores. (2000). Estudio de Pre Factibilidad para la instalación de una fábrica de Confecciones de Jeans y Camisas. Lima, Lima, Perú. Universidad de Lima. Tiene contenido sobre la viabilidad de implementar una fábrica de confecciones. Se utilizará como referencia para los diagramas de bloques, DOP, recorrido y el resto de los procesos.

\subsection{Glosario de términos}

- Biotecnología: según la definición del Convention on Biological Diversity de las Naciones Unidas (Nations, 1992) en su Artículo 2. Use of Terms, la definen como un área multidisciplinaria que se encarga del aprovechamiento de los mecanismos e interacciones biológicas de los seres vivos y/o sus derivados para la creación o modificación de productos o procesos para usos específicos. (Nations, 1992)

- Geovelos: también llamados geotextiles o no tejidos. Son estructuras en forma de telas que consisten en una o más capas o velos de fibras unidas mediante un material ligante o adhesivo.

- Spun-Bonding: es el proceso de formas telas no tejidas mediante la unión continua de capas de fibra sintética inmediatamente después del proceso de extrusión.

- Melblown: es un proceso muy parecido al Spun-Bonding, con la diferencia que se utilizan filamentos de fibras ultradelgados en condiciones más económicas. 
- Needle-Punching: también conocido como punzado, es el proceso de unión de fibras mediante la punción con agujas.

- Polipropileno (PP): es un polímero termoplástico que se obtiene de la polimerización del propileno que posee propiedades químicas, organolépticas, de resistencia y trasparencia.

- Polietileno: polímero preparado a partir del etileno, se emplea para la fabricación de envases, tuberías y recubrimientos de cable.

- Enzimas: proteínas con capacidad de catalizar procesos químicos, facilitándolos y haciéndolos más rápidos. Incorporan sus características a los productos que las contienen.

- Celulosa: es un biopolímero compuesto por moléculas de glucosa.

- Biodegradable: que se descompone en elementos químicos naturales por la acción de agentes biológicos, como el sol, el agua, las bacterias, las plantas o los animales.

- Reciclar:

someter un material de desecho a un proceso de transformación para reutilizarlo. 


\section{CAPÍTULO II: ESTUDIO DE MERCADO}

\subsection{Aspectos generales del estudio de mercado}

\subsubsection{Definición comercial del producto}

\section{Producto básico}

Los uniformes médicos desechables sirven para proteger a médicos, enfermeros, técnicos y tecnólogos de las sustancias de peligro biológico provenientes del lugar de trabajado. Pueden ser utilizados para diferentes tipos de procedimientos.

\section{Producto real}

Dichos uniformes están hechos de tela no tejida de Polipropileno SMS que brindan un producto de alta calidad, seguridad y bajos costos. A diferencia de otros productos similares cuenta con diseños anatómicos que se amoldan mejor al cuerpo permitiendo comodidad y movilidad más eficaz, y vienen en presentaciones de diferentes colores según las necesidades de cada cliente.

\section{Producto aumentado}

El producto brindado posee una ventaja competitiva debido a que el proyecto abarca toda la cadena de suministro, desde el ingreso de la tela no tejida, hasta la confección de los uniformes médicos desechables que es el producto final.

El objetivo es que los uniformes puedan ser usados a nivel nacional por servicios de salud privados, por ello se buscará la lealtad de los clientes cumpliendo con los plazos de entrega diferenciados acorde a las necesidades específicas de los consumidores y con altos estándares de calidad. Además, se enfocará en el apoyo de los proveedores de insumos y tecnologías para cumplir con la demanda del producto a tiempo.

Finalmente se brindarán servicios post-venta, garantía por productos defectuosos y empaques de seguridad esterilizados en donde se encontrará cada prenda para que el usuario final pueda corroborar que no ha sido utilizado por otra persona. 


\subsubsection{Principales características del producto}

\subsubsection{Usos y características del producto}

Principalmente, las batas y los scrubs son utilizados como protección para la realización de los diferentes procedimientos médico/quirúrgicos que realizan los profesionales de la salud en su jornada de trabajo. Esto debido a que en su día a día, tratan a personas con diferentes problemas de salud, lo que los pone en contacto con virus, bacterias y sustancias peligrosas.

Actualmente en la mayoría de centros de salud se utilizan prendas reutilizables que no proporcionan tanta seguridad como la esperada, ya que no existe certeza de que al $100 \%$ fueron esterilizadas poniendo en peligro la vida y salud tanto de los profesionales como de los pacientes. Con ello surge la idea novedosa de incorporar prácticas de seguridad e higiene que ya vienen siendo utilizadas en muchos países del mundo como es el caso de Estados Unidos. El objetivo sigue siendo el mismo, proteger a las personas, y las prendas desechables cubren esa necesidad; ya que están fabricadas con materiales resistentes y permeables a la contaminación, y además porque son utilizadas solo 1 vez disminuyendo el riesgo biológico.

Las propiedades de las materias primas les proporcionan a estas prendas, desechables y ecológicas las, siguientes características:

- Comodidad: permiten que la temperatura del cuerpo se mantenga estable gracias a su triple capa delgada.

- Permeabilidad: las capas externas de Spunbond ofrecen alta permeabilidad, prohibiendo el paso de una gran variedad de sustancias desde líquidos hasta partículas y microorganismos. Esta propiedad también se le conoce como Antifluido.

- Protección: gracias a que entre las capas de Spunbond existe una capa Meltbown cuya función principal es la de absorber cualquier partícula que pudo haber pasado por las capas externas, las prendas ofrecen triple protección a quienes las usen. 


\subsubsection{Bienes sustitutos y complementarios}

En el mercado en estudio, los bienes sustitutos son batas y scrubs que estén confeccionadas de algún material que contenga celulosa o de la reciente innovación de tela de hilos de plata.

La característica principal de estas prendas que las diferencia de las desechables es que pueden ser utilizadas en varias ocasiones debido a que no requiere de lavado por postura y la tela resiste 250 lavados industriales. Por otro lado, los precios varían entre los diferentes productos, debido a que tienen calidades diferentes dependiendo del país en el que fueron confeccionados y de la materia prima utilizada.

Los bienes complementarios vendrían a ser los equipos de protección personal que usan los médicos para realizar diferentes procedimientos médico-quirúrgicos, tales como mascarillas, guantes, entre otros, formarían parte de este grupo. Así mismo se consideran los insumos y materiales necesarios para la producción y confección de las prendas desechables, ya que las variaciones en su disponibilidad y precio podrían afectar el desempeño de las batas y scrubs desechables en el mercado.

\subsubsection{Determinación del área geográfica que abarcará el estudio}

El presente estudio, abarcará el área geográfica del Departamento de Lima y Callao, debido a las siguientes razones:

- Cubrir la demanda de prendas médicas desechables para el sector privado de salud.

- Como se muestra en el Anexo 1, el 64\% de clínicas se encuentran en Lima.

- Lima es la capital del Perú y sería más factible que la planta de fabricación se encuentre en este departamento para tener mayor accesibilidad a las materias primas las cuales serán importadas y a los insumos que podrían ser obtenidos en la capital.

\subsubsection{Análisis del sector}

Con el análisis de las cinco fuerzas de Porter podemos resaltar que la amenaza de los productos sustitutos es alta debido a que existe una gran cantidad de ellos en el sector textil a precios medianos y bajos; respecto al poder de negociación de los consumidores se conoce

que es alto, respecto a la amenaza de nuevos competidores es media debido a que el producto posee alta diferenciación, pero se encuentra en un sector muy competitivo en el que las empresas van evolucionando rápidamente a los requerimientos de la población. 
A continuación, se analizarán las 5 fuerzas de Porter para determinar la intensidad de la competencia en el mercado y evaluar cualitativamente la rentabilidad.

\section{Amenaza de productos sustitutos}

Las características de los productos sustitutos se presentan a continuación:

- Los uniformes presentan grandes beneficios comparados con prendas similares de otros materiales.

- Existe la posibilidad de que los clientes opten por otros proveedores debido a las posibles diferencias en los precios, por eso será importante demostrar la diferenciación en la calidad de los productos para hacerlos más atractivos.

- Los precios comparados con los de los sustitutos son mayores.

Se puede concluir que la amenaza de productos sustitutos es alta debido a que existe una gran cantidad de ellos en el sector textil a precios medianos y bajos, por eso será importante para la viabilidad del proyecto enfocarse en esta fuerza.

\section{Poder de negociación de compradores}

Los clientes potenciales poseen las siguientes características:

- El volumen de compras con respecto a las ventas totales del sector es relativamente bajo, debido a que el producto está orientado a los trabajadores del sector salud.

- La mayoría de productos usan algodón y sus variedades, existe poca o ninguna producción de ropa en base a Polipropileno SMS.

- Debido a que la industria está altamente estandarizada, cambiar de proveedor no con lleva a costos altos.

- Posibilidad de que los compradores se integren hacia atrás y consigan elaborar productos con características similares utilizando otro tipo de materias primas.

En general, el poder de negociación de los consumidores es alto debido a que a pesar de que el volumen de compras no es alto, los clientes potenciales pueden encontrar productos similares a precios más bajos. Por ello, es importante demostrar los beneficios del producto a los consumidores en cuanto a calidad, durabilidad y seguridad; y aprovechar la reducción de costos para obtener precios los más accesibles. 


\section{Amenaza de nuevos competidores}

Entre las características con respecto a las barreras de ingreso al sector tenemos:

- Existe una alta diferenciación del producto debido a que se utiliza una materia prima diferenciada.

- Los accesos en cuanto a los canales de distribución son altos y los accesos a la materia prima podrían aumentar en pocos años.

Entre las características con respecto a la reacción de competidores encontramos:

- Posibilidad de que la gran variedad de empresas en la industria textil en el Perú incursione en la fabricación de prendas ecológicas.

- El crecimiento de sector industrial ha aumentado en los últimos años, sin embargo, la mayoría son empresas entre pequeñas y medianas.

Se puede concluir que la amenaza de nuevos competidores es media debido a que el producto posee alta diferenciación, pero se encuentra en un sector muy competitivo en el que las empresas van evolucionando rápidamente a los requerimientos de la población.

\section{Poder de negociación de proveedores}

Los proveedores del sector se caracterizan por:

- Existe una gran variedad de productos sustitutos a precios más bajos.

- Existe poca posibilidad de que los proveedores de materias primas se integren hacia adelante, debido a que adquirir nuevos procesos y maquinaria resulta poco atractivo.

- Los productos son diferenciados y por ende cambiar de proveedor podría conllevar a costos adicionales.

Se puede concluir que el poder de negociación de los proveedores es bajo, pero que debe tomarse en cuenta la necesidad de establecer buenas relaciones con ellos dada la continua evolución del sector textil. 


\section{Rivalidad entre competidores}

La rivalidad entre competidores se caracteriza en:

- La industria se encuentra altamente fragmentada y posee una gran cantidad de competidores y empresas que fabrican productos sustitutos.

- El sector textil ha venido evolucionando con el paso del tiempo y sigue creciendo, lo que posibilita que las empresas adquieran nuevas tecnologías.

Se llega a la conclusión que la rivalidad entre competidores es baja debido a que no presentan diferenciación en cuanto a las características de los productos lo cual es una ventaja competitiva para este proyecto. Sin embargo, esta fuerza es importante debido a que la puede hacer que las empresas mejoren sus productos.

\subsection{Determinación de la metodología que se empleará en la investigación de mercado}

Para la investigación de mercado se hará el uso de entrevistas de expertos, y herramientas estadísticas para proyectar los datos obtenidos de libros, páginas web y revistas.

\subsection{Demanda Potencial}

\subsubsection{Patrones de consumo: incremento poblacional, consumo per cápita, estacionalidad}

En primer lugar, se delimitó el mercado objetivo del presente estudio para hacer el cálculo de la demanda potencial considerando los siguientes puntos:

- Este es un estudio de factibilidad de la creación una fábrica que confecciona prendas médicas desechables

- Las prendas pueden ser utilizadas por el ámbito de la salud en cualquier tipo de instalación

Dicho lo anterior, considerar que la totalidad del mercado estaría dispuesto a comprar nuestro producto es una suposición que no contemplaría la realidad. Por tal motivo, se tomó la decisión de enfocar este estudio en los procedimientos más frecuentes y que mayor consumo de prendas médicas tendrían en las clínicas del sector privado de Lima y Callao. 
Para todos los cálculos se utilizaron los resultados trimestrales públicos que se encuentran en el portal web SuSalud, el cual concentra la información estadística del sector público y privado de Salud del Perú.

\section{Nacimientos}

Se obtuvo los resultados trimestrales de la cantidad de nacimientos desde el primer trimestre del año 2014 hasta al segundo trimestre del año 2016, publicados en el portal web SuSalud. Con dicha información, se utilizaron 2 gráficos de progresión exponencial para calcular el total de nacimientos y el porcentaje de cesáreas de los 2 trimestres faltantes del 2016. Con ambos datos se calculó el número de cesáreas y partos vaginales de los 2 últimos trimestres del 2016. Finalmente se sumaron los resultados de todos los trimestres para cada año con el fin de obtener la cantidad anual de nacimientos por tipo de procedimiento.

\section{Tabla 2.1}

Nacimientos por tipo de procedimiento y por trimestre

\begin{tabular}{lccccccccccccc}
\hline Año & \multicolumn{4}{c}{$\mathbf{2 0 1 4}$} & \multicolumn{1}{c}{$\mathbf{2 0 1 5}$} & \multicolumn{4}{c}{$\mathbf{2 0 1 6}$} \\
\hline Trimestre & I & II & III & IV & I & II & III & IV & I & II & III & IV \\
\% Cesáreas & $71.6 \%$ & $73.4 \%$ & $76.3 \%$ & $74.8 \%$ & $73.1 \%$ & $74.1 \%$ & $76.7 \%$ & $74.7 \%$ & $76.9 \%$ & $76.9 \%$ & $76.5 \%$ & $76.7 \%$ \\
Cesáreas & 1,831 & 2,062 & 2,282 & 2,036 & 2,199 & 2,556 & 2,370 & 2,375 & 2,139 & 2,372 & 2,418 & 2,439 \\
Parto vaginal & 726 & 749 & 708 & 685 & 809 & 893 & 718 & 807 & 643 & 712 & 743 & 743 \\
Total & 2,557 & 2,811 & 2,990 & 2,721 & 3,008 & 4,449 & 3,088 & 3,182 & 2,782 & 3,084 & 3,161 & 3,182 \\
\hline
\end{tabular}

Fuente: SuSalud (2018)

Figura 2.1

Regresión Exponencial de la tendencia del total de nacimientos

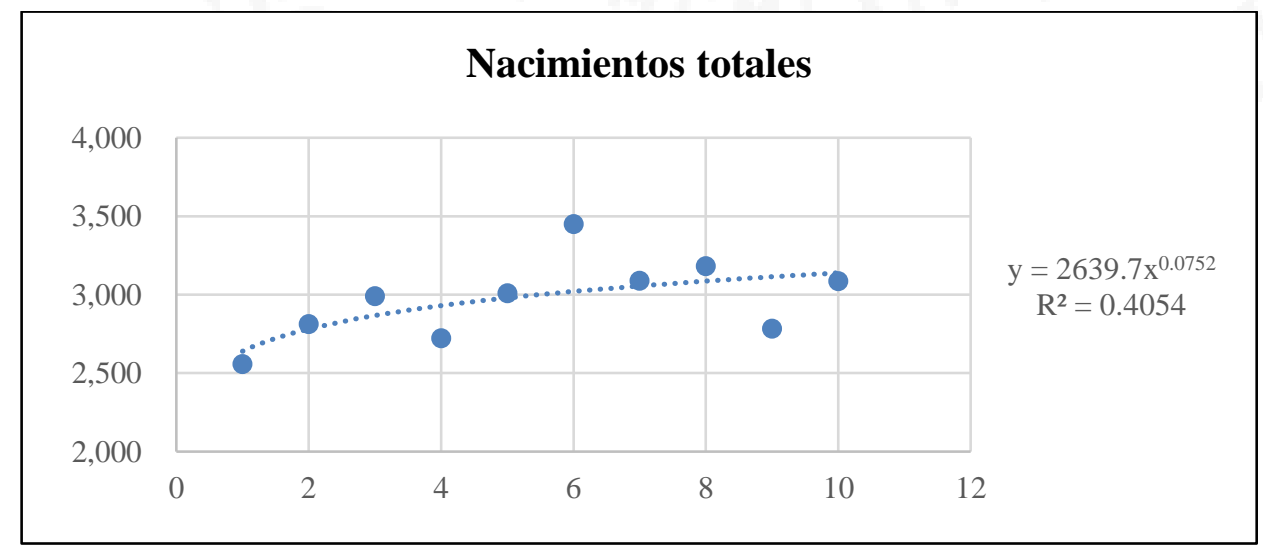

Elaboración propia 
Figura 2.2

Regresión Exponencial de la tendencia del porcentaje de cesáreas

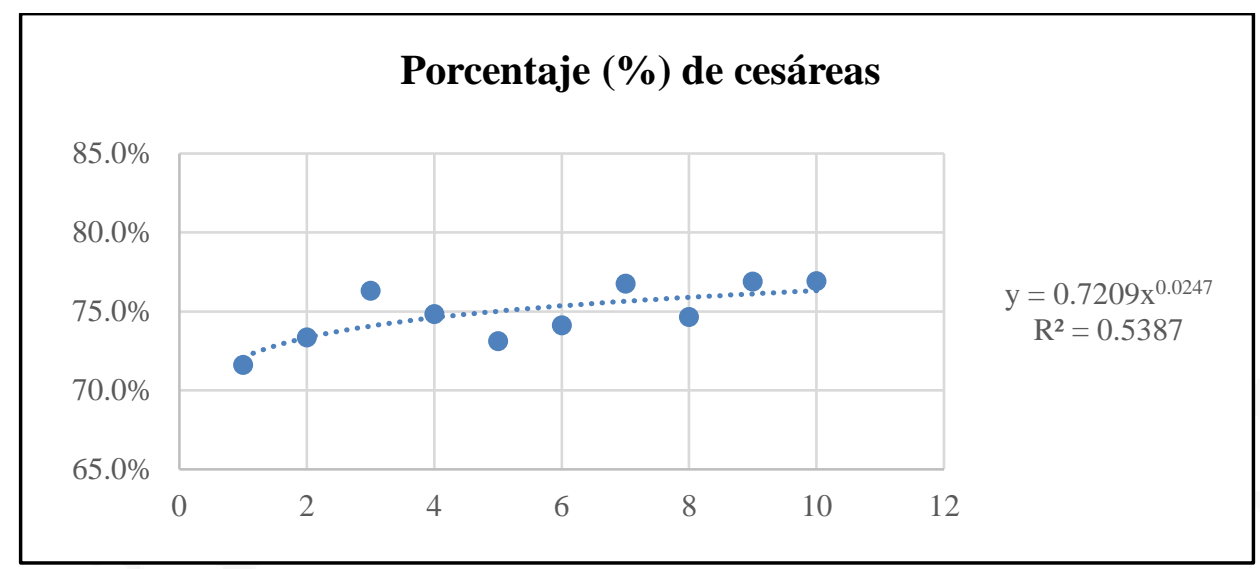

Elaboración propia

Tabla 2.2

Nacimientos anuales por tipo de procedimiento

\begin{tabular}{llll}
\hline Trimestre & $\mathbf{2 0 1 4}$ & $\mathbf{2 0 1 5}$ & $\mathbf{2 0 1 6}$ \\
\hline Cesáreas & 8,211 & 9,500 & 9,368 \\
Parto vaginal & 2,868 & 3,227 & 2,841 \\
\hline
\end{tabular}

Elaboración propia

Finalmente, en base a una encuesta realizada a médicos y especialistas, se determinó que para las cesáreas se necesitan 4 scrubs para los especialistas: gineco-obstetra, neonatólogo, enfermera y obstetriz; y una bata para la parturienta. A continuación, se muestra el cuadro final con la cantidad de prendas necesarias por año, siendo CPC el consumo per cápita por prenda obtenido de la encuesta.

Tabla 2.3

Necesidad anual para nacimientos por prenda y por procedimiento

\begin{tabular}{lcccc}
\hline Año & CPC & $\mathbf{2 0 1 4}$ & $\mathbf{2 0 1 5}$ & $\mathbf{2 0 1 6}$ \\
\hline Cesáreas & & & & \\
$\quad$ Batas & 1 & 8,211 & 9,500 & 9,368 \\
$\quad$ Scrubs & 4 & 32,844 & 38,000 & 37,473 \\
Parto vaginal & & & & \\
$\quad$ Batas & 1 & 2,868 & 3,227 & 2,841 \\
$\quad$ Scrubs & 2 & 5,736 & 6,453 & 5,682 \\
\hline
\end{tabular}

Elaboración propia 


\section{Hospitalizaciones}

Se obtuvo los resultados trimestrales de la cantidad de hospitalizaciones desde el primer trimestre del año 2014 hasta al segundo trimestre del año 2016, publicados en el portal web SuSalud. Con dicha información, se utilizó un gráfico de progresión exponencial para calcular las hospitalizaciones de los 2 trimestres faltantes del 2016. Finalmente se sumaron los resultados de todos los trimestres para cada año con el fin de obtener la cantidad anual de hospitalizaciones.

Tabla 2.4

Hospitalizaciones por trimestre

\begin{tabular}{|c|c|c|c|c|c|c|c|c|c|c|c|c|}
\hline Año & & & 14 & & & & 015 & & & & 16 & \\
\hline Trimestre & & II & III & IV & I & II & III & IV & I & II & III & IV \\
\hline Total & 13,680 & 17,083 & 17,530 & 16,330 & 15,411 & 18,660 & 18,627 & 16,635 & 18,025 & 19,636 & 17,414 & 17,529 \\
\hline
\end{tabular}

Figura 2.3

Regresión Lineal de la tendencia de hospitalizaciones

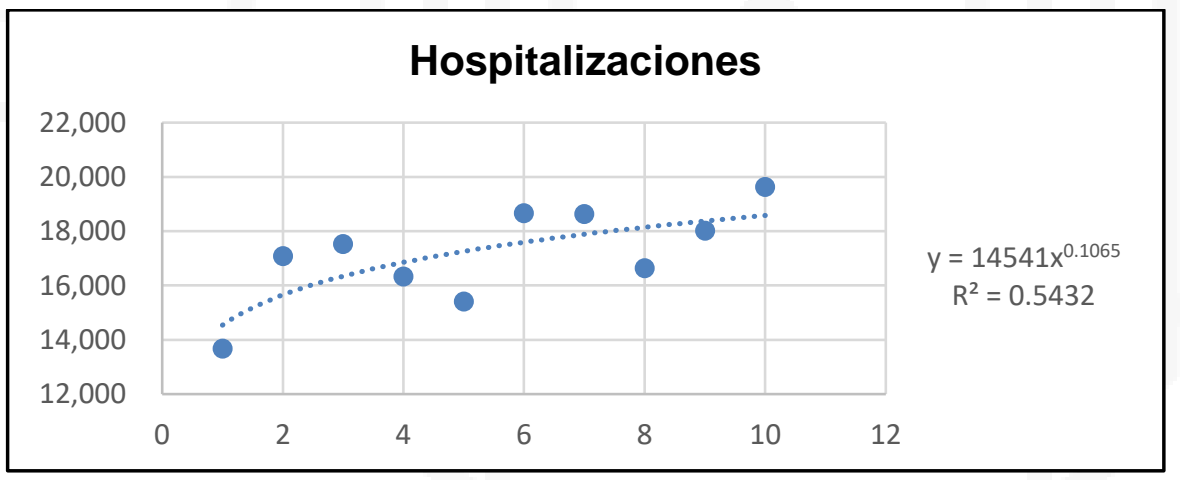

Elaboración propia

Luego, se obtuvo los días de estancia promedio de hospitalizaciones en EsSalud desde el primer trimestre del año 2014 hasta al segundo trimestre del año 2016, publicados en el portal web SuSalud; y con gráficos de tendencia se obtuvo los resultados de los 2 trimestres faltantes del 2016. Finalmente, se obtuvo el promedio de estancia trimestral utilizando los resultados de las 3 redes del sector público de salud más grandes del Perú.

Para el presente trabajo, se asumió que la estancia promedio de hospitalizaciones es similar en el sector público y privado. Bajo esta premisa, se utilizó la estancia promedio 
trimestral para el cálculo de la necesidad trimestral de prendas, multiplicando la estancia promedio por el número de hospitalizaciones. Finalmente se sumaron los montos trimestrales para determinar la necesidad anual. El consumo per cápita para las hospitalizaciones es 1 debido a que solo los pacientes harían uso de la prenda.

Tabla 2.5

Días de estancia promedio en EsSauld

\begin{tabular}{lccccccccccccc}
\hline Año & \multicolumn{1}{c}{$\mathbf{2 0 1 4}$} & \multicolumn{1}{c}{$\mathbf{2 0 1 5}$} & \multicolumn{4}{c}{$\mathbf{2 0 1 6}$} \\
\hline Trimestre & I & II & III & IV & I & II & III & IV & I & II & III & IV \\
Almenara & 6.3 & 6.6 & 6.5 & 6.4 & 6.2 & 6.2 & 6.1 & 6.2 & 5.9 & 5.9 & 5.9 & 5.8 \\
Rebagliati & 8.5 & 8.5 & 8.5 & 7.9 & 7.5 & 7.4 & 7.7 & 7.5 & 7.4 & 7.3 & 7.0 & 6.9 \\
Sabogal & 4.4 & 4.4 & 4.0 & 4.6 & 4.2 & 3.9 & 4.0 & 4.0 & 4.1 & 4.0 & 4.0 & 4.2 \\
Promedio & 6.40 & 6.50 & 6.33 & 6.27 & 5.97 & 5.83 & 5.93 & 5.91 & 5.80 & 5.73 & 5.64 & 5.61 \\
\hline
\end{tabular}

Fuente: SuSalud (2018)

Tabla 2.6

Necesidad trimestral de batas para hospitalizaciones

\begin{tabular}{lcccccccccccc}
\hline \multicolumn{1}{c}{ Año } & \multicolumn{4}{c}{$\mathbf{2 0 1 4}$} & \multicolumn{1}{c}{$\mathbf{2 0 1 5}$} & \multicolumn{2}{c}{$\mathbf{2 0 1 6}$} \\
\hline Trimestre & I & II & III & IV & I & II & III & IV & I & II & III & IV \\
Total & 87,552 & 111,040 & 111,023 & 102,335 & 91,952 & 108,850 & 110,520 & 98,331 & 104,545 & 112,580 & 98,189 & 98,343 \\
\hline Elaboración propia & & & & & & & &
\end{tabular}

Tabla 2.7

Necesidad anual de batas para hospitalizaciones

\begin{tabular}{lccc}
\hline Trimestre & $\mathbf{2 0 1 4}$ & $\mathbf{2 0 1 5}$ & $\mathbf{2 0 1 6}$ \\
\hline Total & 411,950 & 409,654 & 413,657 \\
\hline
\end{tabular}

Elaboración propia 


\section{Intervenciones quirúrgicas}

Se obtuvo los resultados trimestrales de los días de estancia promedio de cirugías mayores y menores en EsSalud desde el primer trimestre del año 2014 hasta al segundo trimestre del año 2016, publicados en el portal web SuSalud. Con dicha información, se utilizaron gráficas de tendencia para calcular los días de estancia de los 2 trimestres faltantes del 2016.

\section{Tabla 2.8}

Cirugías trimestrales en ESalud

\begin{tabular}{|c|c|c|c|c|c|c|c|c|c|c|c|c|}
\hline \multirow{2}{*}{$\frac{\text { Año }}{\text { Trimestre }}$} & \multicolumn{4}{|c|}{2014} & \multicolumn{4}{|c|}{2015} & \multicolumn{4}{|c|}{2016} \\
\hline & I & II & III & IV & I & II & III & IV & I & II & III & IV \\
\hline $\begin{array}{l}\text { Cirugía } \\
\text { mayor }\end{array}$ & 34,895 & 25,022 & 29,521 & 35,801 & 38,053 & 37,252 & 37,928 & 37,744 & 36,481 & 37,113 & 36,992 & 36,308 \\
\hline $\begin{array}{l}\text { Cirugía } \\
\text { menor }\end{array}$ & 5,603 & 3,865 & 4,650 & 5,301 & 5,170 & 5,113 & 5,390 & 5,224 & 5,209 & 5,428 & 5,459 & 5,525 \\
\hline Total & 40,498 & 28,887 & 34,171 & 41,102 & 43,223 & 42,365 & 43,318 & 42,969 & 41,690 & 42,541 & 42,451 & 41,834 \\
\hline
\end{tabular}

Fuente: SuSalud (2018)

Figura 2.4

Regresión Polinómica de la tendencia de cirugías mayores

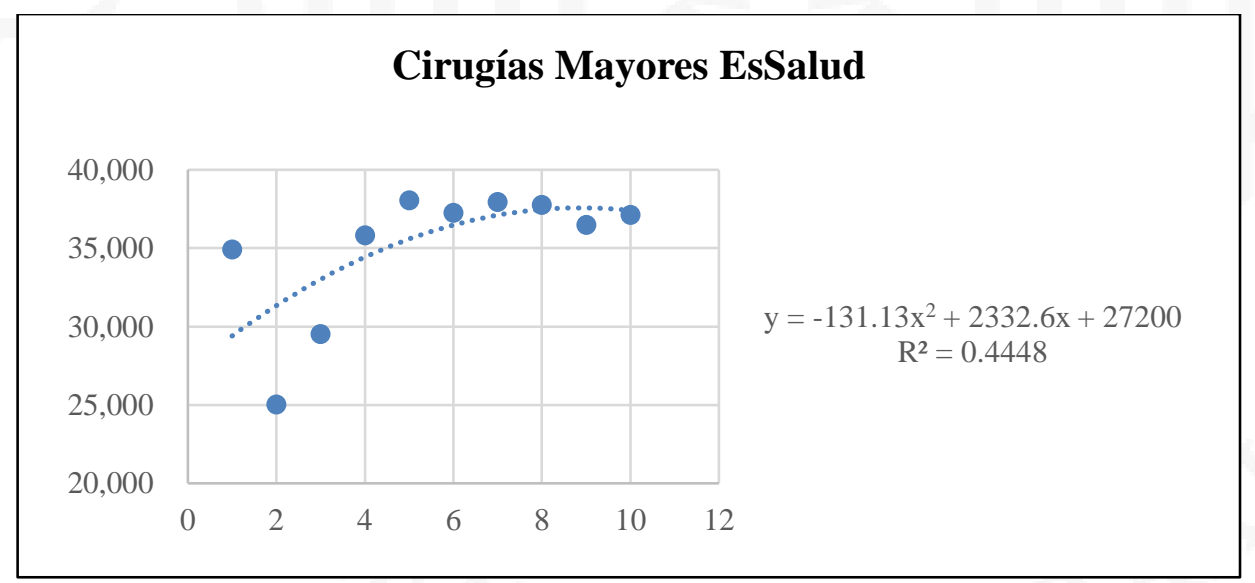

Elaboración propia 
Figura 2.5

Regresión Lineal de la tendencia de cirugías menores

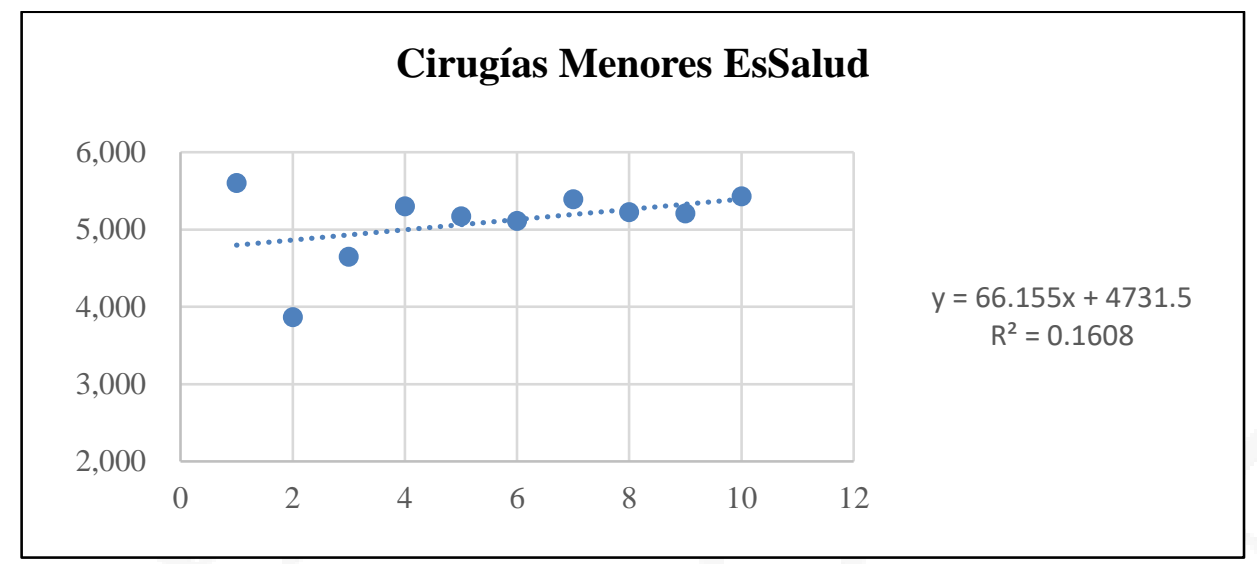

Elaboración propia

Del mismo portal SuSalud, se extrajo la información de la cantidad de nacimientos trimestrales en EsSalud y con un gráfico de regresión exponencial se obtuvo la información de los trimestres faltantes del 2016.

Tabla 2.9

Nacimientos en EsSalud

\begin{tabular}{lcccccccccccc}
\hline \multicolumn{1}{c}{ Año } & \multicolumn{1}{c}{$\mathbf{2 0 1 4}$} & \multicolumn{1}{c}{$\mathbf{2 0 1 5}$} & \multicolumn{4}{c}{$\mathbf{2 0 1 6}$} \\
\hline Trimestre & I & II & III & IV & I & II & III & IV & I & II & III & IV \\
Total & 11,370 & 11,901 & 12,347 & 11,767 & 12,852 & 12,813 & 12,561 & 12,742 & 12,072 & 11,512 & 12,477 & 12,506 \\
\hline
\end{tabular}

Elaboración propia

Figura 2.6

Regresión Exponencial de la tendencia de nacimientos en EsSalud

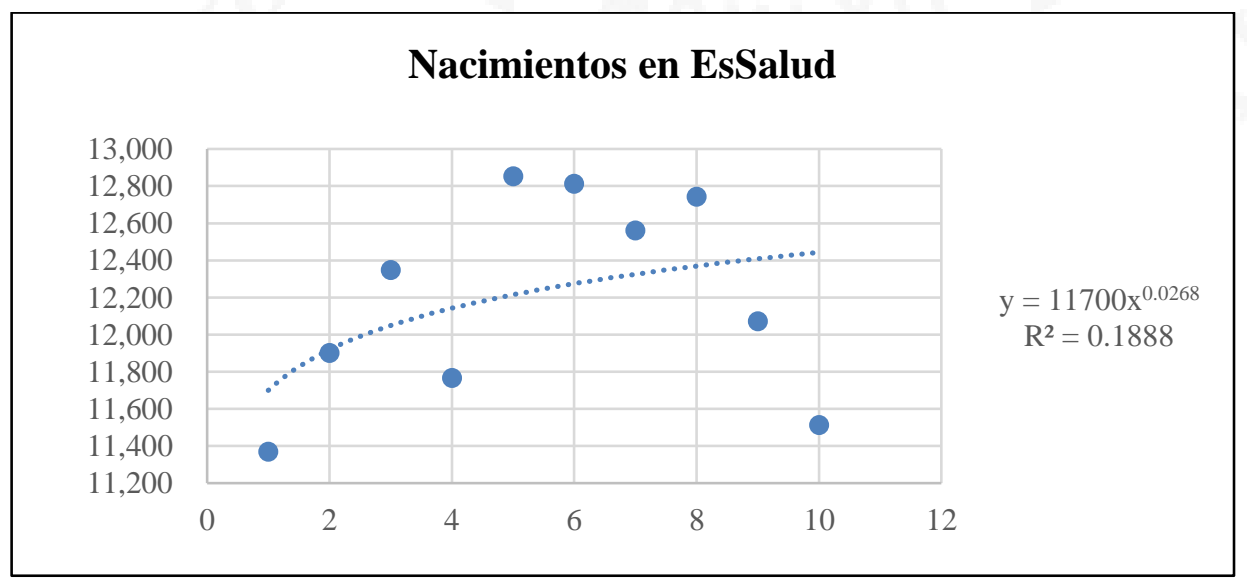

Elaboración propia 
Posteriormente, se calculó el ratio de cirugías por nacimiento del sector público, dividendo la información obtenida de cirugías en EsSalud entre los nacimientos en EsSalud. Debido a que no se encontró información disponible de la cantidad de intervenciones en el sector privado, se utilizó dicho ratio para el cálculo.

Tabla 2.10

Ratio de conversión de EsSalud

\begin{tabular}{lcccccccccccc}
\hline \multicolumn{1}{c}{ Año } & \multicolumn{1}{c}{$\mathbf{2 0 1 4}$} & \multicolumn{1}{c}{$\mathbf{2 0 1 5}$} & \multicolumn{4}{c}{$\mathbf{2 0 1 6}$} \\
\hline Trimestre & I & II & III & IV & I & II & III & IV & I & II & III & IV \\
Total & 3.6 & 2.4 & 2.8 & 3.5 & 3.4 & 3.3 & 3.4 & 3.4 & 3.5 & 3.7 & 3.4 & 3.3 \\
\hline
\end{tabular}

Elaboración propia

Utilizando la información de los nacimientos en el sector privado calculado anteriormente, se obtuvo la cantidad de cirugías trimestrales multiplicando los nacimientos por el ratio de conversión de EsSalud. Luego, se sumaron los montos trimestrales para obtener la necesidad de batas anuales.

\section{Tabla 2.11}

Nacimientos en el sector privado

\begin{tabular}{lccccccccccccc}
\hline \multicolumn{1}{c}{ Año } & \multicolumn{1}{c}{$\mathbf{2 0 1 4}$} & \multicolumn{1}{c}{$\mathbf{2 0 1 5}$} & \multicolumn{4}{c}{$\mathbf{2 0 1 6}$} \\
\hline Trimestre & I & II & III & IV & I & II & III & IV & I & II & III & IV \\
Total & 2,557 & 2,811 & 2,990 & 2,721 & 3,008 & 3,449 & 3,088 & 3,182 & 2,782 & 3,084 & 3,161 & 3,182 \\
\hline Elaboración propia & & & & & & & & & & &
\end{tabular}

\section{Tabla 2.12}

Cirugías trimestrales en el sector privado

\begin{tabular}{lcccccccccccc}
\hline \multicolumn{1}{c}{ Año } & \multicolumn{1}{c}{$\mathbf{2 0 1 4}$} & \multicolumn{10}{c}{$\mathbf{2 0 1 5}$} & \multicolumn{4}{c}{$\mathbf{2 0 1 6}$} \\
\hline Trimestre & I & II & III & IV & I & II & III & IV & I & II & III & IV \\
Total & 9,108 & 6,823 & 8,275 & 9,504 & 10,116 & 11,404 & 10,649 & 10,729 & 9,607 & 11,396 & 10,756 & 10,645 \\
\hline
\end{tabular}

Elaboración propia 
Tabla 2.13

Cirugías anuales en el sector privado

\begin{tabular}{lccc}
\hline Trimestre & $\mathbf{2 0 1 4}$ & $\mathbf{2 0 1 5}$ & $\mathbf{2 0 1 6}$ \\
\hline Total & 33,710 & 42,899 & 42,405 \\
\hline
\end{tabular}

Elaboración propia

En las intervenciones quirúrgicas se necesitan 7 batas considerando: paciente, cirujano principal, 2 cirujanos ayudantes, enfermera, instrumentista y anestesiólogo. Finalmente, siendo el consumo per cápita 7 batas por intervención, se calculó la necesidad de prendas multiplicándolo por la cantidad de cirugías anuales en el sector privado.

\section{Tabla 2.14}

Necesidad de batas anuales para intervenciones quirúrgicas

\begin{tabular}{lccc}
\hline Trimestre & $\mathbf{2 0 1 4}$ & $\mathbf{2 0 1 5}$ & $\mathbf{2 0 1 6}$ \\
\hline Total & 235.971 & 300,291 & 296,834 \\
\hline
\end{tabular}

Elaboración propia

\section{Exámenes radiológicos}

Se obtuvo los resultados trimestrales de la cantidad de consultas médicas desde el primer trimestre del año 2014 hasta al segundo trimestre del año 2016, publicados en el portal web SuSalud. Para los trimestres faltantes del 2016 se promediaron los resultados de los trimestres anteriores.

Tabla 2.15

Consultas médicas por trimestre

\begin{tabular}{lcccccccccccc}
\hline \multicolumn{1}{c}{ Año } & \multicolumn{1}{c}{$\mathbf{2 0 1 4}$} & \multicolumn{1}{c}{$\mathbf{2 0 1 5}$} & \multicolumn{2}{c}{$\mathbf{2 0 1 6}$} \\
\hline Trimestre & I & II & III & IV & I & II & III & IV & I & II & III & IV \\
Total & 745,618 & 875,006 & 880,936 & 842,431 & 853,862 & 788,643 & 872,821 & 803,887 & 820,364 & 907,324 & 839,089 & 839,089 \\
\hline Fuente: SuSalud (2018) & & & & &
\end{tabular}


Tabla 2.16

Consultas médicas por año

\begin{tabular}{lccc}
\hline Trimestre & $\mathbf{2 0 1 4}$ & $\mathbf{2 0 1 5}$ & $\mathbf{2 0 1 6}$ \\
\hline Total & $3,343,991$ & $3,319,213$ & $3,405,866$ \\
\hline
\end{tabular}

Elaboración propia

En la Directiva Sanitaria N$^{\circ}$ MINSA/DGSP-V.01, el Ministerio de Salud publicó los indicadores promedio de exámenes radiológicos por consulta externa para 3 tipos de hospitales. Considerando que el Hospital II-1 tiene las mismas características de infraestructura y capacidad de procedimientos que las clínicas del sector privado, se asumió que el promedio de exámenes radiológicos por consulta externa es similar al de las clínicas.

Finalmente, para el cálculo de prendas médicas se multiplicó el promedio del Hospital II-1 con la cantidad de consultas en el sector privado. En el caso de los exámenes radiológicos, el consumo per cápita es igual a 1 puesto que solo los pacientes necesitarían utilizar batas para dicho procedimiento.

Tabla 2.17

Indicadores de radiodiagnóstico e imágenes

\begin{tabular}{|l|c|c|c|}
\hline \multicolumn{1}{|c|}{ INDICADOR } & \multicolumn{3}{|c|}{ ESTÁNDAR } \\
\cline { 2 - 4 } & HOSPITAL II-1 & HOSPITAL II-2 & HOSPITAL II-3 \\
\hline $\begin{array}{l}\text { Promedio de exámenes radiológicos por consulta } \\
\text { externa }\end{array}$ & 0.05 & 0.10 & 0.20 \\
\hline Promedio de exámenes radiológicos por emergencia & 0.02 & 0.05 & 0.10 \\
\hline
\end{tabular}

Fuente: Directiva Sanitaria N MINSA/DGSP-V.01 (2017)

Tabla 2.18

Necesidad anual de batas para consultas médicas

\begin{tabular}{lccc}
\hline Trimestre & $\mathbf{2 0 1 4}$ & $\mathbf{2 0 1 5}$ & $\mathbf{2 0 1 6}$ \\
\hline Total & 167,200 & 165,961 & 170,293 \\
\hline Elaboración propia
\end{tabular}

Elaboración propia

\subsubsection{Determinación de la demanda potencial}

En primer lugar, se determinó la ratio de conversión de ambas prendas utilizando las dimensiones y el metraje de tela que será requerido para su elaboración. 
Tabla 2.19

Dimensiones de una bata

\begin{tabular}{lccc}
\hline Partes de la bata & Largo $(\mathbf{c m})$ & Ancho $(\mathbf{c m})$ & Área $(\mathbf{c m} 2)$ \\
\hline Cuerpo & 119 & 142 & 16,827 \\
Brazo izquierdo & 60 & 30 & 1,800 \\
Brazo derecho & 60 & 30 & 1,800 \\
Pita 1 & 60 & 3 & 180 \\
Pita 2 & 60 & 3 & 180 \\
Total & & & 20,787 \\
\hline
\end{tabular}

Elaboración propia

Tabla 2.20

Dimensiones de un scrub

\begin{tabular}{lccc}
\hline Partes de la bata & Largo $(\mathbf{c m})$ & Ancho $(\mathbf{c m})$ & Área $(\mathbf{c m} 2)$ \\
\hline Polo & & & \\
Cuerpo - frontal (1) & 83 & 33 & 2,739 \\
Cuerpo - frontal (2) & 60 & 36 & 2,160 \\
Cuerpo - espalda (1) & 83 & 33 & 2,739 \\
Cuerpo - espalda (2) & 60 & 36 & 2,160 \\
Pantalón & & & \\
Pierna izquierda & 108 & 52 & 5616 \\
Pierna derecha & 108 & 52 & 5616 \\
Correa & 106 & 8 & 848 \\
Total & & & 21,878 \\
\hline
\end{tabular}

Elaboración propia

Ratio de conversión $=\frac{20,787}{21,878}=0.95$

Debido a que el ratio de conversión es muy cercano a 1, se asumió que la diferencia de cantidad de tela necesaria no es representativa y que la demanda agregada anual será la suma de todas las demandas por procedimiento calculadas en el punto anterior. 
Tabla 2.21

Demanda Potencial

\begin{tabular}{cccc}
\hline Año & $\begin{array}{c}\text { Demanda } \\
\text { de batas }\end{array}$ & $\begin{array}{c}\text { Demanda } \\
\text { de scrubs }\end{array}$ & $\begin{array}{c}\text { Demanda } \\
\text { Agregada }\end{array}$ \\
\hline 2014 & 826,199 & 38,580 & 864,779 \\
2015 & 888,632 & 44,453 & 933,085 \\
2016 & 892,993 & 46,637 & 936,148 \\
\hline
\end{tabular}

Elaboración propia

\subsection{Determinación de la demanda en base a fuentes secundarias o primarias}

\subsubsection{Demanda histórica}

No es posible calcular la demanda histórica debido a que la tela polipropileno SMS y/o las prendas de dicho material, son importadas, exportadas y producidas en lotes tan pequeños en Perú que no hay registro público válido para calcular la demanda interna aparente. Sin embargo, no se descarta en el futuro hacer esta evaluación con los siguientes datos obtenido tras una investigación:

- El fibras de PP tienen una participación de $21.1 \%$ del total de fibras sintéticas en el mercado.

- Las fibras de PP tienen un valor FOB de 19.68 dólares americanos por kilogramo.

- Cada prenda tiene un peso aproximado de 88 gramos.

Tabla 2.22

Porcentaje de participación

\begin{tabular}{lc}
\hline Porcentaje de participación de las fibras sintéticas en el mercado textil \\
\hline Viscosa & $29.2 \%$ \\
Poliéster & $28.2 \%$ \\
Polipropileno & $21.1 \%$ \\
Poliamida & $5.9 \%$ \\
Otras & $15.6 \%$ \\
\hline
\end{tabular}

Fuente: Revista Mundo Textil - Geovelos (2012)

\subsubsection{Demanda mediante fuentes primarias}

A continuación, se determinará la demanda proyectada tomando en cuenta herramientas y técnicas de estudio de mercado 


\subsubsection{Segmentación del mercado}

En primer lugar, el proyecto pretender cubrir las necesidades de protección e higiene que tiene los profesionales de la salud como consecuencia del riesgo biológico al que están expuestos en sus labores diarias de trabajo.

Todos los profesionales de la salud tienen las mismas características, ya que sin importar el distrito en el que viven, la edad que tengan, o el nivel socioeconómico en el que se encuentren, trabajan en centros de salud expuestos a diferentes enfermedades. Por ello el segmento de mercado al que se quiere llegar son los centros privados de salud que se encuentran en el Departamento de Lima y Callao.

\subsubsection{Selección de mercado meta}

La estrategia para la cobertura de mercado será la Estrategia Concentrada o Nicho, debido a que se quiere dominar el segmento de los centros de salud del sector privado y especializarse en la venta directa de prendas desechables innovadoras.

\subsubsection{Diseño y Aplicación de Encuestas u otras técnicas}

Para el presente estudio, se utilizó la técnica de entrevista para determinar la intención e intensidad de compra y uso de los compradores. Por ello, las entrevistas se realizaron a las personas encargadas de decidir y solicitar la compra de prendas médicas desechables de 3 clínicas del sector privado.

Durante las entrevistas se desarrollaron las siguientes preguntas:

- ¿Cuál es el pedido mensual/trimestral de prendas aproximado?

- ¿En qué actividades / procesos se utilizan?

- ¿Cómo las almacenan?

- ¿Cuál es el tratamiento después de ser usadas?

- ¿Qué les ofrecen las otras empresas adicional producto?

- ¿Estaría dispuesto a cambiar de proveedor?

- ¿Estaría dispuesto a comprar nuestro producto? 
- ¿Con qué intensidad estaría dispuesto a comprar nuestro producto?

Los resultados finales de las entrevistas determinaron que los compradores si estarían dispuestos a comprar nuestros productos con una intensidad del $85 \%$. Con dicho factor de mercado se obtuvo la demanda del proyecto.

Tabla 2.23

Demanda del proyecto

\begin{tabular}{llllll}
\hline Año & Demanda de batas & $\begin{array}{l}\text { Demanda } \\
\text { scrubs }\end{array}$ & de $\begin{array}{l}\text { Demanda } \\
\text { Agregada }\end{array}$ & $\begin{array}{l}\text { Demanda } \\
\text { Proyecto }\end{array}$ & del \\
\hline 2014 & 826,199 & 38,580 & 864,779 & 735,062 \\
2015 & 888,632 & 44,453 & 933,085 & 793,122 \\
2016 & 892,993 & 46,637 & 936,148 & 795,726 \\
\hline
\end{tabular}

Elaboración propia

\subsubsection{Determinación de la Demanda}

Se concluyó que los clientes principales (centros de salud privados) si estarían dispuestos a comprar los productos, debido a que existe una alta disponibilidad de los profesionales si para utilizarlos, debido a las características y beneficios diferenciados, en comparación con los bienes sustitutos que existen en el mercado.

Debido a que se trata de productos altamente necesarios para que los profesionales de la salud y sus estudiantes puedan cumplir con sus labores en el día a día de manera segura, la demanda específica será la misma que la demanda proyectada

\subsubsection{Proyección de la Demanda}

Para la proyección de la demanda, utilizamos la tendencia lineal de la cantidad de batas y scrubs anuales con el objetivo de obtener datos más aproximados a la realidad. Posterior a eso se sumó la cantidad de batas y scrubs por año con el factor de conversión 1 para calcular la demanda agregada, y finalmente se multiplicó por el factor de conversión $41 \%$ para calcular la demanda del proyecto por año. 
Figura 2.7

Regresión Lineal de la tendencia de batas

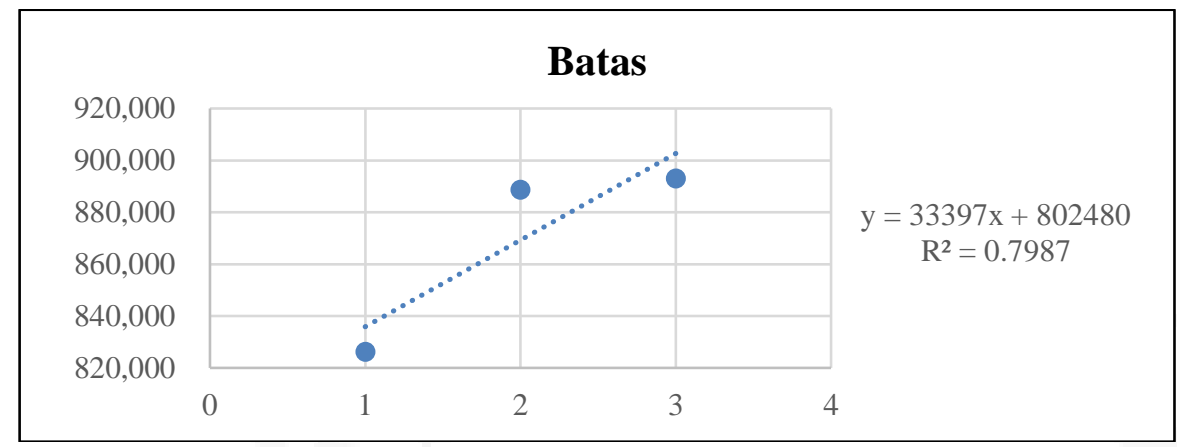

Elaboración propia

Figura 2.8

Regresión Lineal de la tendencia de scrubs

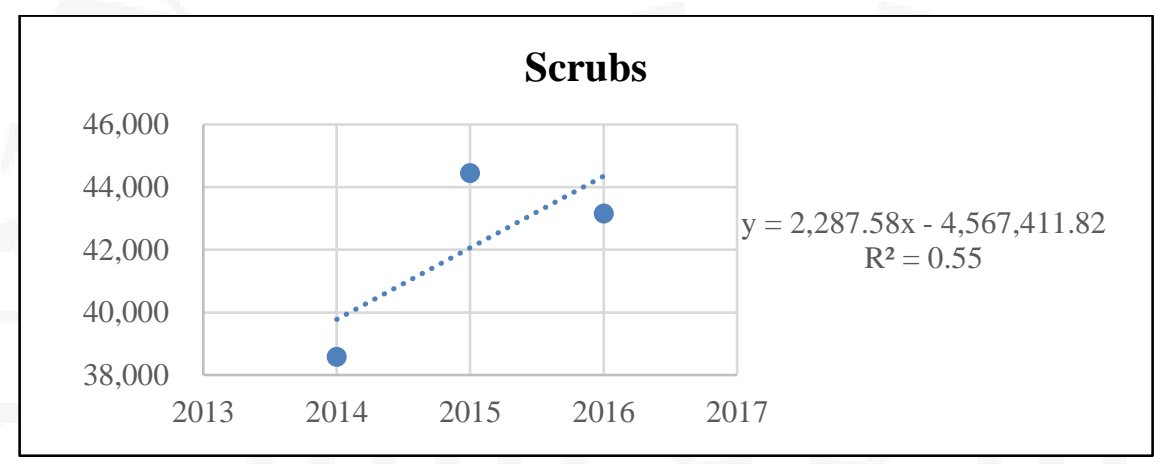

Elaboración propia

Tabla 2.24

Demanda proyectada

\begin{tabular}{llllll}
\hline Año & Demanda de batas & $\begin{array}{l}\text { Demanda } \\
\text { scrubs }\end{array}$ & $\begin{array}{c}\text { de } \\
\text { Demanda } \\
\text { Agregada }\end{array}$ & $\begin{array}{l}\text { Demanda } \\
\text { Proyecto }\end{array}$ & del \\
\hline 2014 & 826,199 & 38,580 & 864,779 & 735,062 \\
2015 & 888,632 & 44,453 & 933,085 & 793,122 \\
2016 & 892,993 & 43,155 & 936,148 & 795,726 \\
2017 & 936,068 & 46,637 & 982,705 & 835,299 \\
2018 & 969,465 & 48,925 & $1,018,390$ & 865,631 \\
2019 & $1,002,862$ & 51,212 & $1,054,074$ & 895,963 \\
2020 & $1,036,259$ & 53,500 & $1,089,759$ & 926,295 \\
2021 & $1,069,656$ & 55,787 & $1,125,443$ & 956,627 \\
2022 & $1,103,053$ & 58,075 & $1,161,128$ & 986,959 \\
2023 & $1,136,450$ & 60,363 & $1,196,813$ & $1,017,291$ \\
\hline
\end{tabular}

Elaboración propia 


\subsubsection{Consideraciones sobre la vida útil del proyecto}

El proyecto tendrá una vida útil de 5 años debido a que se considera que antes de cumplir este periodo podrá recuperarse la inversión hecha. Además, los activos para ese entonces se habrán devaluado y en el último año se pretende realizar la liquidación de activos.

\section{Análisis de la oferta}

\subsubsection{Empresas productoras, importadoras y comercializadoras}

Existe un número muy reducido de empresas productoras, en su mayoría mypes, tales como la Corporación VALTAKS SCRL, que generalmente no se dedican específicamente a la producción de prendas desechables, sino que en base a las fibras de polipropileno producen diversos artículos.

En el caso de las empresas comercializadoras solo existe una en el Perú llamada Grupo Camed S.A., quien trabaja vendiendo prendas médicas, ropa de cama y telas de Polipropileno SMS traídas desde otros países.

Finalmente, en el Perú existen muchos locales, no necesariamente empresas, dedicados a la importación de ropa médica de algodón, spandex, entre otras materias primas diferentes al Polipropileno SMS; es decir, no importan ropa médica desechable. Dichos locales venden en su mayoría productos importados desde Estados Unidos de marcas Dickies, Cherokee, Grey's Anatomy, Crocs, entre otras.

\subsubsection{Competidores actuales y potenciales}

Los principales competidores a los que este proyecto se ve expuesto son las empresas empresas nacionales debido a que tienen bajos precios, pero no cuentan con capacidad suficiente para cubrir toda la demanda, las empresas comercializadoras como el Grupo Camed S.A. debido a que ya son conocidas en el mercado y habrá por ello que posicionarse desde la introducción, y las empresas importadoras porque a pesar de que traen otros productos con precios más altos son de alta calidad. 


\subsection{Definición de la Estrategia de Comercialización}

\subsubsection{Políticas de comercialización y distribución}

Definir la función de distribución es importante para poder determinar los medios mediante los cuales el producto llegará al mercado meta. Por ello en primer lugar la distribución está caracterizada por ser de comercio minorista que realizará las ventas dentro del local comercial que se encontraría dentro de la planta, y fuera del local comercial mediante ventas por correo e internet.

Por otro lado, el tipo de distribución será directa debido a que se establecerá una relación con los consumidores conformados por los centros de atención de salud privados, sin contar con ningún tipo de intermediarios ni distribuidores externos.

Figura 2.9

Distribución directa

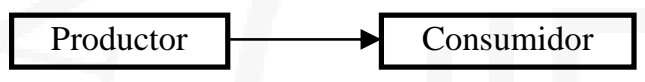

Elaboración propia

Así mismo, el canal de distribución estará conformado por los siguientes flujos:

- El flujo físico conformado por las telas del PP y los hilos proporcionados por los proveedores, y los juegos de scrubs y batas que serán entregados a los clientes.

- El flujo financiero conformado por los desembolsos y créditos otorgados a los clientes y los flujos de pago o endeudamiento contraídos con los proveedores.

- El flujo de información producido por la comunicación entre empresa y clientes.

- El flujo de riesgo ocasionado por las variaciones en los pronósticos realizado para las ventas, la obsolescencia de las máquinas, los productos que tendrán fecha de caducidad, algún tipo de penalidad ocasionada por productos defectuosos, las variaciones en los precios, entre otros.

Existen conflictos llamados verticales debido a que se tratan de problemas entre empresas de diferentes niveles que pertenecen al mismo canal como por ejemplo discordancias entre representantes o por incumplimiento en pagos o en entregas por parte de 
empresa o proveedor. Son los más comunes, y se consideraron como acontecimientos que podrían suceder durante la etapa operativa del proyecto y que deberán evitarse.

La dinámica del canal de mercadotecnia estará caracterizada por un Sistema Multicanal también conocido como Sistema Híbrido de Marketing, ya que las ventas se realizarán de manera directa con el consumidor, de tal manera que la empresa hará de productora, mayorista y detallista. El objetivo será obtener economías de escala para ofrecer productos a bajos costos, eliminar servicios duplicados de tal manera que disminuyan los gastos operativos y administrativos y favorecer la venta personalizada de los productos con las redes privadas de salud. Así mismo, se contempla que a medida que aumenta la demanda y la capacidad de la empresa se logré llegar a otros segmentos de clientes, tales como las redes públicas de salud, con lo cual se podrá obtener mayor penetración de mercado.

La Estrategia de Distribución será Exclusiva, en donde el único distribuidor será la misma empresa, de modo tal que se podrá obtener un mejor control sobre los precios, promociones, programas de créditos a clientes y transporte de mercancías. Esto permite que la empresa proporcione una mejor imagen y obtenga márgenes de ganancia elevados.

\subsubsection{Publicidad y Promoción}

El modelo de promoción incluirá los siguientes elementos:

- La promoción de ventas para incentivar a los clientes por comprar los productos. Para ello se entregarán muestras gratis al inicio para que conozcan los beneficios. Además, se incentivará a la fuerza de ventas de la propia empresa mediante objetivos y comisiones.

- La publicidad será utilizada para dar a conocer los productos y establecer mayor comunicación con los clientes utilizando medios masivos y no masivos.

- La venta personal será se suma importancia debido a que se trata de una distribución directa y exclusiva. Por ello se contará con una fuerza de ventas encargados de establecer una comunicación directa con el comprador, estableciendo una relación estrecha y brindando respuestas rápidas.

- Las relaciones públicas servirán para aumentar el número y tipo de clientes potenciales. Mediante noticias y comerciales en redes sociales, el objetivo será posicionarse en el mercado y destacar una buena imagen corporativa. Este tipo de 
Marketing es una presentación elogiosa y no pagada de la empresa, que tendrá el mismo peso y valor, e incluso mayor importancia que el Marketing pagado. Además, brinda alta credibilidad acerca de los beneficios de las prendas y podría producir sensacionalismo al tratarse de productos novedosos

- Finalmente, el Marketing Directo permitirá que se establezca una comunicación más cercana con los consumidores, brindando respuestas inmediatas y cultivando relaciones sólidas con ellos. Esta comunicación será no pública y personalizada.

Los elementos mencionados anteriormente, tendrán una importancia relativa igual a la de los bienes industriales como se muestra en la siguiente Figura.

Figura 2.10

Importancia relativa de los instrumentos de promoción

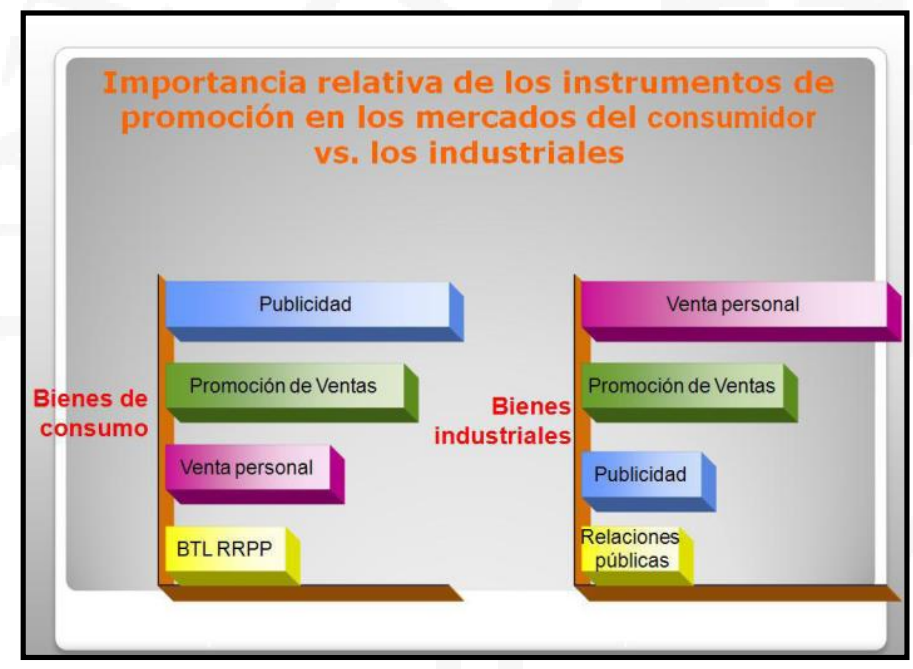

Fuente: Promoción y Publicidad - Marketing (2016)

Para difundir la publicidad de los productos, se utilizarán los siguientes medios publicitarios convencionales:

- Las Revistas Periódicas también podrán ser utilizados como complemento tratando de proporcionar la información que otros medios no se pudo.

- El medio publicitario más importante y de bajo costo que deberá de ser el más estudiado y potenciado serán las Revistas Especializadas, debido a que tratan temas específicos. En el caso del sector salud, existen una diversidad de revistas, tales como el Acta Médica Peruana del Colegio Médico del Perú y La Revista Peruana de 
Medicina Experimental y Salud Pública del Instituto Nacional de Salud. En el caso del sector económico tenemos la Semana Económica, Perú Económico, Revista Business, etc. De esta manera, se llega de manera directa al mercado meta.

- Las Páginas Web es el canal publicitario más utilizado, el más barato, no tiene límite tiempo o espacio y es de fácil acceso. Por ello será importante promocionar las prendas mediante una página propia de la empresa e incursionar en las redes sociales para tener mayor alcance.

Por otro lado, se utilizará la técnica publicitaria Below The Line (BTL), cuyo objetivo será impactar al consumidor mediante medios masivos no tradicionales de publicidad de una manera más creativa, innovadora y sorprendente, a fin de que los mensajes publicitarios atraigan con mayor efectividad la atención de los consumidores y se queden grabados en sus mentes, Esta técnica engloba todas las características de promoción y publicidad mencionadas anteriormente, como el Marketing Directo, las Relaciones Públicas.

Finalmente, se utilizará la Estrategia Push o Empujar de Mezcla de Promoción cuyas actividades de marketing principales son la venta personal y la promoción comercial, a fin de utilizar la fuerza de ventas para desarrollar el producto y promoverlo antes los consumidores. A continuación, en la Figura se muestran las Estrategias de Empujar y Jalar.

Figura 2.11

Estrategias de promoción

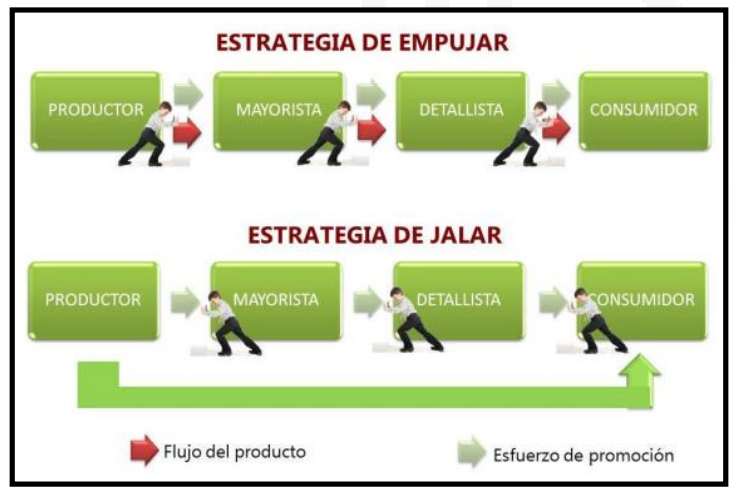

Fuente: Blog Spot (2015) 


\subsubsection{Análisis de precios}

El precio es un factor fundamental de la Mezcla de Marketing que afecta tanto a la competitividad como al posicionamiento en el mercado. El enfoque que se utilizará para la determinación de precios será en base a los costos, en donde la empresa fijará un monto para cubrir los costos y gastos fijos y variables más una utilidad meta. En primer lugar, se determinarán los costos y gastos totales, después se fijará el precio y luego se determinará el valor que será percibido por los clientes. En la siguiente Figura, se puede observar una comparación entre la determinación en base al costo y en base al valor.

Figura 2.12

Determinación de Estratégicas de Precios costo versus valor

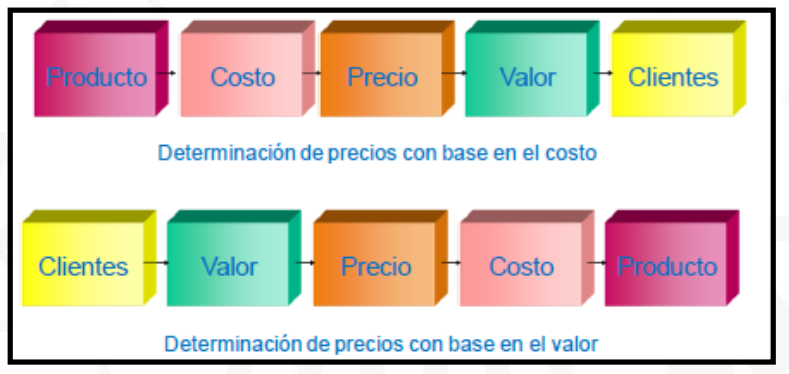

Fuente: Estrategias de Precio - Marketing (2015)

La fijación de precios tiene como objetivos maximizar utilidades, aumentar volumen de ventas, incrementar participación de mercado, estabilizar precios y actuar oportunamente frente a la competencia. Para el presente estudio preliminar se utilizará la técnica de costo más margen, en la que se calculará el costo del producto y se le sumará un margen de utilidad.

Debido a que las prendas desechables son productos nuevos e innovadores para el mercado, se utilizará la Estrategia de Precio de Penetración de Mercado. Esta consistirá en fijar un precio bajo a fin de combatir la competencia y atraer la mayor cantidad de compradores, logrando rápidamente una amplia participación de mercado. Esta es la mejor estrategia debido a que los productos pueden tener un gran mercado masivo, se pueden reducir los costos mediante economías de escala y porque existe fuerte competencia genérica de productos sustitutos.

Finalmente, la Política de Precios buscará mantener las decisiones de la empresa en concordancia con los objetivos financieros y estratégicos. Estas políticas procurarán ser 
permanentes y solo se modificarán para adoptar cambios importantes en el mercado o ante la respuesta de la competencia. Para ello se utilizará la Política de Precios Fijos.

\subsubsection{Tendencia histórica de los precios}

Como se explicó anteriormente, entre los bienes sustitutos existentes se encuentran las batas y scrubs de hilos de plata o en base a yuca, que varían en precios y calidades según su fabricante.

En el caso de las prendas nacionales, se conoce que los precios de las batas se encuentran entre 20 y 30 soles, mientras que un conjunto scrub cuesta entre 50 y 60 soles. Por otro lado, las prendas importadas tienen mejor calidad y duración, y sus precios varían entre las diferentes marcas. Por ejemplo, las batas de las marcas Dickies y Cherokee en el Perú cuestan entre 120 y 150 nuevos soles, y sus conjuntos scrubs entre 180 y 240 soles.

\subsubsection{Precios actuales}

México es uno de los países con mayor producción de prendas desechables de PP, en donde el precio de venta por unidad es 22.6 pesos mexicanos en promedio. A una tasa de 10 pesos mexicanos por cada 2.01 nuevos soles, cada prenda tendría un precio de 4.54 nuevos soles. Por otro lado, China es el país donde se encuentra la mayor producción y los precios más bajos, vende cada prenda de PP SMS en promedio a 0.6 dólares americanos, que a una tasa de 3.18 soles por dólar, cada unidad estaría costando 1.91 nuevos soles.

Los precios de México y China corresponden a los precios más altos y bajos respectivamente, a los cuales se venden las prendas médicas desechables. Por ello la estrategia de precios será conseguir los costos más bajos de producción como en China, para vender los productos a precios asequibles y conseguir la mayor utilidad posible.

Para complementar la información anterior, se introdujo en la parte final de la entrevista, una pregunta que permitió determinar el precio al que los consumidores estaban dispuestos a pagar para adquirir las prendas. Con el resultado se concluyó que una quinta parte de las clínicas compraría los productos a un precio entre 3 y 4 nuevos soles.

Esto significa que, igualando los costos de producción de China, se podría obtener hasta una utilidad de $200 \%$ por unidad vendida. 


\subsection{Disponibilidad de Materias Primas}

\subsubsection{Características de la Materia Prima}

La tela no tejida de Polipropileno está formada por 3 capas, dos externas de tecnología Spunbond y una interna de tecnología Meltblown.

Para el presente proyecto se considerarán como materias primas las telas de polipropileno Spunbond y Meltblown, y en la siguiente Figura 2.9 se puede observar la forma en la que ambas telas se unen para formar la tela no tejida de Polipropileno SMS.

Figura 2.13

Partes de la tela de Polipropileno SMS

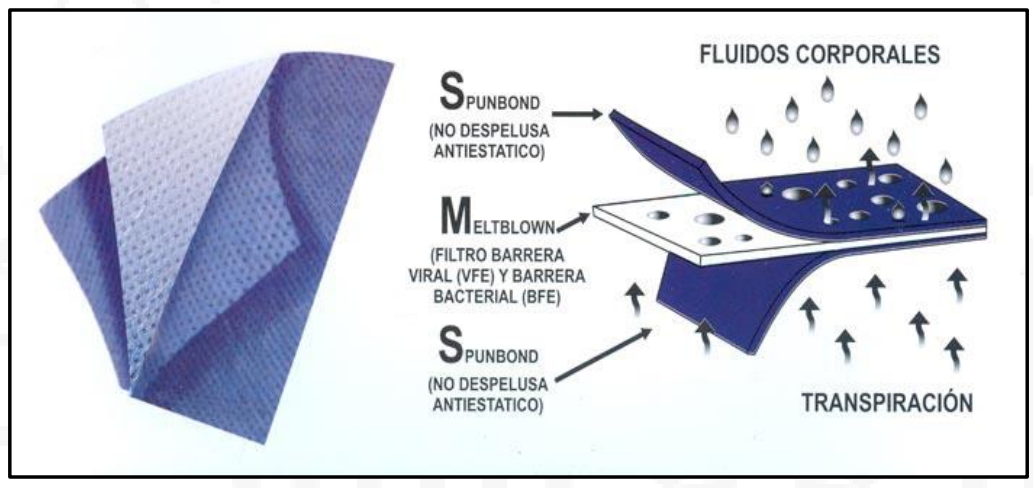

Fuente: Grupo Camed (2015)

Las propiedades y beneficios de las prendas desechables ecológicas radican en las propias características de las materias primas, las cuales se detallan a continuación.

- Compuestas 100\% de polipropileno SMS.

- Posee una alta tenacidad (valor: 7), resistencia a la abrasión y fuerte elongación

- El acabado hidrofílico debido a sus 3 capas de tela permite que sea permeable.

- Se produce mediante un proceso que permite que este estabilizada térmicamente y que las capas estén adheridas unas a otras.

- Tiene alta resistencia a ataques microbianos, lo cual permite la protección a la salud de las personas.

- Es anticorrosiva gracias a su resistencia a ácidos y soda cáustica. 
- Baja carga electrostática no atrae el polvo a la superficie de la tela, lo que genera menor ensuciamiento y mejor limpieza.

- Son no tóxicas, suaves y ligeras

- Resistente a altas temperaturas y fuerte elongación.

Los geotextiles tienen diferentes aplicaciones en la industria, ya que además de ser utilizados para prendas médicas desechables, también pueden utilizarse como filtros, bolsas para transporte de productos, para la confección de pañales, como maleta interlínea agrícola para cubiertas, entre otros usos en diferentes sectores económicos.

\subsubsection{Disponibilidad y costos de la materia prima}

En el Perú, el mercado de producción de geotextiles se encuentra en plena etapa de introducción, razón por la cual existen aún muy pocas empresas constituidas capaces de abastecer pedidos de grandes volúmenes. Mediante a un pequeño sondeo entre especialistas, se ha detectado la presencia de pequeñas empresas que producen bajas cantidades de tela no tejida con locaciones en el Distrito de San Miguel.

En vista de que la producción peruana de estas telas podría ser insuficiente, se ha recurrido a investigar empresas de otros países de las cuales se podrían importar estos productos. A continuación, se muestran empresas provenientes de China que exportan Geotextiles a diferentes partes del mundo, indicando para cada una de ellas el precio promedio FOB en dólares americanos por cada tonelada, la máxima capacidad de suministro en toneladas al año y el plazo de entre de los pedidos en días. 
Tabla 2.25

Listado de proveedores de tela no tejida de polipropileno

\begin{tabular}{llll}
\hline Nombre de la empresa & $\begin{array}{l}\text { Precio } \\
\text { Promedio } \\
\text { FOB } \mathbf{\$} / \mathbf{t n})\end{array}$ & $\begin{array}{l}\text { Capacidad de } \\
\text { suministro } \\
\text { (tn/año) }\end{array}$ & $\begin{array}{l}\text { Plazo } \\
\text { entrega } \\
\text { (días) }\end{array}$ \\
\hline Qingdao Lanrungroup Industrial Co., Ltd & 1,866 & 5,000 & 9 \\
Shandong Laifen Nonwoven Fabric Co., Ltd & 1,825 & 8,000 & 7 a 10 \\
Beijing Beichuang non Woven Fabric Co., Ltd & 2,300 & 3,650 & 15 \\
Changle Heng Hua Plastics Co., Ltd & 1,625 & 5,400 & 10 \\
Sunshine Nonwoven Fabric Co., Ltd & 2,000 & 9,600 & 15 \\
Guangzho Xinhuilian Non-Woven Fabric Co., Ltd & 1,650 & 28,800 & 7 \\
Quanzhou Golden Nonwoven Co., Ltd & 2,722 & 12,600 & 15 \\
Shouguang Fenghui New Materials Co., Ltd & 2,350 & 20,000 & 16 \\
Xiamen Xiyao Nonwoven Trading Co., Ltd & 1,650 & 18,000 & 7 a 15 \\
Guangzhou Huahao Non-Woven fabric Co., Ltd & 1,850 & 18,000 & 7 \\
Foshan Ruixin non Woven Co., Ltd & 2,075 & 10,800 & 7 \\
Sunshine Nonwoven Fabric \& Clothes Co., Ltd & 1,750 & 18,000 & 15 \\
Dongguan Hengli Nonwoven fabric Co., Ltd & 2,200 & 1,800 & 7 \\
Guangzhou Jinsheng Huihuang Fabric Industrial C., Ltd & 2,350 & 25,200 & 10 \\
Dongxiang Chemicl \& Light Industrial Textile Co., Ltd & 1,825 & 10,800 & 10 a 20 \\
Promedio & $\mathbf{1 , 9 3 6}$ & $\mathbf{1 2 , 6 0 3}$ & $\mathbf{1 1}$ \\
\hline
\end{tabular}

Nota: $\mathrm{FOB}=$ Free on Board.

Fuente: Datos obtenidos de Alibaba (2017)

Al final de la tabla anterior, se calculó un promedio de los indicadores mencionados anteriormente y se llegó a las siguientes conclusiones:

- El precio promedio FOB es de 272,290 dólares americanos por cada tonelada de tela de polipropileno.

- La capacidad de abastecimiento máxima promedio al año que contaría la empresa es de 12603.33 toneladas.

- Aproximadamente los pedidos se demoran en llegar entre 1 y dos semanas, dependiendo de la capacidad semanal de cada empresa. 


\section{CAPÍTULO III: LOCALIZACIÓN DE PLANTA}

\subsection{Identificación y análisis detallado de los factores de localización}

Para este análisis es necesario evaluar factores económicos, sociales, tecnológicos y de mercado, los cuales permitirán tomar la mejor decisión de localización. A continuación, se presentan los factores considerados como fundamentales:

- Disponibilidad de materia prima: este factor es sumamente importante para la evaluación debido a que la tela SMS no se encuentran fácilmente en el mercado nacional, pero si en el internacional.

- Cercanía al mercado: debido a que se desarrollara venta directa a las principales clínicas y hospitales del país, este es un factor importante que evaluar para garantizar la rapidez de entregas y el contacto con el cliente.

- Costo promedio del terreno: es de suma importancia esta evaluación, de manera que permita calcular la inversión en construcción o alquiler de la plata, así mismo se debe considerar el costo promedio de los terrenos en zonas estratégicas.

- Acceso a puertos: este factor es importante debido a que debemos considerar la accesibilidad que van a tener los barcos que traen la materia prima a la zona de producción.

- Seguridad ciudadana: debido a que se debe contemplar un establecer la planta en un distrito seguro para los colaboradores y clientes que la visitarán.

\subsection{Identificación y descripción de las alternativas de localización}

Respecto a las alternativas de localización a nivel regional (macro localización), se consideró Arequipa, La Libertad y Lima, debido a que se encuentran en la costa del Perú con acceso a los principales puertos de Ilo, Salaverry y Callao, los cuales con su cercanía reducirían los costos en la importación de materia prima y maquinarias. Así mismo, cuentan con aeropuertos cercanos, que facilitaran el contacto con los clientes y proveedores a nivel nacional e internacional. Estas regiones están inmunes a la desaceleración y se espera un crecimiento de $10 \%$ en los próximos años, lo cual las hace más atractivas. Cabe resaltar que 
en estas regiones se cuenta con grandes hospitales, clínicas y universidades, las cuales son un amplio mercado para este producto.

Se tomarán los siguientes factores para elegir la mejor alternativa:

- Disponibilidad de materia prima

- Cercanía al mercado

- Costo promedio del terreno

- Cercanía a puertos

\section{Región de Arequipa}

Respecto al factor de disponibilidad de materia prima, en esta ciudad no se cuenta con fábricas que produzcan telas de polipropileno SMS, sin embargo, se encuentra cerca del puerto de Matarani e Ilo, donde pueden arribar las importaciones desde China y esto podría tardar aproximadamente 30 días en llegar desde que se hace el pedido según lo cotizado con el proveedor Quanzhou Golden Nonwoven CO LTD. La ruta desde el puerto de Matarani hasta la ciudad de Arequipa tiene una distancia de 116 km, la cual tardaría 1 hora y 40 minutos en ser recorrida yendo a una velocidad promedio de $69 \mathrm{~km} / \mathrm{h}$, según la página http://es.distancias.himmera.com/

En cuanto a la cercanía al mercado según el informe "Infraestructura del Sector Salud por tipo de establecimiento, según departamento, 2016" presentado por el INEI, Arequipa cuenta con 857 establecimientos, institutos de salud, hospitales, postas y centros de salud. Comparado con el resto de las regiones ocupa el segundo lugar.

Respecto al costo del terreno en la región Arequipa varian desde los 1,000 USD hasta 192 USD el $\mathrm{m}^{2}$ dependiendo de las zonas industriales en las que se encuentren, en base a los precios públicos de la venta de terrenos que se encuentran en los principales portales inmobiliarios, se puede concluir que el costo promedio del m2 en la ciudad de Arequipa es de 597 USD.

La ciudad de Arequipa cuenta con acceso a un puerto que se encuentra a una hora y cuarenta minutos de la ciudad, el cual está en el distrito de Islay y lleva por nombre Matarani. $\mathrm{Su}$ área de influencia es Arequipa, Moquegua, Puno y Cusco. Una de sus potencialidades es el gran comercio macrorregional. Respecto a los servicios portuarios con los que cuenta este puerto se tiene amarraderos, almacenes y manipuleo de las cargas, los cuales pueden 
funcionar en simultaneo para atender hasta 3 naves. Debido a que la materia prima se importara en contenedores es importante evaluar el metraje del almacén de contenedores del puerto, el cual en este caso es de $22,112.21 \mathrm{~m}^{2}$.

\section{Región de La Libertad}

Respecto al factor de disponibilidad de materia prima, en esta ciudad no se cuenta con fábricas que produzcan telas de polipropileno SMS, sin embargo, se encuentra cerca del puerto de Salaverry, donde pueden arribar las importaciones desde China y esto podría tardar aproximadamente 30 días en llegar desde que se hace el pedido según lo cotizado con el proveedor Quanzhou Golden Nonwoven CO LTD. La ruta desde el puerto de Salaverry hasta la ciudad de Trujillo tiene una distancia de $14.5 \mathrm{~km}$, la cual tardaría 25 minutos en ser recorrida yendo a una velocidad promedio de $35 \mathrm{~km} / \mathrm{h}$, según la página http://es.distancias.himmera.com/

En cuanto a la cercanía al mercado según el informe "Infraestructura del Sector Salud por tipo de establecimiento, según departamento, 2016" presentado por el INEI, La Libertad cuenta con 602 establecimientos, institutos de salud, hospitales, postas y centros de salud. Comparado con el resto de las regiones ocupa el tercer lugar.

Respecto al costo del terreno en la región La Libertad varían desde los 163 USD hasta 119 USD el $\mathrm{m}^{2}$ dependiendo de las zonas industriales en las que se encuentren, en base a los precios públicos de la venta de terrenos que se encuentran en los principales portales inmobiliarios, se puede concluir que el costo promedio del $\mathrm{m}^{2}$ en la ciudad de La Libertad es de 147 USD.

La Libertad cuenta con acceso al puerto de Salaverry que se encuentra a 28 minutos de la ciudad de Trujillo, el cual está en el distrito de Salaverry y su área de influencia es La Libertad, Lambayeque, Cajamarca y Lima. Respecto a los servicios portuarios con los que cuenta este puerto se tiene amarraderos, almacenes y manipuleo de las cargas, los cuales pueden funcionar en simultaneo para atender hasta 2 naves. Debido a que la materia prima se importara en contenedores es importante evaluar el metraje del almacén de contenedores del puerto, el cual en este caso es de $7,440 \mathrm{~m}^{2}$. 


\section{Región de Lima}

Respecto al factor de disponibilidad de materia prima, en esta ciudad no se cuenta con fábricas que produzcan telas de polipropileno SMS, sin embargo, se encuentra cerca del puerto del Callao, donde pueden arribar las importaciones desde China y esto podría tardar aproximadamente 30 días en llegar desde que se hace el pedido según lo cotizado con el proveedor Quanzhou Golden Nonwoven CO LTD. La ruta desde el puerto del Callao hasta la ciudad de Lima tiene una distancia de $10.7 \mathrm{~km}$, la cual tardaría 18 minutos en ser recorrida yendo a una velocidad promedio de $33 \mathrm{~km} / \mathrm{h}$, según la página http://es.distancias.himmera.com/

En cuanto a la cercanía al mercado según el informe "Infraestructura del Sector Salud por tipo de establecimiento, según departamento, 2016" presentado por el INEI, Arequipa cuenta con 6251 establecimientos, institutos de salud, hospitales, postas y centros de salud. Comparado con el resto de regiones ocupa el primer lugar.

Respecto al costo del terreno en la región Lima varian desde los 1300 USD hasta 229 USD el $\mathrm{m}^{2}$ dependiendo de las zonas industriales en las que se encuentren, en base a los precios públicos de la venta de terrenos que se encuentran en los principales portales inmobiliarios, se puede concluir que el costo promedio del $\mathrm{m}^{2}$ en la ciudad de Lima es de 609 USD.

Lima es la ciudad capital de Perú y cuenta, con tres vías de acceso terrestres, el puerto del Callao y un aeropuerto a través de las cuales se puede recibir de manera rápida la materia prima.

Lima cuenta con acceso a un puerto del Callao y que se encuentra a 42 minutos de la ciudad de Lima, el cual está en la provincia constitucional del Callao y su área de influencia es Lima, Cerro de Pasco, Huánuco, Ayacucho, Junín y Huancavelica. Respecto a los servicios portuarios con los que cuenta este puerto se tiene amarraderos, almacenes y manipuleo de las cargas, los cuales pueden funcionar en simultaneo para atender hasta 8 naves. Debido a que la materia prima se importara en contenedores es importante evaluar el metraje del almacén de contenedores del puerto, el cual en este caso es de $215,000 \mathrm{~m}^{2}$. 


\subsection{Determinación del modelo de evaluación a emplear}

Para realizar esta evaluación se aplicará ranking de factores, la cual debe evaluar la importancia relativa, empleando los puntajes que se muestran a continuación.

\section{Tabla 3.1}

Puntuación de factores

\begin{tabular}{ll}
\hline Puntaje & Situación \\
\hline 1 & Más o igualmente importante \\
0 & Menos importante \\
\hline $\begin{array}{l}\text { Nota: } \text { Puntaje para el ranking de factores. } \\
\text { Elaboración propia }\end{array}$
\end{tabular}

Posteriormente la tabla de enfrentamiento muestra la importancia relativa de cada factor la cual luego se califica según el criterio mostrado a continuación.

Tabla 3.2

Escala de calificación

\begin{tabular}{ll}
\hline Puntaje & Calificación \\
\hline 6 & Bueno \\
4 & Regular \\
2 & Deficiente \\
\hline
\end{tabular}

Nota: Escala de calificación para el ranking de factores.

Elaboración propia

\subsection{Evaluación y selección de la localización}

\subsubsection{Evaluación y selección de la macro localización}

Se ha determinado como factor más importante la cercanía a puertos, debido a que el proceso posee como materia prima principal la tela SMS importada de China. En segundo lugar, de importancia, se considera la cercanía del mercado, debido a la importancia del número de establecimientos en cada ciudad, como la cantidad de establecimientos de salud y el número de profesionales de la salud. En tercer lugar, de importancia se deben considerar el costo promedio del terreno, ya que representa un costo significativo en la inversión del proyecto.

En cuarto lugar, de importancia se ubica la disponibilidad de materia prima, ya que esta solo se encuentra en el extranjero y debe ser importada por lo cual ninguno de los departamentos tiene ventaja competitiva con el otro. 
Finalmente, con la importancia de los factores definida, se procede a realizar la tabla de enfrentamiento para comparar uno con otro como se muestra a continuación.

\section{Tabla 3.3}

Tabla de enfrentamiento y Tabla de Ranking de Factores

\section{Factores de Localización}

a. Disponibilidad de Materia Prima

b. Cercanía de mercado

c. Costo promedio del terreno

d. Cercanía a puertos

\begin{tabular}{|c|c|c|c|c|c|c|c|c|c|c|c|c|}
\hline \multicolumn{7}{|c|}{ Tabla de Enfrentamiento } & \multicolumn{6}{|c|}{ Tabla de Ranking de Factores } \\
\hline \multirow{2}{*}{ Factor } & \multirow{2}{*}{$\mathbf{a}$} & \multirow{2}{*}{ b } & \multirow{2}{*}{ c } & \multirow{2}{*}{ d } & \multirow{2}{*}{\multicolumn{2}{|c|}{ Conteo Ponderación }} & \multicolumn{2}{|c|}{ Arequipa } & \multicolumn{2}{|c|}{ La libertad } & \multicolumn{2}{|c|}{ Lima } \\
\hline & & & & & & & Calificación & Puntaje & Calificación & Puntaje & Calificación & Puntaje \\
\hline $\mathbf{a}$ & & 0 & 0 & 0 & 0 & 0.00 & 2 & 0.00 & 2 & 0.00 & 2 & 0.00 \\
\hline b & 1 & & 1 & 0 & 2 & 0.33 & 2 & 0.67 & 4 & 1.33 & 6 & 2.00 \\
\hline c & 1 & 0 & & 0 & 1 & 0.17 & 4 & 0.67 & 2 & 0.33 & 6 & 1.00 \\
\hline d & 1 & 1 & 1 & & 3 & 0.50 & 2 & 1.00 & 4 & 2.00 & 6 & 3.00 \\
\hline & & Tota & & & 6 & 1.00 & & 2.33 & & 3.67 & & 6.00 \\
\hline
\end{tabular}

Elaboración propia

\section{Escala de Calificación}

6 Bueno

4 Regular

2 Deficiente

Como se muestra en el cuadro anterior se define Lima como región para ubicar la planta, debido a que obtuvo el mejor puntaje en el análisis.

\subsubsection{Evaluación y selección de la micro localización}

Luego de realizar la macro localización y elegir la región Lima, es necesario analizar en el que localidad se ubicará la planta. Este departamento cuenta con gran número de distritos y es necesario hacer una evaluación considerando reducir costos y maximizar utilidades.

Los distritos que fueron elegidos para ubicar la planta son Ate, Chilca y Cercado de Lima, ya que en estos se concentra gran parte de las fábricas industriales.

Así mismo, los factores a considerar son:

- Trámites municipales

- Seguridad ciudadana

- Alquiler del terreno

- Costo de los servicios públicos

Se ha determinado como factor más importante el valor del alquiler del terreno, debido a que el proceso requiere un aseguramiento de este recurso. En segundo lugar, costos de 
servicios públicos que es muy importante para reducir costos que básicos que en otros distritos pueden ser más elevados. En tercer lugar, está el factor de seguridad ciudadana que hace referencia al número de internos en un penal por distrito, debido a que es importante garantizar una buena protección de los activos y del personal que concurrirán a aquel distrito. En cuarto lugar, está el costo de los trámites municipales.

Finalmente, con la importancia de los factores definida, se procede a realizar la tabla de enfrentamiento para comparar uno con otro como se muestra a continuación.

\section{Distrito de Ate}

Respecto a los trámites municipales, según la Municipalidad de Ate, el tiempo que podría tardar obtener una licencia puede depender del metraje cuadrado de las instalaciones, en caso se trate de una licencia de funcionamiento G2 para un recinto mayor a los $100 \mathrm{~m}^{2}$ y menor a los $500 \mathrm{~m}^{2}$, el tiempo sería de 12 días hábiles; de ser una licencia de funcionamiento G1 para un área menor a los $100 \mathrm{~m}^{2} \mathrm{o}$ una licencia de funcionamiento $\mathrm{G} 3$ para un área mayor a los $500 \mathrm{~m}^{2}$ el tiempo sería de 7 días.

Respecto a la seguridad ciudadana, el $5.54 \%$ de los habitantes del distrito están internos en un penal, según el Informe Estadístico Penitenciario, agosto 2016, INPE (2016).

Para la evaluación de alquiler de terreno, cabe resaltar, que en los últimos años el precio de metro cuadrado se ha inflado $50 \%$ y aproximadamente alcanza los 873 dólares, según la Asociación de Empresas Inmobiliarias del Perú (ASEI).

Finalmente, se evaluó el costo de servicios públicos, específicamente del m3 de agua el cual esta zona bordea los 7.05 Soles.

\section{Distrito de Chilca}

Respecto a los trámites municipales, según la Municipalidad de Ate, el tiempo que puede llegar a tomar obtener una licencia de funcionamiento para un establecimiento industrial es de 15 días.

Respecto a la seguridad ciudadana, basándonos en el tamaño de la población del distrito de Chilca y comparándolo con un distrito de Lima debido a su cercanía, se aproxima que el $2.34 \%$ de los habitantes del distrito están internos en un penal, según el Informe 
Estadístico Penitenciario, agosto 2016, INPE (2016) y los Censos Nacionales de Población y Vivienda 1993,2007,2017.

Para la evaluación del alquiler de terrenos, Chilca es un distrito en el que el costo del terreno el cual bordea los 180 dólares el metro cuadrado, según Colliers International en su publicación "Precios de venta (precio de lista) de locales industriales - por corredor" en julio del 2017. Finalmente, se evaluó el costo de servicios públicos, específicamente del m3 de agua el cual esta zona bordea los 7.05 Soles.

\section{Distrito de Cercado de Lima}

Respecto a los trámites municipales el tiempo que puede llegar a tomar obtener una licencia de funcionamiento para un establecimiento industrial es de 30 días, según la Municipalidad de Lima.

Respecto a la seguridad ciudadana, el $3.28 \%$ de los habitantes del distrito están internos en un penal, según el Informe Estadístico Penitenciario, agosto 2016, INPE (2016).

Para la evaluación de alquiler de terrenos, el Cercado de Lima es un distrito en el que el costo del terreno el cual bordea los 1388 USD el metro cuadrado, según la Asociación de Empresas Inmobiliarias del Perú (ASEI).

Finalmente, se evaluó el costo de servicios públicos, específicamente del m3 de agua el cual esta zona bordea los 7.051 Soles.

\section{Tabla 3.4}

Tabla de enfrentamiento y Tabla de Ranking de Factores

\section{Factores de Localización}

a. Trámites municipales

b. Seguridad ciudadana

c. Alquiler de terreno

d. Costo de los servicios públicos

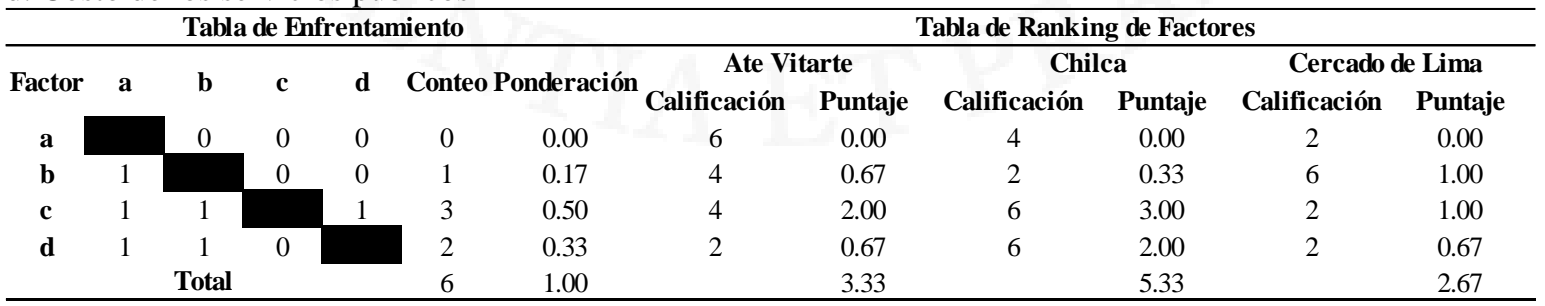

Escala de Calificación

6 Bueno

4 Regular

2 Deficiente

Elaboración propia 


\section{CAPÍTULO IV: TAMAÑO DE PLANTA}

\subsection{Relación tamaño-mercado}

Esta relación establece el límite superior, para determinar el tamaño de planta, siendo este el máximo que podrá alcanzar la unidad productiva. Para este cálculo se requiere de la demanda, la cual se debe proyectar para los años del proyecto, debido a que la demanda del último año es la que determina el tamaño de planta.

Debido a que se ofrecen dos productos, es necesario hacer una demanda agregada, para la que se consideró la suma de ambas demandas debido a que la diferencia entre ambas es de un bajo margen.

\section{Tabla 4.1}

Demanda agregada proyectada

\begin{tabular}{llll}
\hline Años & Demanda de batas & $\begin{array}{l}\text { Demanda } \\
\text { Scrubs }\end{array}$ & $\begin{array}{l}\text { de } \\
\text { Demanda } \\
\text { Proyecto }\end{array}$ \\
\hline 2014 & 826199 & 38580 & 735062 \\
2015 & 888632 & 44453 & 793122 \\
2016 & 892993 & 43155 & 795726 \\
2017 & 936068 & 46637 & 835299 \\
2018 & 969465 & 48925 & 865631 \\
2019 & 1002862 & 51212 & 895963 \\
2020 & 1036259 & 53500 & 926295 \\
2021 & 1069656 & 55787 & 956627 \\
2022 & 1103053 & 58075 & 986959 \\
2023 & 1136450 & 60363 & 1017291 \\
\hline
\end{tabular}

Nota: Se consideró para la demanda agregada la proporción de uno a uno. Elaboración propia

\subsection{Relación tamaño-recursos productivos}

Para esta evaluación se analizará la disponibilidad de materia prima que requiere el proceso productivo, lo cual permitirá reconocer este factor como limitante o no. Para este proyecto se evaluará la disponibilidad de polipropileno SMS, debido a que esta es la materia prima principal para el proceso. 
En el desarrollo de estos cálculos como input se obtuvo información del Instituto Nacional de Estadística e Informática (INEI) y TradeNosis- COMEX, siendo esta la que se aplicó a la fórmula para obtener la cantidad de materia prima ofertada.

Cantidad de Materia Prima = Producción Nacional + Importaciones - Exportaciones

Finalmente, teniendo la información desde el año 2012 al 2016, se utilizó la regresión lineal de la oferta anual para la proyección hasta el 2013. Además, con la información del capítulo anterior, sabemos que las fibras de polipropileno corresponden al $21.1 \%$ de las fibras sintéticas, dato con el que se obtuvo la cantidad de kilogramos de polipropileno SMS anuales. Por último, el peso de cada prenda es de 22 gramos, con esta información calculamos la cantidad de prensas médicas que podrían producirse con la oferta de polipropileno, asumiendo que el $100 \%$ se podría utilizar para el sector textil.

\section{Tabla 4.2}

Oferta de Materia Prima para Perú

\begin{tabular}{lllllll}
\hline \multicolumn{7}{l}{ Telas de fibra sintética } \\
\hline Año & $\begin{array}{l}\text { Producción } \\
(\mathbf{k g})\end{array}$ & $\begin{array}{l}\text { Exportación } \\
(\mathbf{k g})\end{array}$ & $\begin{array}{l}\text { Importaciones } \\
(\mathbf{k g})\end{array}$ & Oferta $(\mathbf{k g})$ & $\begin{array}{l}\text { Tela } \\
\text { Polopropileno } \\
\text { SMS (kg) }\end{array}$ & $\begin{array}{l}\text { Prendas } \\
\text { médicas } \\
\text { (und.) }\end{array}$ \\
2012 & $3,536,270$ & $1,725,000$ & $4,445,250$ & $6,256,520$ & $1,320,126$ & $60,005,715$ \\
2013 & $3,126,275$ & $2,300,000$ & $5,927,000$ & $6,753,275$ & $1,424,941$ & $64,770,047$ \\
2014 & $2,738,767$ & $3,202,000$ & $6,028,000$ & $5,564,767$ & $1,174,166$ & $53,371,174$ \\
2015 & $2,751,425$ & $2,357,000$ & $10,103,000$ & $10,497,425$ & $2,214,957$ & $100,679,849$ \\
2016 & $2,282,683$ & $1,205,000$ & $9,357,500$ & $10,435,183$ & $2,201,824$ & $100,082,887$ \\
2017 & & & & $11,531,879$ & $2,433,227$ & $110,601,203$ \\
2018 & & & & $12,742,027$ & $2,688,568$ & $122,207,623$ \\
2019 & & & & $13,952,175$ & $2,943,909$ & $133,814,042$ \\
2020 & & & & $15,162,323$ & $3,199,250$ & $145,420,462$ \\
2021 & & & & $16,372,471$ & $3,454,591$ & $157,026,881$ \\
2022 & & & & $17,582,619$ & $3,709,933$ & $168,633,300$ \\
2023 & & & & $18,792,767$ & $3,965,274$ & $180,239,720$ \\
\hline
\end{tabular}

Nota: Se calcula la oferta considerando la Producción, Exportación e Importación considerando que el 100\% puede utilizarse en la industria textil.

Elaboración propia 
Figura 4.1

Regresión para proyección de oferta

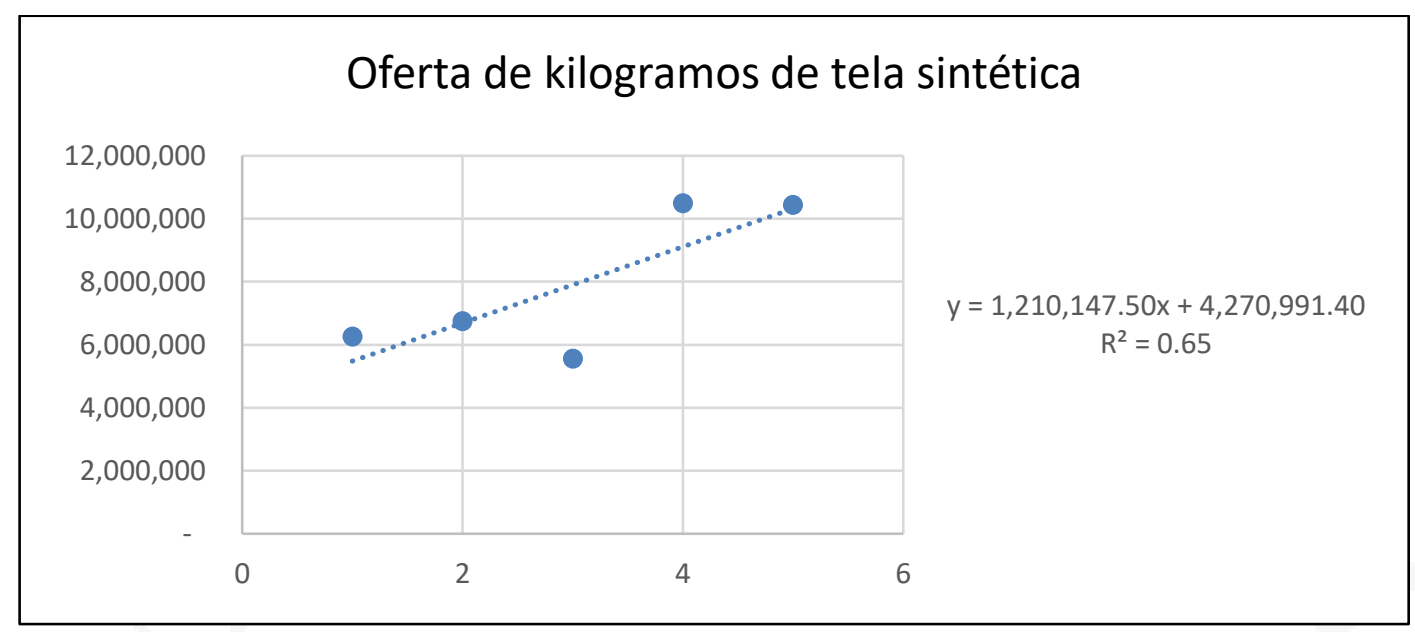

Elaboración propia

Finalmente, se concluye que se cuenta con recurso productivo suficiente para cubrir la demanda, lo cual no lo convierte en limitante para el tamaño de planta.

\subsection{Relación tamaño- tecnología}

Para el desarrollo de este factor se tecnología se consideró:

- 2 turnos/día

- 8 horas/turno

- 6 días/ semana

- 52 semanas/año

Generando un total de 4992 horas/año. A continuación, se presenta el cuadro con el balance de materia. 
Tabla 4.3

Cálculo de Tamaño- tecnología

\begin{tabular}{|c|c|c|c|c|c|c|c|c|c|c|c|c|c|c|}
\hline & & Qe & $\mathbf{P}$ & & $\mathbf{M}$ & $\mathbf{D} / \mathbf{S}$ & S/M & $\mathbf{H} / \mathbf{T}$ & $\mathbf{T}$ & $\mathbf{U}$ & $\mathbf{E}$ & $\mathrm{CO}$ & F/Q & $\mathrm{CO} * \mathrm{~F} / \mathrm{Q}$ \\
\hline Operación & Cantidad & Unidad & Prod/hora & Unidad & $\begin{array}{c}\text { \#Maqo } \\
\text { Persona } \\
\text { s }\end{array}$ & $\begin{array}{l}\text { Días/ } \\
\text { Sem }\end{array}$ & $\begin{array}{l}\text { Sem/ } \\
\text { Año }\end{array}$ & $\begin{array}{c}\text { Horas/T } \\
\text { urno }\end{array}$ & Turnos & $\begin{array}{c}\text { Factor } \\
\text { utilizació } \\
\mathbf{n}\end{array}$ & $\begin{array}{c}\text { Factor } \\
\text { eficienci } \\
\text { a }\end{array}$ & $\begin{array}{c}\mathbf{P} * \mathbf{M} * \mathbf{D} / \mathbf{S} * \mathbf{S} / \\
\mathbf{M} * \mathbf{M} / \mathbf{A}^{*} \mathbf{H} / \mathbf{T} \\
{ }^{*} \mathbf{T} * \mathbf{U}^{*} \mathbf{E}\end{array}$ & $\begin{array}{c}\text { Factor de } \\
\text { conversión }\end{array}$ & Cap de prod \\
\hline Inspección & $1,080,853$ & $\mathrm{~m} 2$ & 1,000 & $\mathrm{~m} 2 /$ hora & 1 & 6 & 52 & 8 & 2 & 0.85 & 0.90 & $3,818,880$ & 15 & $57,283,200$ \\
\hline Tendido y tizado & $1,059,236$ & $\mathrm{~m} 2$ & 100 & $\mathrm{~m} 2 /$ hora & 1 & 6 & 52 & 8 & 2 & 0.85 & 0.90 & 381,888 & 15 & $5,728,320$ \\
\hline Corte & $1,059,236$ & $\mathrm{~m} 2$ & 270 & batas/hora & 2 & 6 & 52 & 8 & 2 & 0.85 & 0.90 & $2,062,195$ & 1 & $2,062,195$ \\
\hline Cosido elastico a las mangas & $1,038,052$ & batas en piezas & 600 & batas/hora & 2 & 6 & 52 & 8 & 2 & 0.85 & 0.90 & $4,582,656$ & 1 & $4,491,003$ \\
\hline Sellado del resto de piezas & $1,038,052$ & batas en piezas & 600 & batas/hora & 1 & 6 & 52 & 8 & 2 & 0.85 & 0.90 & $2,291,328$ & 1 & $2,245,501$ \\
\hline Inspección y conteo & $1,038,052$ & Batas & 520 & batas/hora & 1 & 6 & 52 & 8 & 2 & 0.85 & 0.90 & $1,985,818$ & 1 & $1,946,101$ \\
\hline Etiquetado & $1,017,291$ & Batas & 360 & batas/hora & 2 & 6 & 52 & 8 & 2 & 0.85 & 0.90 & $2,749,594$ & 1 & $2,749,594$ \\
\hline Doblado y embolsado & $1,017,291$ & Batas & 360 & batas/hora & 1 & 6 & 52 & 8 & 2 & 0.85 & 0.90 & $1,374,797$ & 1 & $1,374,797$ \\
\hline Esterilizado & $1,017,291$ & Batas & 8,000 & batas/hora & 1 & 6 & 52 & 8 & 2 & 0.85 & 0.90 & $30,551,040$ & 1 & $30,551,040$ \\
\hline \multirow[t]{2}{*}{ Empaquetado } & $1,017,291$ & cajas & 200 & cajas/hora & 2 & 6 & 52 & 8 & 2 & 0.85 & 0.90 & $1,527,552$ & 1 & $1,527,552$ \\
\hline & $1,017,291$ & Batas & & & 14 & & & & & & & & & \\
\hline
\end{tabular}

\begin{tabular}{|l|r|}
\hline CB (cap) & $\mathbf{1 , 3 7 4 , 7 9 7}$ batas \\
\hline
\end{tabular}

CB: Etiquetado

Elaboración propia 
Tomando como base el tiempo disponible, capacidad de procesamiento y tamaño de planta se define como cuello de botella el acabado con 687,398 batas/año.

\subsection{Relación tamaño- punto de equilibrio}

El punto de equilibrio es el nivel de ventas de unidades monetarias y físicas donde el valor de las utilidades es igual a cero, donde no se gana ni se pierde. Además, desde este punto se comienza a generar utilidades por las ventas.

Se evaluará el punto de equilibrio de las batas, el cual determina el tamaño mínimo o volumen mínimo de la planta de producción. A continuación, se presenta la fórmula de Punto de Equilibrio:

$$
\text { Punto de Equilibrio }=\frac{\text { Costos fijos }}{\text { Margen de contribución }}
$$

Se estableció como precio de la bata S/. 3.20, el cual puede ser usado para calcular el punto de equilibrio en términos monetarios. Del mismo modo es necesario, calcular el costo variable, que comprende el costo de materia prima, materiales y fabricación como se muestra a continuación. La inflación es de 3.5\%.

\section{Tabla 4.4}

Cálculo Punto de Equilibrio

\begin{tabular}{lcccccc}
\hline \multicolumn{1}{c}{ Año } & 2018 & 2019 & 2020 & 2021 & 2022 & 2023 \\
\hline P unit (S//Bata) & 3.30 & 3.42 & 3.54 & 3.66 & 3.79 & 3.92 \\
CV unit (S//Bata) & 1.70 & 1.76 & 1.82 & 1.89 & 1.95 & 2.02 \\
CF (S/.) & $1,382,205$ & $1,382,205$ & $1,382,205$ & $1,382,205$ & $1,382,205$ & $1,382,205$ \\
PE (Bata) & 864,540 & 835,305 & 807,058 & 779,766 & 753,397 & 727,920 \\
PE (S/) & $2,852,983$ & $2,852,983$ & $2,852,983$ & $2,852,983$ & $2,852,983$ & $2,852,983$ \\
\hline
\end{tabular}

Elaboración propia

\subsection{Selección del tamaño de planta}

Finalmente, se determinará el tamaño óptimo de planta, el cual debe encontrarse entre el tamaño máximo, que proviene de la demanda, y el tamaño mínimo, que representa al punto de equilibrio. 


\section{Tabla 4.5}

Selección de tamaño de planta

\begin{tabular}{lllllll}
\hline \multicolumn{1}{c}{ Año } & \multicolumn{1}{c}{2018} & \multicolumn{1}{c}{2019} & 2020 & 2021 & \multicolumn{1}{c}{2022} & 2023 \\
\hline Demanda & 865,631 & 895,963 & 926,295 & 956,627 & 986,959 & $1,017,291$ \\
Materia prima & & & & & $157,026,881$ & $168,633,300$ \\
& $122,207,623$ & $122,207,623$ & $133,814,042$ & $157,026,881$ & & $1,374,797$ \\
Capacidad & $1,374,797$ & $1,374,797$ & $1,374,797$ & $1,374,797$ & $1,374,797$ & 727,920 \\
Punto equilibrio & 864,540 & 835,305 & 807,058 & 779,766 & 753,397 & $1,017,291$ \\
Tamaño de & 865,631 & 895,963 & 926,295 & 956,627 & 986,959 & \\
planta & & & & & & \\
\hline
\end{tabular}

\begin{tabular}{l|l|l|l|l|l|l|} 
Se considera: & Demanda & Demanda & Demanda & Demanda & Demanda & Demanda
\end{tabular}

Nota: El limitante es la demanda, por lo tanto, este define el tamaño de planta. Elaboración propia

Se puede concluir que el tamaño óptimo de planta es la demanda, la cual se encuentra superior al punto de equilibrio, siendo esto una ventaja para la compañía. 


\section{CAPÍTULO V: INGENIERÍA DEL PROYECTO}

\subsection{Definición técnica del producto}

Los uniformes médicos desechables están hechos de tela no tejida de Polipropileno SMS que permiten un producto de alta calidad y bajos costos. A diferencia de otros productos similares cuenta con diseños anatómicos que se amoldan mejor al cuerpo permitiendo comodidad y movilidad más eficaz, y vienen en presentaciones de diferentes colores según las necesidades de cada cliente. Así mismo, la calidad será un rasgo importante que brindará alta seguridad a los usuarios.

\subsubsection{Especificaciones técnicas, composición y diseño del producto}

Las prendas están confeccionadas con tela de polipropileno SMS. Esta tela, está conformada por 3 capas que le brindan las características de permeabilidad, comodidad y protección como se explicó en el capítulo 2. A continuación se muestra el diseño de las batas y scrubs.

\section{Figura 5.1}

Modelo de uniformes tipo batas y tipo scrubs
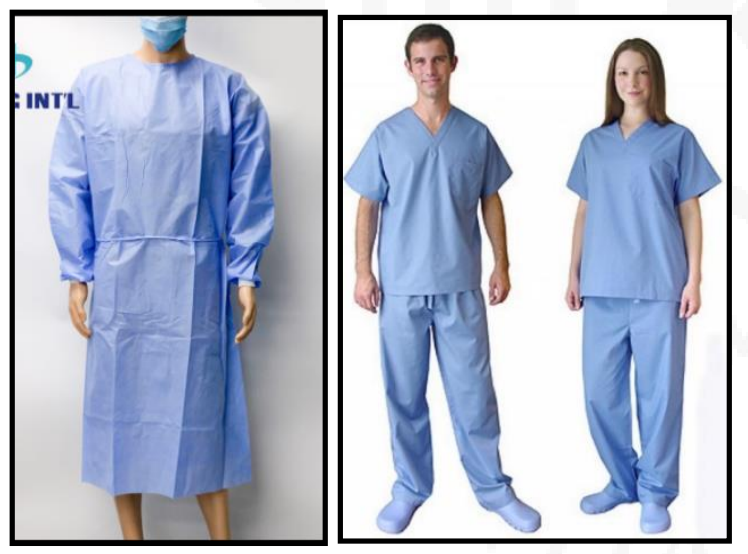

Fuente: Red Textil Argentina, (2015); Info Comercial, (2015)

Finalmente se muestra un cuadro de especificaciones técnicas de ambas prendas debido a que poseen las mismas características. 
Tabla 5.1

Especificaciones técnicas de calidad del producto

\begin{tabular}{|c|c|c|c|c|c|c|}
\hline \multicolumn{7}{|c|}{ CUADRO DE ESPECIFICACIONES TÉCNICAS DE CALIDAD } \\
\hline Nombre & \multicolumn{3}{|c|}{ Prendas médicas desechables } & Costo & \multicolumn{2}{|l|}{$S / .0 .24$} \\
\hline Función & \multicolumn{3}{|c|}{ Protección biológice e higiene } & Desarrollado por & \multicolumn{2}{|c|}{ Cinthia Cabrera Guerrero } \\
\hline Tamaño & \multicolumn{3}{|c|}{$1.5 \mathrm{~m} \times 1.5 \mathrm{~m}$} & Verificado por & \multicolumn{2}{|c|}{ Andrea Talavera Delgado } \\
\hline \multirow{2}{*}{ Insumos requeridos } & \multirow{2}{*}{\multicolumn{3}{|c|}{$\begin{array}{l}\text { Fibras de Polipropileno } \\
\text { Hilos de costura }\end{array}$}} & Autorizado por & \multicolumn{2}{|c|}{ José Espinoza Matos } \\
\hline & & & & Fecha & \multicolumn{2}{|c|}{$01 / 10 / 2015$} \\
\hline Características & Tipo & Criticidad & $\mathrm{VN}+/$ - total & Medion de control & Tipo de inspeccion & NCA \\
\hline Homogenieidad del color & A & Mayor & Al tono de la muestra & Datacolor & Muestreo & $2.000 \%$ \\
\hline Textura & A & Mayor & Suave & Tacto & Mues treo & $0.100 \%$ \\
\hline $\begin{array}{c}\text { Ausencia de agujeros en } \\
\text { la bata }\end{array}$ & A & Crítica & No debe tener ninguno & Vista & Muestreo & $0.001 \%$ \\
\hline $\begin{array}{l}\text { Ausencia de agujeros en } \\
\text { el empaque }\end{array}$ & A & Crítica & No debe tener ninguno & Vista & Muestreo & $0.001 \%$ \\
\hline Forma anatómica & A & Mayor & $\begin{array}{l}\text { Debe tener una forma amoldable } \\
\text { al cuerpo }\end{array}$ & Vista & Mues treo & $2.000 \%$ \\
\hline Muy baja inflamabilidad & A & Mayor & $\begin{array}{l}\text { Contracción desde } 110+C \\
\text { Fundición desde } 130 * \mathrm{C}\end{array}$ & Vista & Muestreo & $0.100 \%$ \\
\hline Estéril & v & Crítica & $>=99.9 \%$ & Test de esterilidad & Muestreo & $0.001 \%$ \\
\hline Peso & v & Menor & $16+/-1$ gr. & Balanza analítica & Muestreo & $3.000 \%$ \\
\hline Impermeabilidad & v & Crítica & $>=98 \%$ & Vista & Mues treo & $0.001 \%$ \\
\hline Tenacidad & A & Mayor & $\begin{array}{c}\text { Alta cohesión y resistencia la } \\
\text { deformación }\end{array}$ & $\begin{array}{c}\text { Ensayo de impacto } \\
\text { de Charny }\end{array}$ & Muestreo & $0.010 \%$ \\
\hline Resistencia a abrasión & v & Crítica & $>=$ Clase 2 & Ensayo de Abrasión & Muestreo & $0.001 \%$ \\
\hline Anticorrosión & A & Crítica & $\begin{array}{l}\text { Resistencia a sustancias y } \\
\text { líquidos hospitalarios }\end{array}$ & Vista & Muestreo & $0.001 \%$ \\
\hline Baja carga electrostática & v & Mayor & $1.25 \mathrm{~V}+/-20 \%$ & $\begin{array}{l}\text { Medidor de campo } \\
\text { electrostático }\end{array}$ & Mues treo & $0.100 \%$ \\
\hline Límite microbiano & v & Crítica & $\begin{array}{c}<100 \mathrm{ufc} / \mathrm{g} \\
\text { Hongos y levaduras ausentes }\end{array}$ & $\begin{array}{c}\text { Filtración / } \\
\text { Microoscopio }\end{array}$ & Muestreo & $0.001 \%$ \\
\hline $\begin{array}{c}\text { Eficiencia de protección } \\
\text { bacterial }\end{array}$ & v & Crítica & $>=98 \%$ & $\begin{array}{c}\text { Filtración / } \\
\text { Microoscopio }\end{array}$ & Muestreo & $0.001 \%$ \\
\hline
\end{tabular}

Nota: NCA= Nivel de calidad aceptable. VN= Valor nominal.

Elaboración propia 


\subsubsection{Marco regulatorio para el producto}

En el Perú no se cuenta con una norma técnica que regule la producción de ropa hecha de fibras no convencionales. Sin embargo, en otros países del mundo si existe normas regulatorias de ropa quirúrgica desechable. A continuación, se listan las Nomas Internacionales que nos servirán como guía para elaborar productos que poseen altos estándares de calidad para ser competitivos en el ámbito nacional e internacional.

- Norma E.N. 13795 (Europa)

- Normas técnicas sobre esterilización y desinfección de Elementos Clínicos (Chile).

\subsection{Tecnologías existentes y procesos de producción}

\subsubsection{Naturaleza de la tecnología requerida}

\subsubsection{Selección de la tecnología}

Para el proceso de producción se utilizará la tecnología de innovación, el cual es la máquina de sellado ultrasónico, la cual nos permite una producción rápida y eficiente, además se contará con máquinas convencionales de corte y cocido.

\subsubsection{Proceso de producción}

A continuación, se explicará el proceso productivo para la elaboración de las prendas médicas desechables.

\subsubsection{Descripción del proceso}

A continuación, se explicará brevemente el proceso de fabricación de prendas médicas desechables de la tela no tejida de Polipropileno SMS.

Es importante recalcar que toda el área de producción y empaque está debidamente esterilizada y todas las personas involucradas en el proceso de producción utilizan batas, gorras, mascarillas y botas de protección para evitar alguna contaminación.

El proceso inicia con la recepción de los metros de tela, los cuales pasan al almacén de materia prima para su inspección y pesaje. 
Finalizada la inspección, los metros son transportados a la zona de tendido, luego pasa al tizado, donde se dibujan los moldes y se inicia el corte, donde se obtiene las partes que conforman las prendas: delantera, espalda, las mangas, la colateral y cordón. Mediante una selladora ultrasónica se unen la delantera a la espalda, lo cual en adelante se llamará el cuerpo. Luego ingresa el elástico y el hilo para ser cocidos en ambas mangas, las cuales posteriormente serán selladas con el sellado ultrasónico al cuerpo, luego se une la collatera al cuerpo con sellado y finalmente el cordón es sellado por ambos lados para luego ser cocido al resto del cuerpo. Al finalizar la unión de todas las partes se realiza una inspección final para verificar que el producto se encuentre en las condiciones adecuadas.

A continuación, ingresan las etiquetas y son colocadas en las batas, las cuales se doblan. Luego ingresan las bolsas para colocar la bata en la empaquetadora al vacío para ser enviadas al proceso de esterilización y se acomoda 48 batas embolsadas por caja. Finalmente se tiene cajas de 48 batas.

\subsubsection{Diagrama de proceso}




\section{Figura 5.2}

Diagrama de Operaciones del Proceso para la Fabricación de prendas médicas desechables de polipropileno SMS

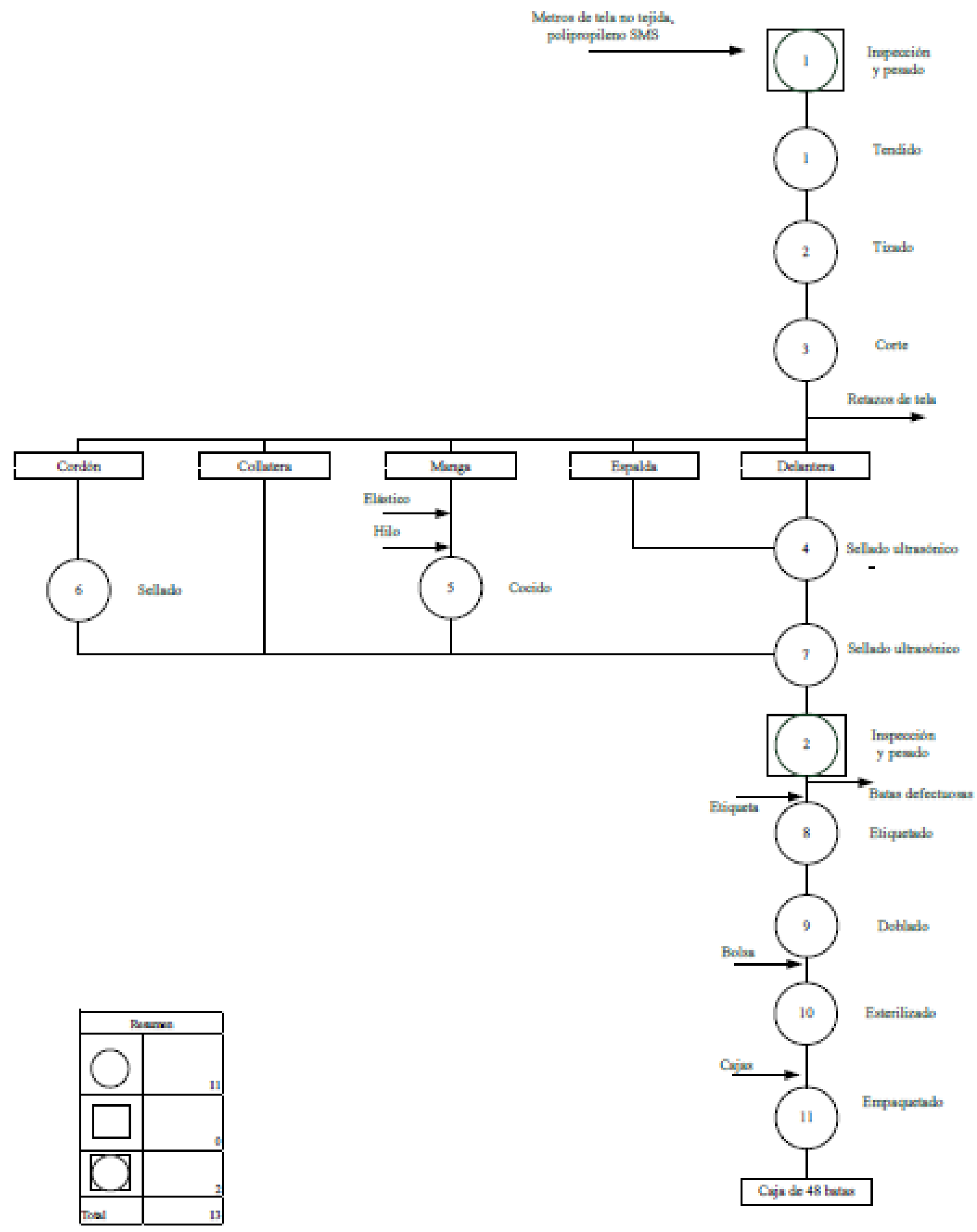

Elaboración propia 


\subsubsection{Balance de materia}

Figura 5.3

Balance de materia

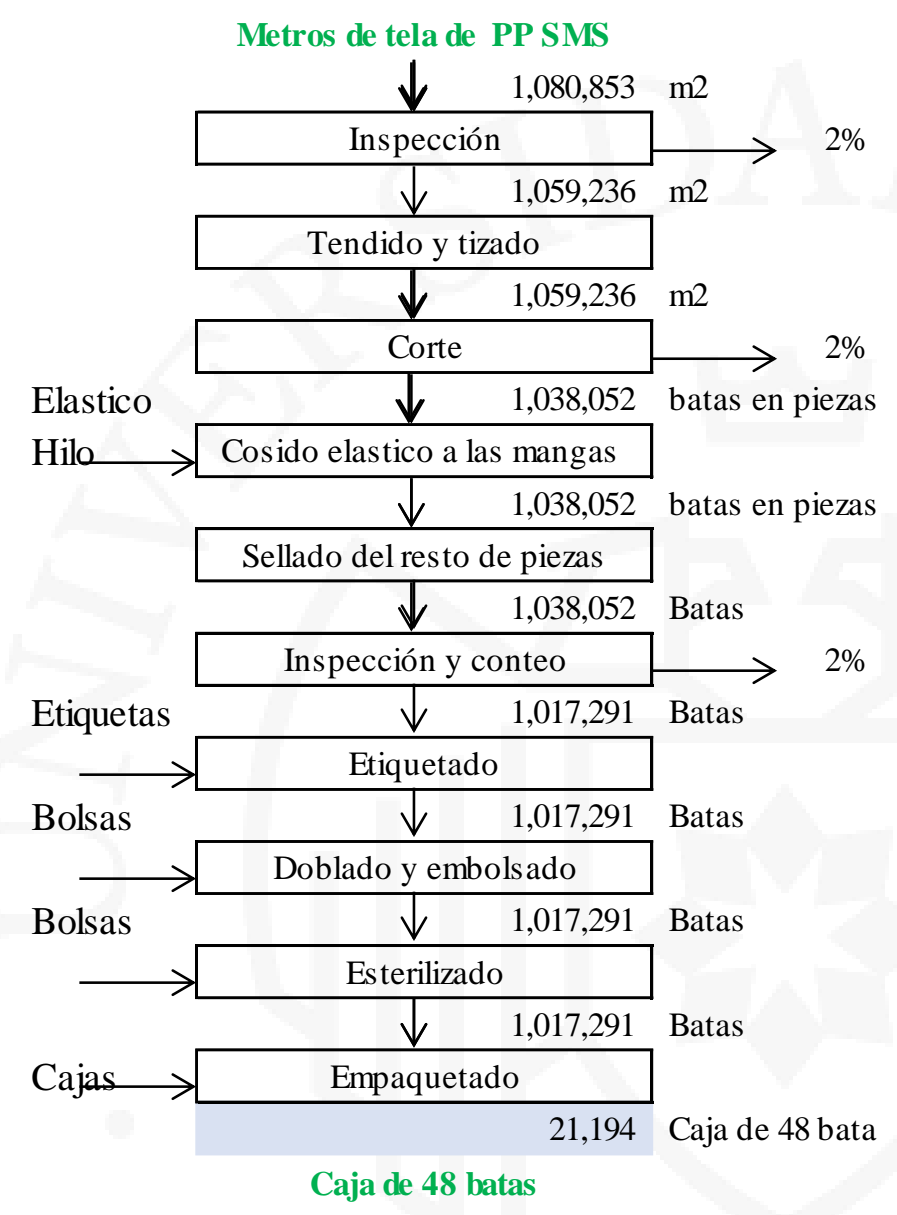

Elaboración propia

\subsection{Características de las instalaciones y equipos}

\subsubsection{Selección de la maquinaria y equipos}

El proceso de fabricación de prendas cuenta con 4 actividades en los cuales se requiere el uso de maquinaria. En la etapa de cortado de los rollos de tela se tendrá una cortadora especial para poder realizar estos moldes de manera más rápida y eficiente.

En la etapa de formación de la prenda se seleccionó la máquina de sellado ultrasónico, una tecnología poco utilizada en el Perú que no requiere de hilos para unir varias partes de 
tela. Unas de las ventajas más evidentes de utilizar esta tecnología es que al ser semiautomática tiene una capacidad de procesamiento mucho mayor que otras máquinas de costura y que no requiere mucha experiencia del operario al ser fácil de utilizar.

En la etapa de cocido de elástico en las mangas se necesitará que ingrese hilo y elástico para realizar el cocido, el cual estará a cargo de un operario.

En la etapa de empaquetado se utilizó la técnica al vacío debido a que permite que el producto final ocupe menos espacio, y logra que el empaque proporcione seguridad al cliente debido a que solo permite la primera apertura por única vez.

En la etapa de esterilización se envían las batas embolsadas a la planta del proveedor que presta el servicio de radiación con rayos gamma para que puedan ser esterilizadas y luego empacadas para la venta.

Finalmente, para cada proceso se eligió el modelo de las máquinas que brinde menores costos a la empresa pero que proporcione calidad al producto y genere productividad a la empresa al hacer un uso eficiente de los recursos y materias primas.

\subsubsection{Especificaciones de la maquinaria}

Después de realizar un estudio de las especificaciones técnicas de cada modelo se eligieron los que se muestran a continuación según cada máquina.

\section{Figura 5.4}

\section{Máquina de coser}

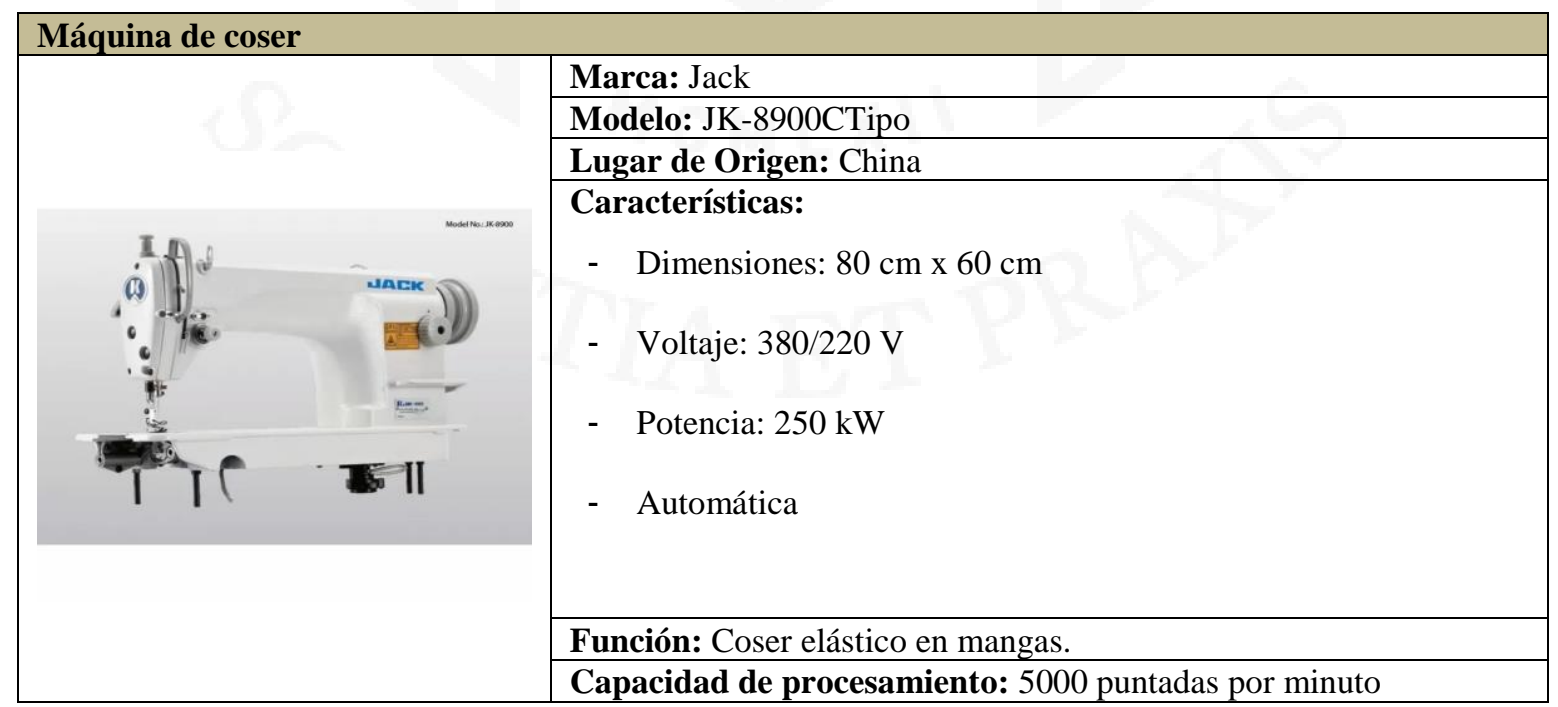

Fuente: Mercado Libre (2018) 


\section{Figura 5.5}

Empaquetadora al vacío

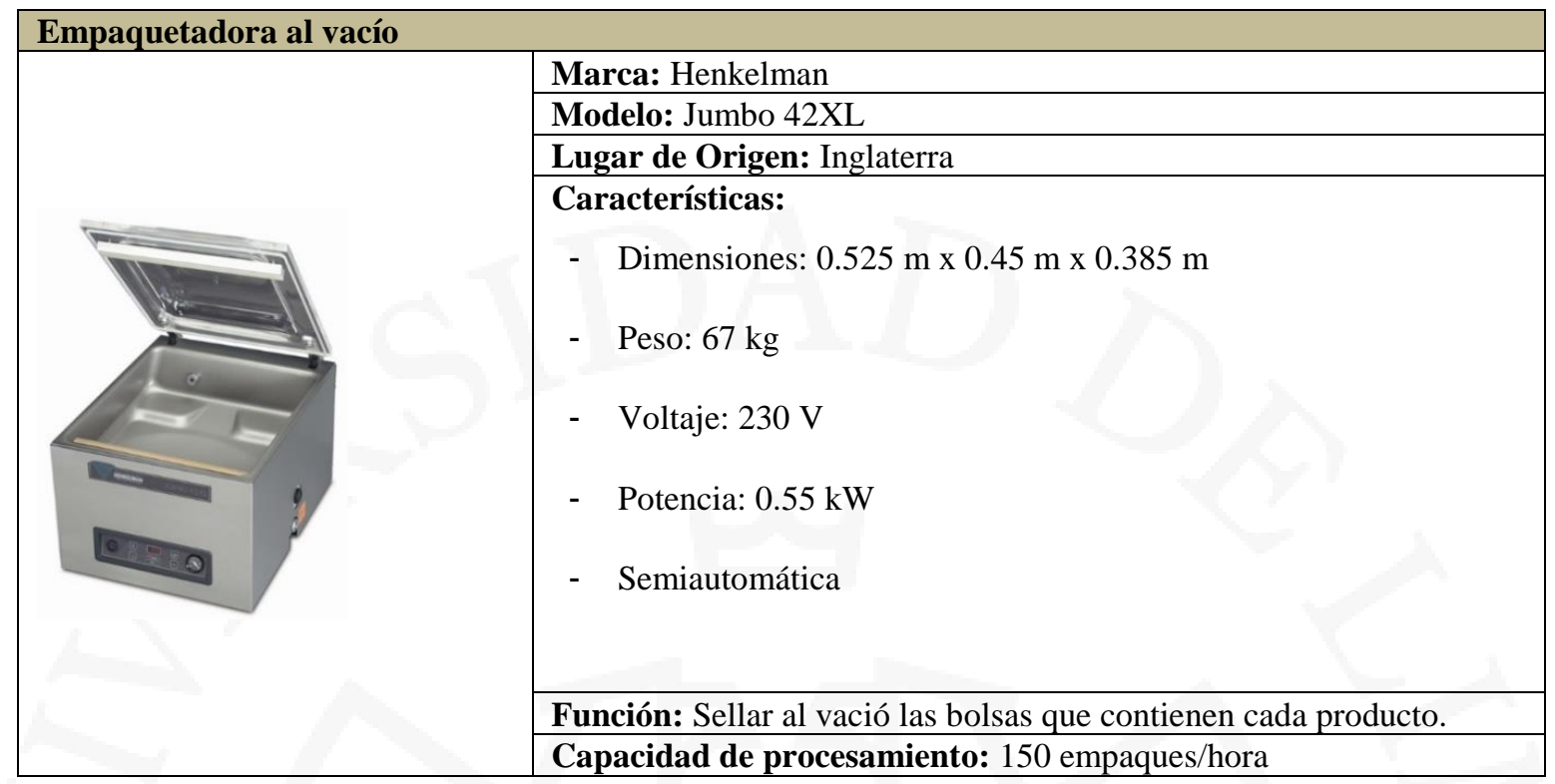

Fuente: Alibaba (2018)

\section{Figura 5.6}

Selladora Ultrasónica

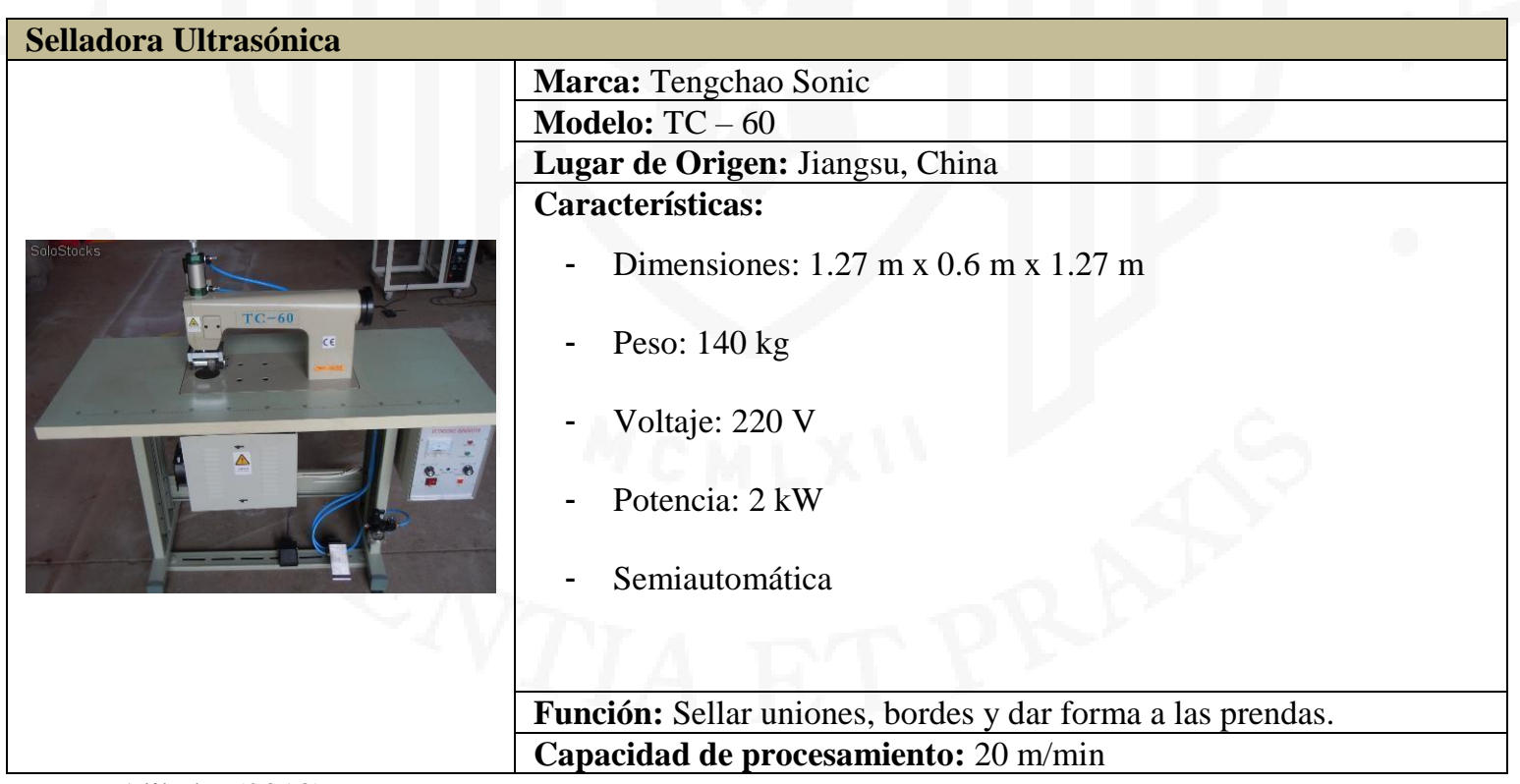

Fuente: Alibaba (2018) 


\subsection{Capacidad instalada}

\subsubsection{Cálculo detallado del número de máquinas y operarios requeridos}

Para desarrollar el proceso productivo se requieren 14 operarios para cada turno, siendo un total de 28 operarios los necesarios para el trabajo diario. Respecto a la maquinaria se requieren 7 máquinas que serán detalladas a continuación.

\section{Tabla 5.2}

Número de máquinas y operarios por turno

\begin{tabular}{lll}
\hline Operación & Máquinas & Operarios/Turno \\
\hline Inspección & 0 & 1 \\
Estirado y tizado & 0 & 1 \\
Coser muñequeras & 2 & 2 \\
Corte & 2 & 2 \\
Sellado Ultrasónico & 1 & 1 \\
Inspección y conteo & 0 & 1 \\
Etiquetado & 0 & 2 \\
Doblado y & 0 & 1 \\
embolsado & 0 & 1 \\
Esterilizado & 2 & 2 \\
Empaquetado & 7 & 14 \\
Total & &
\end{tabular}

\subsubsection{Cálculo de la capacidad instalada}

Para el cálculo de la capacidad instalada se consideró la información proporcionada anteriormente en las especificaciones de las máquinas, el número de operarios, máquinas para cada operación y balance de materia que se muestra a continuación: 
Tabla 5.3

Cálculo de Capacidad Instalada

\begin{tabular}{|c|c|c|c|c|c|c|c|c|c|c|c|c|c|c|c|}
\hline & & & Qe & $\mathbf{P}$ & & M & $\mathbf{D} / \mathbf{S}$ & $\mathbf{S} / \mathbf{M}$ & $\mathbf{H} / \mathbf{T}$ & $T$ & $\mathbf{U}$ & $\mathbf{E}$ & $\mathrm{CO}$ & F/Q & $\mathrm{CO} * \mathrm{~F} / \mathrm{Q}$ \\
\hline Operación & & Cantidad & Unidad & Prod/hora & Unidad & $\begin{array}{c}\text { \#Maqo } \\
\text { Persona } \\
\text { s }\end{array}$ & $\begin{array}{l}\text { Días/ } \\
\text { Sem }\end{array}$ & $\begin{array}{l}\text { Sem/ } \\
\text { Año }\end{array}$ & $\begin{array}{c}\text { Horas/T } \\
\text { urno }\end{array}$ & Turnos & $\begin{array}{c}\text { Factor } \\
\text { utilizació } \\
\text { n }\end{array}$ & $\begin{array}{c}\text { Factor } \\
\text { eficienci } \\
\text { a }\end{array}$ & $\begin{array}{c}\mathbf{P} \mathbf{M}^{*} \mathbf{D} / \mathbf{S} * \mathbf{S} / \\
\mathbf{M}^{*} \mathbf{M} / \mathbf{A}^{*} \mathbf{H} / \mathbf{T} \\
{ }^{*} \mathbf{T}^{*} \mathbf{U}^{*} \mathbf{E}\end{array}$ & $\begin{array}{l}\text { Factor de } \\
\text { conversión }\end{array}$ & Cap de prod \\
\hline Inspección & & $1,080,853$ & $\mathrm{~m} 2$ & 1,000 & $\mathrm{~m} 2 /$ hora & 1 & 6 & 52 & 8 & 2 & 0.85 & 0.90 & $3,818,880$ & 15 & $57,283,200$ \\
\hline Tendido y tizado & & $1,059,236$ & $\mathrm{~m} 2$ & 100 & $\mathrm{~m} 2 /$ hora & 1 & 6 & 52 & 8 & 2 & 0.85 & 0.90 & 381,888 & 15 & $5,728,320$ \\
\hline Corte & & $1,059,236$ & $\mathrm{~m} 2$ & 270 & batas/hora & 2 & 6 & 52 & 8 & 2 & 0.85 & 0.90 & $2,062,195$ & 1 & $2,062,195$ \\
\hline Cosido elastico a las mangas & & $1,038,052$ & batas en piezas & 600 & batas/hora & 2 & 6 & 52 & 8 & 2 & 0.85 & 0.90 & $4,582,656$ & 1 & $4,491,003$ \\
\hline Sellado del resto de piezas & & $1,038,052$ & batas en piezas & 600 & batas/hora & 1 & 6 & 52 & 8 & 2 & 0.85 & 0.90 & $2,291,328$ & 1 & $2,245,501$ \\
\hline Inspección y conteo & & $1,038,052$ & Batas & 520 & batas/hora & 1 & 6 & 52 & 8 & 2 & 0.85 & 0.90 & $1,985,818$ & 1 & $1,946,101$ \\
\hline Etiquetado & & $1,017,291$ & Batas & 360 & batas/hora & 2 & 6 & 52 & 8 & 2 & 0.85 & 0.90 & $2,749,594$ & 1 & $2,749,594$ \\
\hline Doblado y embolsado & & $1,017,291$ & Batas & 360 & batas/hora & 1 & 6 & 52 & 8 & 2 & 0.85 & 0.90 & $1,374,797$ & 1 & $1,374,797$ \\
\hline Esterilizado & & $1,017,291$ & Batas & 8,000 & batas/hora & 1 & 6 & 52 & 8 & 2 & 0.85 & 0.90 & $30,551,040$ & 1 & $30,551,040$ \\
\hline Empaquetado & & $1,017,291$ & Batas & 200 & batas/hora & 2 & 6 & 52 & 8 & 2 & 0.85 & 0.90 & $1,527,552$ & 1 & $1,527,552$ \\
\hline & & $1,017,291$ & Batas & & & 14 & & & & & & & & & \\
\hline
\end{tabular}

\begin{tabular}{|l|r|}
\hline CB (cap) & $\mathbf{1 , 3 7 4 , 7 9 7}$ batas \\
\hline
\end{tabular}

CB: Etiquetado

Nota: Se realizó el cálculo de la capacidad instalada, concluyendo que el cuello de botella se encuentra en el acabado.

Elaboración propia 


\subsection{Resguardo de la calidad y/o inocuidad del producto}

Para conservar la calidad de los productos es necesaria una evaluación de cada una de las partes involucradas, desde los insumos, proceso y producto final. Así mismo se aspira a desarrollar un sistema de calidad total, donde se ve involucrado el medio ambiente, personal, materiales, métodos y equipo.

\subsubsection{Calidad de la materia prima, de los insumos, del proceso y del producto}

\section{Calidad materia prima e insumos:}

Se realizó una muy buena homologación de proveedores, con gran énfasis en la calidad, para que así se permita brindar un buen producto al cliente y reducir el número de fallas. Se definió que se toleraría como máximo $2 \%$ de defectuosos.

\section{Calidad en el proceso:}

Respecto a la calidad del proceso se elaboró un plan HACCP con el que se pretende definir los peligros específicos (véase Tabla 5.4) y medidas de control para los principales puntos críticos (véase Tabla 5.5) que posteriormente deben ser limitados y controlados. Por otro lado, también se contempló los aspectos de impacto ambiental y las medidas preventivas que se deben tomar para cada actividad (véase Tabla 5.6).

\section{Calidad en el producto:}

Posterior a los controles anteriores se realizará un control del producto final, en el que se evaluaran los detalles de la apariencia, acabado y empaquetado. Se debe verificar que el producto se encuentre en condiciones óptimas y con los estándares de calidad establecidos. 
Tabla 5.4

Plan HACCP y Análisis de los PCC

\begin{tabular}{|c|c|c|c|c|c|}
\hline Bata quirurgica & Peligro & \begin{tabular}{|c|} 
Algun peligro \\
significativo para la \\
seguridad del \\
producto
\end{tabular} & Justificación & $\begin{array}{l}\text { ¿Qué medidas preventivas se pueden } \\
\text { aplicar? }\end{array}$ & $\begin{array}{l}\text { ¿Es esa } \\
\text { etapa un } \\
\text { PCC? }\end{array}$ \\
\hline $\begin{array}{l}\text { Inspección de materia } \\
\text { prima }\end{array}$ & $\begin{array}{l}\text { Biológico: Crecimiento bacteriano y hongos. } \\
\text { Químico: Descomposición. } \\
\text { Físico: Deterioro por radiación. } \\
\text { Deteriro por ataque de insectos y roedores }\end{array}$ & SI & $\begin{array}{l}\text { La mate ria prima puede ser victima de la aparición } \\
\text { de hongos producto del clima de la ciudad. Se puede } \\
\text { modificar el color de los hilos, producto de las } \\
\text { radiaciones. Existe la posibilidad de que por la zona } \\
\text { haya presencia de roedores, los cuales pueden } \\
\text { afectar la calidad de los insumos. }\end{array}$ & $\begin{array}{l}\text { Implementar un sistema } \\
\text { deshumedecedor. Conservar los hilos } \\
\text { en zonas donde lo reciban mucha luz } \\
\text { solar. Colocar veneno para roedores. }\end{array}$ & SI \\
\hline Corte & Físico: desperdicio de tela por malos cortes. & NO & $\begin{array}{l}\text { Por falta de especialización y técnica no se realiza un } \\
\text { corte proporcionado. }\end{array}$ & $\begin{array}{l}\text { Se puede aplicar una capacitación y } \\
\text { supervisión en los cortes }\end{array}$ & NO \\
\hline Sellado Ultrasónico & Físico: derretir la tela por excesivo calor. & SI & $\begin{array}{l}\text { La máquina de sellado ultrasónico trabaja con altas } \\
\text { temperaturas, las cuales deben ser bien calibradas. }\end{array}$ & $\begin{array}{l}\text { Capacitar al operario y tener una hoja } \\
\text { de ayuda con las temperaturas } \\
\text { detalladas, para que el operario no falle }\end{array}$ & SI \\
\hline Collaretado & Físico: mala técnica de costura. & NO & Personal con poca capacitación o experiencia. & Capacitar al operario en costura. & NO \\
\hline Acabado & Físico: mala técnica de doblado. & No & Personal con poca capacitación o experiencia. & Capacitar al operario en doblado. & NO \\
\hline Empaquetado & Físico: mala técnica de sellado de bolsas. & No & Altas temperaturas de la selladora y mala técnica. & Calibrar la temperatura y capacitar. & NO \\
\hline Almacenar & Deteriro por ataque de insectos y roedores. & $\mathrm{SI}$ & $\begin{array}{l}\text { Existe la posibilidad de que por la zona haya } \\
\text { presencia de roedores. }\end{array}$ & Colocar veneno para roedores. & NO \\
\hline
\end{tabular}

\begin{tabular}{|c|c|c|c|c|c|c|c|c|c|}
\hline \multirow{2}{*}{$\begin{array}{c}\text { Puntos de Control } \\
\text { Críticos }\end{array}$} & \multirow[b]{2}{*}{ Peligros significatios } & \multirow{2}{*}{$\begin{array}{l}\text { límites críticos para cada } \\
\text { medida preventiva }\end{array}$} & \multicolumn{4}{|c|}{ Monitoreo } & \multirow{2}{*}{$\begin{array}{l}\text { Acciones } \\
\text { Correctoras }\end{array}$} & \multirow[b]{2}{*}{ Registros } & \multirow[b]{2}{*}{ Verificación } \\
\hline & & & Que & Como & Frecuencia & Quien & & & \\
\hline $\begin{array}{l}\text { Inspección de } \\
\text { materia prima }\end{array}$ & $\begin{array}{l}\text { Biológico: Crecimiento bacteriano y hongos. } \\
\text { Químico: Descomposición. } \\
\text { Físico: Deterioro por radiación. } \\
\text { Deteriro por ataque de insectos y roedores }\end{array}$ & $\begin{array}{l}\text { Humedad relativa: 30\%-40\% } \\
\text { Rango de nivel de luz: } \\
\text { 10-50 Luz (1-15fc) }\end{array}$ & $\begin{array}{l}\text { Temperatura } \\
\text { Radiación } \\
\text { de luz }\end{array}$ & $\begin{array}{l}\text { Termometro } \\
\text { Espectometro }\end{array}$ & $\begin{array}{l}\text { Cada lote } \\
\text { recepcionado }\end{array}$ & $\begin{array}{l}\text { Inspector } \\
\text { de calidad }\end{array}$ & $\begin{array}{l}\text { Sistema } \\
\text { deshumedecedor } \\
\text {, veneno para } \\
\text { roedores y reducir } \\
\text { la presencia de luz } \\
\text { en la zona. }\end{array}$ & $\begin{array}{l}\text { Registron }{ }^{\circ} \\
\text { Re-001 } \\
\text { Nivel de humedad } \\
\text { Nivel de Luz } \\
\end{array}$ & $\begin{array}{l}\text { Recuento } \\
\text { diario de } \\
\text { humedady } \\
\text { radiación }\end{array}$ \\
\hline Sellado Ultrasónico & Físico: derretir la tela por excesivo calor. & Temperatura $30-35^{\circ} \mathrm{C}$ & Temperatura & Calibrador & \begin{tabular}{|l|} 
Cada lote que \\
ingrese al \\
selladoultrasonico
\end{tabular} & $\begin{array}{l}\text { Operario } \\
\text { de la } \\
\text { máquina }\end{array}$ & \begin{tabular}{|l|} 
Capacitar al \\
operario y una \\
hoja de ayuda.
\end{tabular} & $\begin{array}{l}\text { Registro } n^{\circ} \\
\text { Se-003 }\end{array}$ & $\begin{array}{l}\text { Verificar en } \\
\text { cada } \\
\text { proceso }\end{array}$ \\
\hline
\end{tabular}

Nota: PCC $=$ Puntos Críticos de Control.

Elaboración propia 


\subsection{Estudio de Impacto Ambiental}

Tabla 5.5

Estudio de impacto ambiental

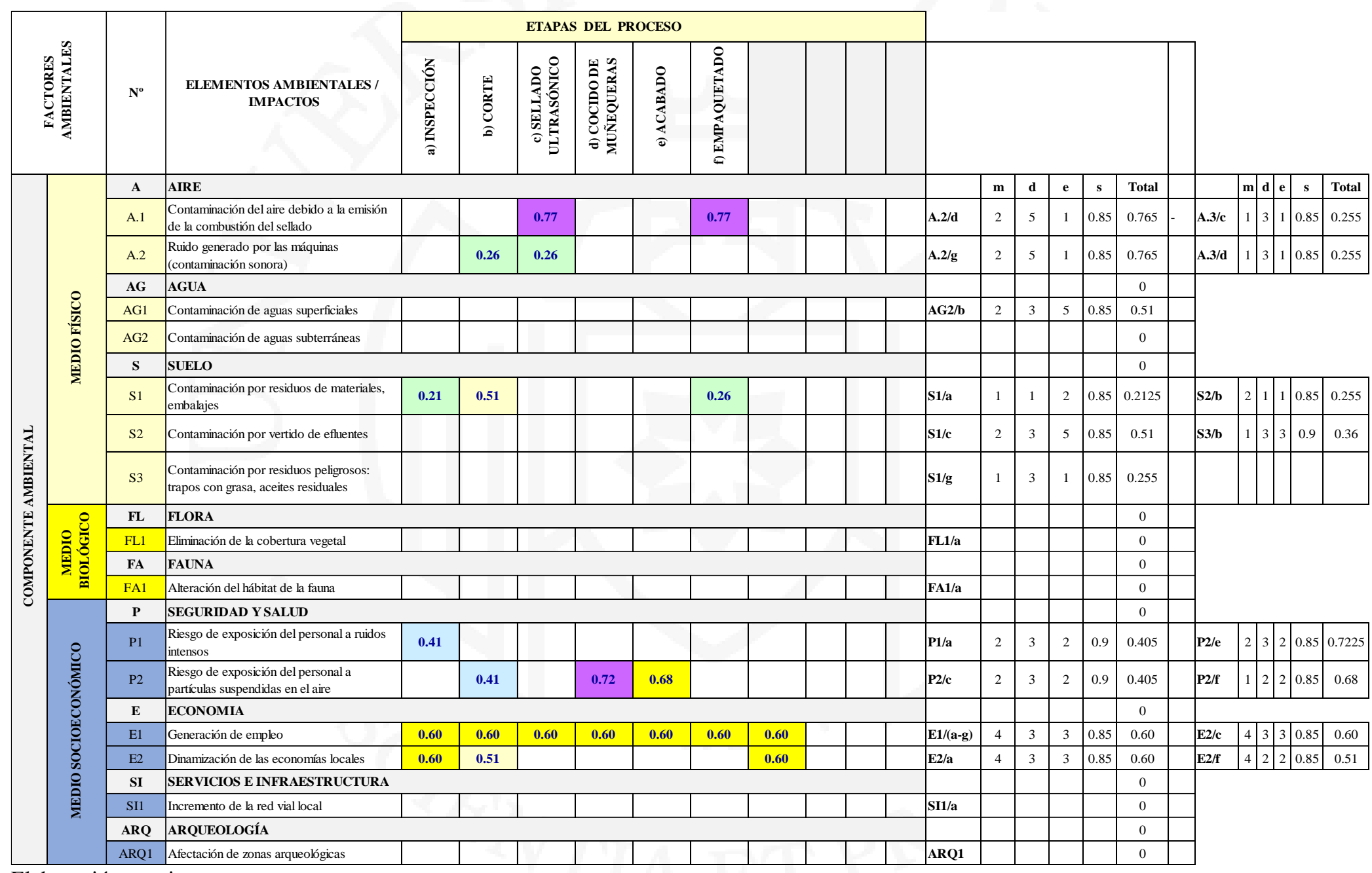

Elaboración propia 
Por otro lado, se ha contemplado los aspectos, el impacto ambiental y las medidas preventivas que se deben tomar por cada actividad del proceso

\section{Tabla 5.6}

Estudio de impacto ambiental

\begin{tabular}{llll}
\hline \multicolumn{1}{c}{ Actividad } & \multicolumn{1}{c}{ Aspecto Ambiental } & \multicolumn{1}{c}{ Impacto ambiental } & \multicolumn{1}{c}{ Medidas Preventivas } \\
\hline Inspección & Generación de polvo & Potencial contaminación del aire & Uso de mascarillas e instalación de scrubber \\
Tendido y Tizado & Generación de microparticulas & Potencial contaminación del aire & Uso de mascarillas e instalación de scrubber \\
Corte & Generación residuos & Potencial contaminación del suelo & Gestion de residuos \\
Cosido elastico a las mangas & Generación de microparticulas & Potencial contaminación del aire & Uso de mascarillas e instalación de scrubber \\
Sellado del resto de piezas & Generación de vapor & Potencial contaminación del aire & Uso de mascarillas e instalación de scrubber \\
Insepcción y conteo & Generación de residuos & Potencial contaminación del suelo & Gestion de residuos \\
Etiquetado & Geracion de residuos & Potencial contaminación del suelo & Gestion de residuos \\
Doblado & Generación de microparticulas & Potencial contaminación del aire & Uso de mascarillas e instalación de scrubber \\
Esterilizado & Generacion de rayos gamma & Potencial alteración genetica & Proteccion con vestimenta de placas de plomo \\
Empaquetado & Generación de microparticulas & Potencial contaminación del aire & Uso de mascarillas e instalación de scrubber \\
\hline
\end{tabular}

Elaboración propia

Por otro lado, es importante que se evalue cual será el tratamiento de los residuos solidos que generan los uniformes médicos desechables, el cual será explicado a continuación.

\section{Tratamiento del residuo patológico que genera el producto}

Basado en la Norma Técnica de Salud: "Gestión y Manejo de Residuos Sólidos en Establecimientos de Salud y Servicios Médicos de Apoyo a nivel Nacional” se ha obtenido la información necesaria para definir cuál serían los pasos adecuados para llevar una gestión de las batas médicas desechables:

Educación, Concientización y Compromiso de todos los trabajadores para lograr un adecuado manejo de los residuos, de tal manera que se puedan obtener beneficios como:

- Aumento de los niveles de seguridad de todas las personas internas y externas de los SMA o EESS.

- Disminución del impacto ambiental

- Mejora de las condiciones ambientales y estéticas del EESS o SMA.

- Incentivar un mejor costeo del manejo de residuos

El Comité de Gestión y Manejo de Residuos Sólidos identificará en cada una de las áreas/servicios/unidades que integran el EESS o SMA a los actores que se involucrarían en la Elaboración del Diagnóstico inicial para el Plan de manejo de residuos sólidos del EESS o SMA 
Al definir que los residuos sólidos producto del uso de los uniformes médicos desechables pertenecen a la clase de patogenicidad se puede seguir dos tipos de tratamientos que son usados en el país y en el extranjero, los cuales son el autoclave y la incineración.

\section{Autoclave}

El tratamiento recomendado para este tipo de residuos es el autoclave, el cual utiliza vapor saturado en una cámara, a la que se someten los residuos a altas temperaturas con el fin de destruir los agentes patógenos que estén presentes en las prendas desechables. Los parámetros principales involucrados en este tratamiento son la temperatura, tiempo y presión. Los rangos de temperatura que se manejan son entre 135 a $137^{\circ} \mathrm{C}$, por un tiempo mínimo de 30 minutos, acto seguido se inyecta vapor a la cámara para mantener la temperatura deseada por el tiempo que dure el proceso.

Una de las ventajas que se tiene de usar este tratamiento es que se cuenta con diferentes tamaños y capacidades para tratar de desde varios kilos a varias toneladas de desechos por hora. Otra ventaja es que el costo de adquisición de un autoclave es más económico que otras tecnologías, como por ejemplo la incineración. Una desventaja es que los residuos no se vuelven irreconocibles luego del tratamiento, al menos que se acompañe de un tratamiento posterior como por ejemplo la trituración y la incineración.

En la actualidad existen autoclaves avanzadas que proponen incorporar tratamientos complementarios al proceso para así volver irreconocibles los residuos médicos. Por ejemplo:

- Vació; tratamiento por vapor; compactación.

- Tratamiento vapor-mezcla-fragmentación; secado; trituración.

- Trituración; tratamiento vapor-mezcla-fragmentación; secado.

- Trituración; tratamiento vapor-mezcla-fragmentación-secado; limpieza química.

\section{Incineración}

La incineración es un tratamiento que se puede utilizar para tratar residuos médicos que posean agentes patógenos. Gracias a la oxidación a alta temperatura, los compuestos orgánicos se convierten en óxidos gaseosos, principalmente en dióxido de carbono y agua. Los componentes inorgánicos se convierten en minerales y cenizas. 
Finalmente, estos residuos que ya fueron descontaminados en el autoclave o en el proceso de incineración, pueden ser sometidos a algún proceso de reciclado de polipropileno para extender su vida y disminuir la contaminación ambiental.

\subsection{Seguridad y Salud ocupacional}

Algunos de los riesgos principales son los siguientes:

\section{Lesiones físicas:}

Los operarios están obligados a utilizar fajas para cargar los sacos de fibra y las batas como producto terminado, de tal manera que se evita daños en la columna.

\section{Quemaduras:}

Es probable que los operarios que utilizan la selladora de ultrasonido y la empaquetadora sufran pequeñas quemaduras, ya que estas trabajan a altas temperaturas. Se recomienda tener cuidado al utilizarlas y realizar una buena calibración de la temperatura.

\section{Incendio:}

Existe el riesgo de que se produzca un incendio de manera inevitable, ya que la line de producción y el resto de las máquinas de coser requieren de algo voltaje para su funcionamiento. De tal manera, que para proteger al personal se debe colocar extintores en la planta, almacenes y áreas administrativas, así mismo un pozo a tierra protegerá y garantizará un mejor desempeño de los equipos. Es importante también, colocar interruptores diferenciales ya que los equipos son importados.

Es de suma importancia realizar una evaluación de los principales peligros, riesgos, causas y efectos a los que se enfrentan los trabajadores en el día a día. Así mismo, realizar de manera proactiva controles y capacitaciones sobre la salud y seguridad en el área de trabajo. Por otro lado, se considera indispensable la presencia de extintores y un botiquín en la planta.

Debido a que la seguridad y salud en el trabajo es una condición indispensable para el desarrollo de las relaciones en el trabajo y la protección del personal de manera apropiada, 
se hace referencia al Reglamento de Seguridad y Salud en el Trabajo (DS 009-2005-TR) del cual se rescata las pautas a realizar:

- Vigilancia y control de seguridad y salud en el trabajo

- Identificar deficiencias o fallas en el Sistema de Gestión de la Seguridad y Salud en el Trabajo (SGSST).

- Optar por medidas preventivas y correctivas para eliminar y controlar los peligros que se suscitan en el trabajo.

- Es necesario realizar una investigación de los accidentes, incidentes y enfermedades relacionadas con el trabajo, de tal manera que se encuentre las causas inmediatas, básicas o cualquier deficiencia del SGSST.

- Realizar auditorías periódicas para corroborar que el Sistema de Gestión de Seguridad y Salud en el Trabajo está siendo aplicado de manera adecuada y eficaz.

- Contar con un Comité de Seguridad, ya que la compañía cuenta con más de 25 trabajadores. Este comité debe nombrar y calificar un supervisor que controlara el cumplimiento del Reglamento Interno del SGSST.

- Es necesario la elaboración de un Mapa de Riesgos, con el que se tendrá la visión de los posibles riesgos que se presentarían en el área.

\subsection{Sistema de mantenimiento}

Un sistema de mantenimiento permite la conservación de un equipo o proceso para evitar su degradación y conservar su buen estado; de tal manera que se optimice el proceso, se eviten fallas, se alargue la vida útil, disminuyen los tiempos de reparación, la operación se hace más segura y se reducen los costos de mantenimiento y producción, debido a que se reducen el número de paradas.

El mantenimiento se puede presentar de distintas maneras, según sea la situación que lo amerite. Para esta planta, se ha establecido realizar mantenimientos preventivos cada seis meses dirigidos por técnicos especialistas, de tal manera que estos arrojen información acerca del estado de las máquinas y los ajustes que esta necesite. Gracias a este tipo de mantenimiento se puede reducir la posibilidad de ocurrencia de fallas, mejorar el desempeño, reducir el número de paradas, proteger al operario haciendo más segura la operación y reducir el costo de mantenimiento reactivo. 
Sin embargo, es inevitable la presencia de fallas, ya que estas son aleatorias; por lo tanto, es necesario realizar mantenimientos reactivos cuando estas ocurren, para este tipo de mantenimiento se requiere de especialistas que puedan cubrir esta operación y de un stock de repuestos que cubran las emergencias de fallas y eviten paradas.

Tabla 5.7

Programa semestral de mantenimiento de máquinas y equipos

\begin{tabular}{|c|c|c|c|c|c|c|c|c|c|c|c|c|c|c|c|c|c|c|c|c|c|c|c|c|}
\hline & \multicolumn{24}{|c|}{ PROGRAMA SEMESTRAL DE MANTENIMIENTO DE MÁQUINAS Y EQUIPOS } \\
\hline & \multicolumn{15}{|c|}{ A\&C Medical Clothing S.A. } & \multicolumn{9}{|c|}{$\begin{array}{l}\text { Elaborado por: Cinthia Cabrera } \\
\text { Revisado por: Andrea Talavera }\end{array}$} \\
\hline Semestre & \multicolumn{24}{|c|}{ Semestre 2016-1 } \\
\hline Mes & \multicolumn{4}{|c|}{ Enero } & \multicolumn{4}{|c|}{ Febrero } & \multicolumn{4}{|c|}{ Marzo } & \multicolumn{4}{|c|}{ Abril } & \multicolumn{4}{|c|}{ Mayo } & \multicolumn{4}{|c|}{ Junio } \\
\hline Maquinaria y equipo & 1 & 2 & 3 & 4 & 1 & 2 & 3 & 4 & 1 & 2 & 3 & 4 & 1 & 2 & 3 & 4 & 1 & 2 & 3 & 4 & 1 & 2 & 3 & 4 \\
\hline Linea SMS & & & & & & & & $\mathrm{X}$ & & & & & & & & $\mathrm{x}$ & & & & & & & & $\mathrm{X}$ \\
\hline \begin{tabular}{|l|} 
Selladora \\
\end{tabular} & $\mathrm{x}$ & & & & $\mathrm{x}$ & & & & $\mathrm{x}$ & & & & $\mathrm{x}$ & & & & $\mathrm{x}$ & & & & $\mathrm{x}$ & & & \\
\hline Cortadora & & & $\mathrm{X}$ & & & & $\mathrm{x}$ & & & & $\mathrm{x}$ & & & & $\mathrm{x}$ & & & & $\mathrm{x}$ & & & & $\mathrm{x}$ & \\
\hline Empaquetadora & & $\mathrm{x}$ & & & & $\mathrm{x}$ & & & & $\mathrm{x}$ & & & & $\mathrm{x}$ & & & & $\mathrm{x}$ & & & & $\mathrm{x}$ & & \\
\hline Etiquetadora & & & & & & & & & $\mathrm{x}$ & & & & & & & & & & & & $\mathrm{x}$ & & & \\
\hline Tanque de aguas residuales & $\mathrm{x}$ & $\mathrm{x}$ & $\mathrm{x}$ & $\mathrm{X}$ & $\mathrm{x}$ & $\mathrm{x}$ & $\mathrm{x}$ & $\mathrm{x}$ & $\mathrm{X}$ & $\mathrm{X}$ & $\mathrm{x}$ & $\mathrm{X}$ & $\mathrm{X}$ & $\mathrm{X}$ & $\mathrm{X}$ & $\mathrm{x}$ & $\mathrm{x}$ & $\mathrm{X}$ & $\mathrm{x}$ & $\mathrm{x}$ & $\mathrm{X}$ & $\mathrm{x}$ & $\mathrm{x}$ & $\mathrm{X}$ \\
\hline Tanque de telas residuales & $\mathrm{X}$ & $\mathrm{X}$ & $\mathrm{x}$ & $\mathrm{X}$ & $\mathrm{x}$ & $\mathrm{x}$ & $\mathrm{x}$ & $\mathrm{x}$ & $\mathrm{X}$ & $\mathrm{X}$ & $\mathrm{x}$ & $\mathrm{X}$ & $\mathrm{x}$ & $\mathrm{X}$ & $\mathrm{X}$ & $\mathrm{x}$ & $\mathrm{X}$ & $\mathrm{X}$ & $\mathrm{x}$ & $\mathrm{X}$ & $\mathrm{X}$ & $\mathrm{X}$ & $\mathrm{x}$ & $\mathrm{X}$ \\
\hline Sistema de ventilación & & & & $\mathrm{X}$ & & & & & & & & $\mathrm{X}$ & & & & & & & & $\mathrm{X}$ & & & & \\
\hline Panel y Sistema Eléctrico & $\mathrm{X}$ & & & & & & & & & & & & & & & & & & & & & & & \\
\hline Vehículos & & & & & & & & & & & & & & & & & & & & & & & & $\mathrm{x}$ \\
\hline
\end{tabular}

Elaboración propia

\subsection{Diseño de la Cadena de Suministro}

La cadena de suministro permite la coordinación sistemática y estratégica de las funciones tradicionales del negocio y de las entidades involucradas dentro y a través de la cadena de suministros, teniendo, así como objetivo mejorar la eficiencia de las operaciones de las partes involucradas y la empresa central.

- Proveedores de insumos: se tendrá un contrato con una empresa China desde donde se importará la tela SMS. Otro insumo necesario es el hilo y las muñequeras, el cual se comprará en el Emporio de Gamarra. Respecto al embalaje se requiere de bolsas y pita para el amarre en el apilamiento de las bolsas, los cuales se comprarán en el Centro de Lima.

- Planta: es aquí donde se realiza la confección de las batas, para este proceso se cuenta con una Línea de producción que realiza toda la transformación de la fibra en tela, acto seguido se inicia con la confección de las prendas, donde se cuenta con los 
operarios y maquinas especiales que producen batas resistentes y de buena calidad. Por último, las batas deben ser embaladas y colocadas en racks para su almacenaje.

- Distribución: las batas son retiradas del almacén y transportadas en camiones hacia el cliente final.

- Cliente: el producto final es entregado a las instituciones médicas, clínicas o universidades. Conservando siempre un buen servicio, entregas a tiempo y completas

Figura 5.7

Balance de materia

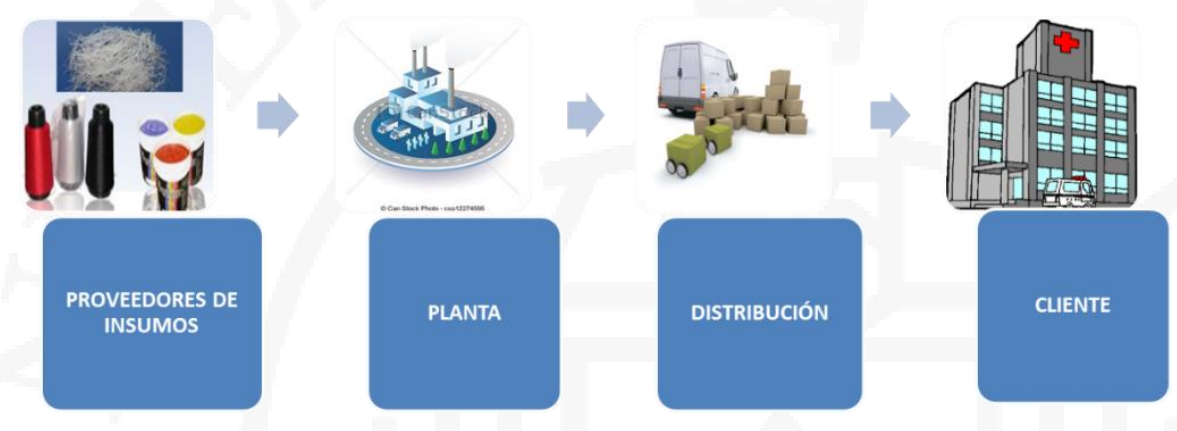

\section{Aprovisionamiento} Distribución

Logística Integral

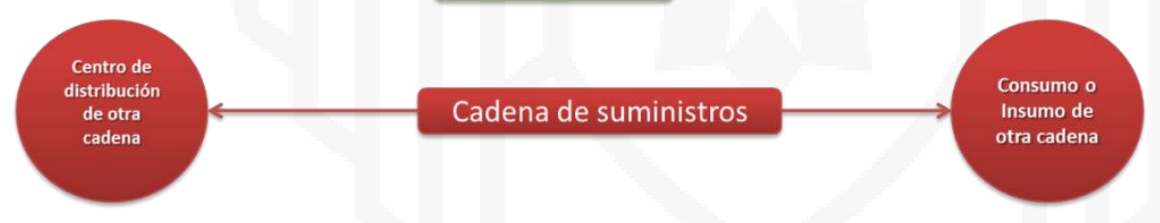

Elaboración propia

Así mismo, cabe resaltar que se realizan cuatro flujos de información en toda la cadena:

- Flujo de producto: el cuál es el movimiento físico de bienes y materiales.

- Flujo de información: con este principalmente se permite el flujo de productos, toma de decisiones y colaboraciones de la cadena de suministros.

- Flujo de efectivo: administración del capital de trabajo.

- Flujo de la demanda: se verifica la información de la demanda para sincronizarla con la oferta. 


\subsection{Programa de producción}

El periodo de vida útil de este proyecto es de 5 años, es decir del año 2016 hasta el año 2020, se espera obtener retorno de la inversión en este periodo de tiempo.

Para la elaboración del Programa Maestro de Producción se consideró la demanda del proyecto, un stock de seguridad y la cantidad a producir (Q). Respecto al stock de seguridad se consideró un $2 \%$ de la demanda; por otro lado, la cantidad a producir (Q) se inflo un $1.5 \%$ el primer año, de tal manera que se genera un inventario que cubrirá los próximos pedidos y se pretende conservar ese $\mathrm{Q}$ para los siguientes años.

Tabla 5.8

Programa maestro de producción

\begin{tabular}{lrrrrr}
\hline \multicolumn{5}{c}{ Año } & \multicolumn{5}{c}{ Batas (unidades) } \\
& $\mathbf{2 0 1 9}$ & $\mathbf{2 0 2 0}$ & $\mathbf{2 0 2 1}$ & \multicolumn{1}{c}{$\mathbf{2 0 2 2}$} & \multicolumn{1}{c}{$\mathbf{2 0 2 3}$} \\
& Año 1 & \multicolumn{1}{c}{ Año 3 } & \multicolumn{1}{c}{ Año 4 } & \multicolumn{1}{c}{ Año 5 } & \multicolumn{1}{c}{ Año 6 } \\
\hline Dem total & 895,964 & 926,295 & 956,627 & 986,959 & $1,017,291$ \\
Inv Seg (SS) & 13,440 & 13,895 & 14,350 & 14,805 & 15,260 \\
Q & 909,404 & 913,310 & 943,187 & 973,064 & $1,002,941$ \\
Inv inicial & - & 26,880 & 27,790 & 28,700 & 29,610 \\
PMP & $\mathbf{9 0 9 , 4 0 4}$ & $\mathbf{9 1 3 , 3 1 0}$ & $\mathbf{9 4 3 , 1 8 7}$ & $\mathbf{9 7 3 , 0 6 4}$ & $\mathbf{1 , 0 0 2 , 9 4 1}$ \\
Inv final & $\mathbf{2 6 , 8 8 0}$ & $\mathbf{2 7 , 7 9 0}$ & $\mathbf{2 8 , 7 0 0}$ & $\mathbf{2 9 , 6 1 0}$ & $\mathbf{3 0 , 5 2 0}$ \\
\hline Elaboración propia & & & & &
\end{tabular}

Tabla 5.9

Programa maestro de producción semanal

\begin{tabular}{|c|c|c|c|c|c|c|c|c|}
\hline \multicolumn{9}{|c|}{ Batas (unidades) } \\
\hline Semana & Sem 1 & Sem 2 & Sem 3 & $\operatorname{Sem} 4$ & Sem 5 & Sem 6 & Sem 7 & Sem 8 \\
\hline Dem total & 18,980 & 18,980 & 18,980 & 18,980 & 18,980 & 18,980 & 18,980 & 18,980 \\
\hline Inv Seg (SS) & 284 & 284 & 284 & 284 & 284 & 284 & 284 & 284 \\
\hline Q & 18,980 & 18,980 & 18,980 & 18,980 & 18,980 & 18,980 & 18,980 & 18,980 \\
\hline Inv inicial & 28,700 & 28,984 & 29,268 & 29,552 & 29,836 & 30,120 & 30,404 & 30,688 \\
\hline PMP & 18,980 & 18,980 & 18,980 & 18,980 & 18,980 & 18,980 & 18,980 & 18,980 \\
\hline Inv final & 28,984 & 29,268 & 29,552 & 29,836 & 30,120 & 30,404 & 30,688 & 30,972 \\
\hline
\end{tabular}

Elaboración propia 


\subsection{Requerimiento de insumos, servicios y personal indirecto}

\subsubsection{Materia prima, insumos y otros materiales}

En este proceso productivo para obtener el producto final se requiere como materia prima principal a la fibra de polipropileno, la cual al pasar por la línea de producción se convierte en tela que posteriormente será transformada, gracias al proceso de confección en batas quirúrgicas.

Respecto a la confección, en la etapa de cocido de muñequeras, se requiere de hilo para coserlas.

Cabe resaltar que las batas serán embolsadas en bolsas plásticas transparentes para garantizar que se conserve su calidad y buen estado. A continuación, se presenta los requerimientos de la materia prima e insumos necesarios:

Figura 5.8

Diagrama de Gozinto

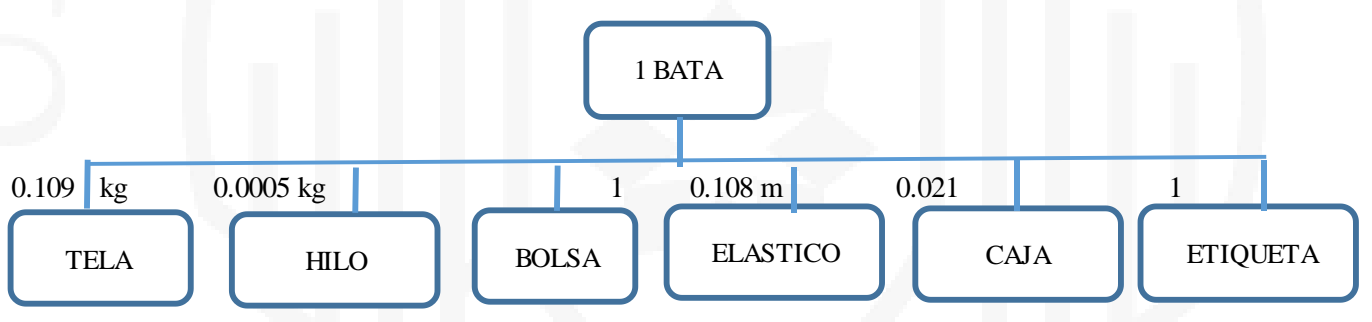

Elaboración propia

\section{MRP Batas}

- Defectuosos: 2\%

- LT: 1 semana.

$$
L T=\frac{8,806 \text { batas } \times \frac{0.000044 \text { horas }}{\text { bata }}}{\frac{8 \text { horas }}{\text { turno }} \times \frac{2 \text { turnos }}{\text { día }} \times \frac{5 \text { días }}{\text { semana }} \times 0.9 \times 0.85}=\frac{1}{61}=0.006=1 \text { semana }
$$


Tabla 5.10

MRP semanal de Batas

\begin{tabular}{|c|c|c|c|c|c|c|}
\hline \multirow{2}{*}{ Batas } & \multicolumn{6}{|c|}{ Semanas } \\
\hline & -52 & 1 & 2 & 3 & 4 & 5 \\
\hline Requerimiento Bruto & & 18,980 & 18,980 & 18,980 & 18,980 & 18,980 \\
\hline \multicolumn{7}{|l|}{ Recepción Programada } \\
\hline Inv. Seguridad & & 228 & 228 & 228 & 228 & 228 \\
\hline Inv. Disponible & 29,610 & 10,402 & - & - & - & - \\
\hline Requerimiento Neto & - & - & 8,806 & 19,208 & 19,208 & 19,208 \\
\hline Plan de Pedidos & - & - & 8,806 & 19,208 & 19,208 & 19,208 \\
\hline Lanzamiento & - & 8,806 & 19,208 & 19,208 & 19,208 & - \\
\hline
\end{tabular}

Elaboración propia

\section{MRP Tela}

- Lote: 42 kg/rollo.

- LT: 1 semana.

$$
L T=\frac{2,142 \mathrm{~kg} \text { de tela } \times \frac{0.00277 \text { horas }}{\mathrm{kg}}}{\frac{8 \text { horas }}{\text { turno }} \times \frac{2 \text { turnos }}{\text { día }} \times \frac{5 \text { días }}{\text { semana }} \times 0.9 \times 0.85}=\frac{6}{61}=0.097=1 \text { semana }
$$

Tabla 5.11

MRP semanal de Tela

\begin{tabular}{|c|c|c|c|c|c|c|}
\hline \multirow{2}{*}{ Tela (kg) } & \multicolumn{6}{|c|}{ Semanas } \\
\hline & -52 & 1 & 2 & 3 & 4 & 5 \\
\hline Requerimiento Bruto & - & 961 & 2,096 & 2,096 & 2,096 & - \\
\hline \multicolumn{7}{|l|}{ Recepción Programada } \\
\hline Inv. de seguridad & & 11 & 23 & 23 & 23 & - \\
\hline Inv. Disponible & 3,231 & 2,259 & - & - & 23 & - \\
\hline Requerimiento Neto & - & - & - & 2,119 & 2,119 & - \\
\hline Plan de Pedidos & - & - & - & 2,142 & 2,142 & - \\
\hline Lanzamiento & - & - & 2,142 & 2,142 & - & - \\
\hline
\end{tabular}

Elaboración propia 


\section{MRP Hilo}

- Lote: $5000 \mathrm{~kg} / \mathrm{rollo}$

- LT: 1 semana.

$$
L T=\frac{5000 \mathrm{~kg} \text { de Hilo } \times \frac{0.3 \text { horas }}{\mathrm{kg}}}{\frac{8 \text { horas }}{\text { turno }} \times \frac{2 \text { turnos }}{\text { día }} \times \frac{5 \text { días }}{\text { semana }} \times 0.9 \times 0.85}=\frac{1500}{61}=25=25 \text { semanas }
$$

Tabla 5.12

MRP semanal de Kg de hilo

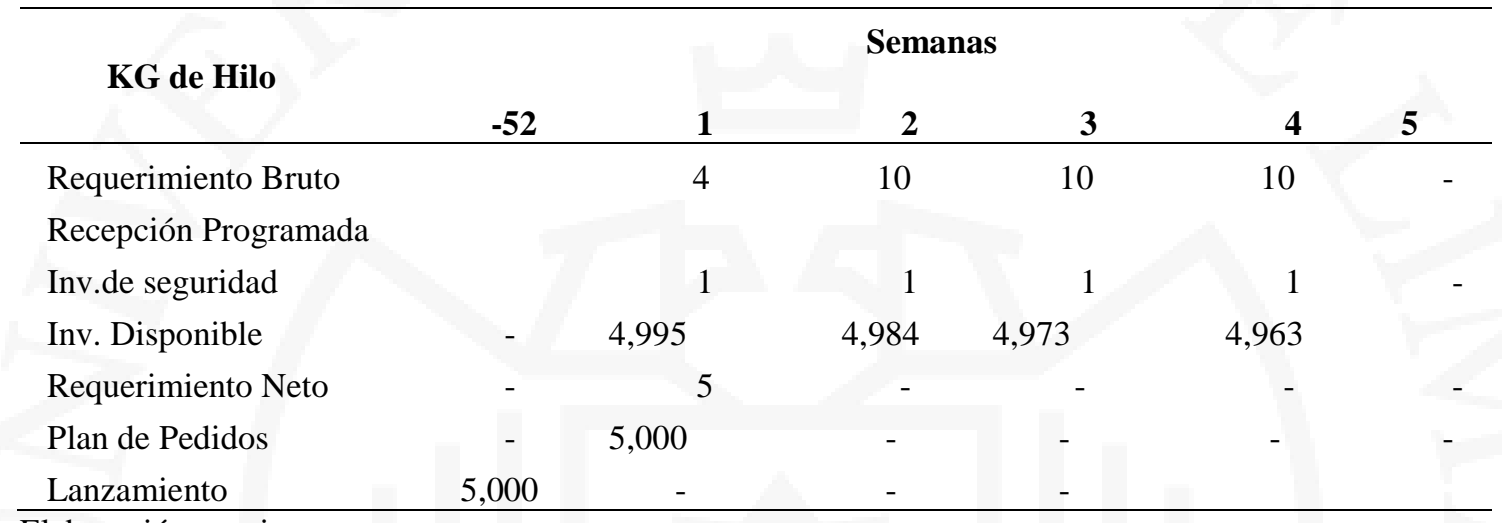

Elaboración propia

\section{MRP Bolsas}

- Lote: 1000

- LT: 1 semana.

$$
L T=\frac{9,000 \text { bolsas } \times \frac{0.005 \text { horas }}{\text { bolsa }}}{\frac{8 \text { horas }}{\text { turno }} \times \frac{2 \text { turnos }}{\text { día }} \times \frac{5 \text { días }}{\text { semana }} \times 0.9 \times 0.85}=\frac{45}{61}=0.735=1 \text { semanas }
$$


Tabla 5.13

MRP semanal de Unidades de Bolsas

\begin{tabular}{|c|c|c|c|c|c|c|}
\hline \multirow{2}{*}{ Und Bolsas } & \multicolumn{6}{|c|}{ Semanas } \\
\hline & -51 & -52 & 1 & 2 & 3 & 4 \\
\hline Requerimiento Bruto & & 8,806 & 19,208 & 19,208 & 19,208 & - \\
\hline Recepción Programada & & & & & & \\
\hline Inv. de seguridad & & 133 & 289 & 289 & 289 & - \\
\hline Inv. Disponible & - & 61 & 564 & 67 & 570 & \\
\hline Requerimiento Neto & - & 8,939 & 19,436 & 18,933 & 19,430 & - \\
\hline Plan de Pedidos & - & 9,000 & 20,000 & 19,000 & 20,000 & - \\
\hline Lanzamiento & 9,000 & 20,000 & 19,000 & 20,000 & & \\
\hline
\end{tabular}

Elaboración propia

\section{MRP elasticos}

- Lote: $3000 \mathrm{~m} / \mathrm{cono}$

- LT: 1 semana.

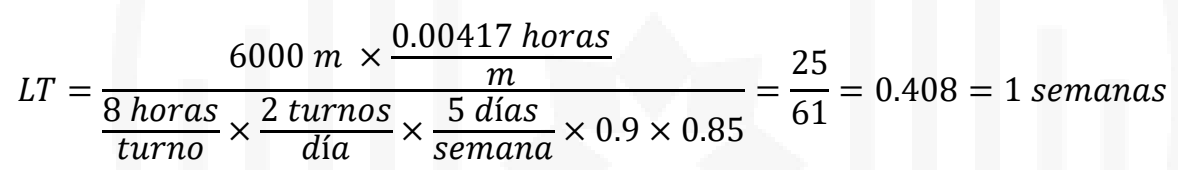

Tabla 5.14

MRP semanal de elásticos

\begin{tabular}{lcrrrrr}
\hline \multicolumn{1}{c}{ M de elástico } & \multicolumn{7}{c}{ Semanas } \\
& $\mathbf{- 5 2}$ & $\mathbf{1}$ & $\mathbf{2}$ & $\mathbf{3}$ & $\mathbf{4}$ & $\mathbf{5}$ \\
\hline Requerimiento & - & 5,284 & 11,525 & 11,525 & 11,525 & - \\
Bruto & & & & & & \\
Recepción Programada & & & 173 & 173 & 173 & - \\
Inv. de seguridad & - & 716 & 1,192 & 1,667 & - & - \\
Inv. Disponible & - & 5,364 & 10,981 & 10,506 & - & - \\
Requerimiento Neto & - & 6,000 & 12,000 & 12,000 & - & - \\
Plan de Pedidos & 6,000 & 12,000 & 12,000 & - & - & \\
Lanzamiento & & & & &
\end{tabular}

Elaboración propia 


\section{MRP cajas}

- Lote: 1000 cajas

- LT: 1 semana.

$$
L T=\frac{1000 \text { cajas } \times \frac{0.00287 \text { horas }}{\text { caja }}}{\frac{8 \text { horas }}{\text { turno }} \times \frac{2 \text { turnos }}{\text { día }} \times \frac{5 \text { días }}{\text { semana }} \times 0.9 \times 0.85}=\frac{3}{61}=0.045=1 \text { semanas }
$$

Tabla 5.15

MRP semanal de cajas

\begin{tabular}{lcccccc}
\hline \multicolumn{1}{c}{ Und Cajas } & \multicolumn{5}{c}{ Semanas } \\
& $\mathbf{- 5 1}$ & $\mathbf{- 5 2}$ & $\mathbf{1}$ & $\mathbf{2}$ & $\mathbf{3}$ & $\mathbf{4}$ \\
\hline Requerimiento Bruto & & 183 & 400 & 400 & 400 & - \\
Recepción Programada & & & & & & \\
Inv. de seguridad & & 3 & 7 & 7 & 7 & - \\
Inv. Disponible & - & 814 & -594 & 999 & -408 & - \\
RequerimientoNeto & - & 186 & -406 & 1,001 & -592 & - \\
Plan de Pedidos & - & 1,000 & $-1,000$ & 2,000 & $-1,000$ & - \\
Lanzamiento & 1,000 & $-1,000$ & 2,000 & $-1,000$ & & \\
\hline Elaboracion pran
\end{tabular}

Elaboración propia

\section{MRP etiquetas}

- Lote: 1000 cajas

- LT: 1 semana.

$$
L T=\frac{9000 \text { etiquetas } \times \frac{0.005 \text { horas }}{\text { etiquetas }}}{\frac{8 \text { horas }}{\text { turno }} \times \frac{2 \text { turnos }}{\text { día }} \times \frac{5 \text { días }}{\text { semana }} \times 0.9 \times 0.85}=\frac{45}{61}=0.735=1 \text { semanas }
$$

Tabla 5.16

MRP semanal de cajas

\begin{tabular}{lcrrrrr}
\hline \multicolumn{1}{c}{ Und Bolsas } & \multicolumn{5}{c}{ Semanas } \\
& $\mathbf{- 5 1}$ & $\mathbf{- 5 2}$ & $\mathbf{1}$ & $\mathbf{2}$ & $\mathbf{3}$ & $\mathbf{4}$ \\
\hline Requerimiento Bruto & & 8,806 & 19,208 & 19,208 & 19,208 & - \\
Recepción Programada & & & & & & \\
Inv. de seguridad & & 133 & 289 & 289 & 289 & - \\
Inv. Disponible & - & 61 & 564 & 67 & 570 & \\
Requerimiento & - & 8,939 & 19,436 & 18,933 & 19,430 & - \\
Neto & - & 9,000 & 20,000 & 19,000 & 20,000 & - \\
Plan de Pedidos & 9,000 & 20,000 & 19,000 & 20,000 & & \\
Lanzamiento & & & & & & \\
\hline Elaracon
\end{tabular}

Elaboración propia 


\subsubsection{Servicios: energía eléctrica, agua.}

Como servicios indispensables para el funcionamiento de la planta se requiere de:

- Energía eléctrica: debido a que la planta tendrá locación en la ciudad de Lima, se cuenta con un gran abastecimiento de energía eléctrica ya que esta ciudad cuenta con 16 centrales de energía y genera alrededor del $44.4 \%$ de la electricidad del país. Este servicio lo brindara Luz del Sur.

- Agua: el abastecimiento de agua lo brindara la empresa. Este servicio lo brindara SEDAPAR.

- Telefonía e internet: el cual servirá para la comunicación con los clientes, publicidad vía web, contacto con proveedores, entre otras actividades. Este servicio lo brindara Movistar Perú.

\subsubsection{Determinación del número de trabajadores indirectos}

Para determinar los trabajadores indirectos en el proceso de producir, es decir aquellos que no intervienen en el proceso de transformación de la materia prima a producto final.

Tabla 5.17

Trabajadores indirectos

\begin{tabular}{lr}
\hline Trabajores indirectos & Cantidad \\
\hline Jefe de producción & 1 \\
Supervisor & 3 \\
\hline Elaboración propia &
\end{tabular}

\subsubsection{Servicios de terceros}

Respecto a servicios de terceros, se considera los siguientes:

- Vigilancia.

- Limpieza.

- Mantenimiento de equipos.

- Combustible. 


\subsection{Disposición de planta}

\subsubsection{Características físicas del proyecto}

\section{Factor Material}

Este factor incluye las materias primas, los materiales y los insumos necesarios para la producción y los procesos en la planta. Con ayuda de Diagrama de Gozinto se pudo determinar el requerimiento de materiales e insumos para la elaboración de prendas médicas desechables, el resumen se muestra a continuación.

\section{Tabla 5.18}

Factor Material

\begin{tabular}{lccccc}
\hline Requerimiento & $\mathbf{2 0 1 9}$ & $\mathbf{2 0 2 0}$ & $\mathbf{2 0 2 1}$ & $\mathbf{2 0 2 2}$ & \multicolumn{1}{c}{$\mathbf{2 0 2 3}$} \\
\hline Demanda de prendas & 895,963 & 926,295 & 956,627 & 986,959 & $1,017,291$ \\
Kg. de tela prolipropileno & 105,025 & 108,580 & 112,136 & 115,691 & 119,247 \\
SMS & 472 & 488 & 503 & 519 & 535 \\
Kg. de hilo & \multicolumn{1}{l}{} & & & & \\
\hline
\end{tabular}

Nota: Se calculó el movimiento con el Punto de inicio y de llegada Elaboración propia

\section{Factor Maquinarias y Hombre}

Se calcularon en el capítulo anterior.

\section{Factor Movimiento}

Las batas y los scrubs son productos muy similares, por lo que necesitarán las mismas unidades y los mismos métodos de transporte. A continuación, se detallan los contenedores necesarios para el transporte de cada material dentro de la planta, desde el punto de inicio hasta el punto de llegada. 
Tabla 5.19

Factor Movimiento

\begin{tabular}{llll}
\hline Material & Contenedor & Punto de Inicio & Punto de llegada \\
\hline Rollos de tela SMS & Montacargas & Patio de Maniobras & Almacén \\
Rollos de tela SMS & Montacargas & Almacén & Corte \\
Producto en proceso & Carretillas hidráulicas & Corte & Almacén \\
Producto en proceso 1 & Carretillas hidráulicas & Almacén & Sellado \\
Producto en proceso 2 & Carretillas hidráulicas & Sellado & Cocido \\
Paquetes de plástico & Carretillas hidráulicas & Almacén & Empaquetado \\
Producto terminado & Carretillas hidráulicas & Empaquetado & Almacén \\
\hline
\end{tabular}

Nota: Se calculó el movimiento con el Punto de inicio y de llegada.

Elaboración propia

Análisis de necesidad de medios de acarreo:

A continuación, detallaremos el uso de los equipos de acarreo necesarios.

a) Montacargas: Es un excelente equipo para transportar diversos tipos de materiales y una gran diversidad de terrenos, a velocidades que oscilan entre 7 y $4 \mathrm{~km} / \mathrm{h}$. Para el cálculo de los pasillos de la planta, se tomó en cuanto el radio de giro del montacargas y sus dimensiones. Con los montacargas se realizaría el transporte de los materiales más pesados: las fibras de polipropileno que vienen en bolsas de 7.2 kilogramos cada una, y para los rollos de tela que son productos en proceso a almacenar hasta el momento del corte. Además, se utilizarán los montacargas para el almacenamiento de los pedidos volumétricos de los productos y el transporte de estos al camión para su respectivo transporte a nuestros clientes.

Figura 5.9

Montacarga

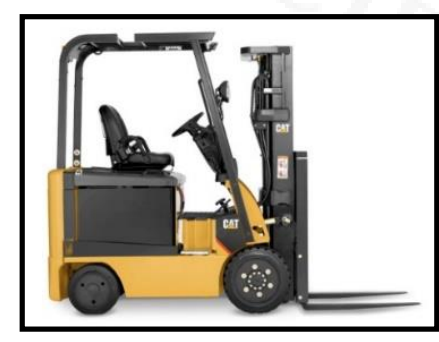

Fuente: Enciclopedia de Clasificaciones. (2016). 
b) Carretillas hidráulicas: Son equipos más versátiles para utilizar dentro de las áreas productivas debido a que tienen menor tamaño que los montacargas y son fáciles de utilizar. Serán utilizadas para el transporte de productos en proceso y materias primas como las enzimas y los paquetes de plástico. Se tomó en cuenta las dimensiones de las carretillas a adquirir para el ancho de los pasillos entre las máquinas en el área de producción.

Figura 5.10

Carretilla hidráulica

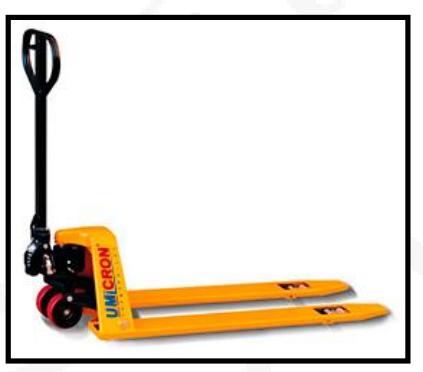

Fuente: Umina. (2015)

\section{Factor Medio Ambiente}

El factor medio ambiente presenta una gran importancia en este proyecto de investigación, debido a que el motor de este estudio es desarrollar nuevos productos de vestir en base a biotecnología, con el objetivo de reducir el impacto de la industria y el consumo en nuestro hábitat. Además, es esencial para alcanzar el desarrollo sostenible de tal manera que la empresa logre un crecimiento económico balanceado, que produzca una mejora en la calidad de vida de los trabajadores, los inversionistas y la comunidad que la rodea.

Por tal motivo, se buscará establecer y promover la Estrategia Producción Más Limpia (PML), definida por la Organización de las Naciones Unidas para el Desarrollo Industrial (ONUDI) como la aplicación continua de una estrategia ambiental preventiva que se encuentra integrada en procesos, productos y servicios para incrementar la eficiencia global y así reducir los riesgos para los seres vivos y el medio ambiente. Este enfoque se centrará en el ahorro de materias primas y energía.

A continuación, se presenta una lista de actividades para mitigar los posibles impactos ambientales. 
- Se realizará un tratamiento y almacenaje de aguas y telas residuales con el objetivo de que puedan ser utilizados en otros procesos, promoviendo el reciclaje.

- Capacitar a los operarios y al personal administrativo sobre la necesidad, los retos y los beneficios de implementar una estrategia de PML.

- Trabajar junto con todos los eslabones de la cadena de suministro para que contar con un adecuado Sistema de Gestión Ambiental (SGA).

- Realizar constantes investigaciones para descubrir y utilizar maquinarias más ecoamigables.

Finalmente, a través de la Matriz de Evaluación de Impacto Ambiental se pudo concluir que el presente proyecto es viable desde el punto de vista ambiental debido a que emite muy bajo impacto al Medio Ambiente.

\section{Factor Espera}

Durante el proceso productivo existen momentos en el que los materiales, al ingresar o salir de una máquina o equipo, aguardan a ser utilizados, a los cuales se les conoce como puntos de espera. Estos puntos pueden encontrarse en cualquiera de los lados de la maquinaria o del operario como a continuación se detallan:

Tabla 5.20

Punto de espera

\begin{tabular}{lll}
\hline Ubicación & Punto de espera & Material \\
\hline Corte & $\mathrm{Al}$ costado anterior de la máquina & Tela SMS \\
Corte & $\mathrm{Al}$ costado posterior de la máquina & Cortes de tela SMS \\
Sellado ultrasónico & $\mathrm{Al}$ costado anterior de la máquina & Cortes de tela SMS \\
Sellado ultrasónico & $\mathrm{Al}$ costado posterior de la máquina & Prendas incompletas \\
Cocido de elástico & $\mathrm{Al}$ costado anterior de la máquina & Prendas incompletas \\
Cocido de elástico & $\mathrm{Al}$ costado anterior de la máquina & Elástico/hilo \\
Cocido de elástico & $\mathrm{Al}$ costado posterior de la máquina & Prendas finales \\
Acabado y doblado & $\mathrm{Al}$ costado anterior de la máquina & Prendas finales \\
Acabado y doblado & $\mathrm{Al}$ costado posterior de la máquina & Prendas finales \\
Empaquetado y etiquetado & $\mathrm{Al}$ costado anterior de la máquina & Prendas finales \\
Empaquetado y etiquetado & $\mathrm{Al}$ costado anterior de la máquina & Plástico \\
Empaquetado y etiquetado & $\mathrm{Al}$ costado posterior de la máquina & Prendas empaquetadas \\
\hline
\end{tabular}

Nota: se calculó con la ubicación y el material.

Elaboración propia 


\section{Factor Servicio}

a) Vías de acceso: Existirán dos puertas de entrada, una para el ingreso de camiones en el patio de maniobras y otra para el ingreso del personal en el frontis de la empresa. Además, por razones de seguridad, las puertas tendrán un ancho mínimo de $0.8 \mathrm{~m}$ por cada $1000 \mathrm{~m} 2$ construidos y los pasadizos en el área administrativa tendrán un ancho mínimo de $1.2 \mathrm{~m}$. Así mismo, tanto operarios como personal administrativo contarán con estacionamientos.

b) Instalaciones sanitarias: Como se observa en las especificaciones de OSHA, debido a que la planta cuenta con 49 trabajadores, se debe tomar en cuenta un mínimo de 3 inodoros. La planta contará con 4 instalaciones sanitarias, 2 en la zona del personal administrativo y 2 en la zona de producción, esto con el fin de facilitar el acceso a los servicios. Considerando que existirán 16 trabajadores en el área administrativa, se necesita como mínimo 2 indodoro por baño; por ello el servicio higiénico para mujeres contará con 3 inodoros y 2 lavamanos, mientras que el de hombres contará con 2 lavamanos, 2 inodoros y 2 urinarios. Por otro lado, considerando que trabajarán 14 operarios por turno y tomando en cuenta un número equitativo de hombres y mujeres y el tiempo promedio que demoran en usar las instalaciones sanitarias, se tomarán en cuenta 2 baños separados. El servicio higiénico de mujeres contará con 4 lavamanos, 6 inodoros y un área de vestuarios y lockers; el de hombres contará con 4 lavamanos, 4 inodoros, 2 urinarios y área de vestuarios y lockers. Para el cálculo del área mínima requerida por servicio higiénico, se tomó en consideración que según la OSHA se necesitan $3.5 \mathrm{~m}^{2}$ por cada inodoro. Por consiguiente, el área mínima requerida por cada servicio higiénico es de $21 \mathrm{~m}^{2}$.

$$
\text { Área de cada SS.HH. }=\frac{3.5 \mathrm{~m}^{2}}{\text { inodoro }} \times \frac{6 \text { inodoros }}{\text { baño }}=21 \mathrm{~m}^{2}
$$

\section{Tabla 5.21}

Número de trabajadores

\begin{tabular}{ll}
\hline Tipo de área & Número de trabajadores \\
\hline Área de Producción & 32 \\
Área Administrativa & 12 \\
Total & 44 \\
\hline
\end{tabular}

Elaboración propia 
Tabla 5.22

Número mínimo de W.C

\begin{tabular}{|c|c|}
\hline Número de empleados & Número mínimo de W.C. \\
\hline $1-15$ & 1 \\
\hline $16-35$ & 2 \\
\hline $36-55$ & 3 \\
\hline $56-80$ & 4 \\
\hline $81-110$ & 5 \\
\hline $111-150$ & 6 \\
\hline Más de 150 & Uno más por cada 40 empleados \\
\hline
\end{tabular}

c) Servicio de alimentación: Los empleados dispondrán de un comedor provisionado con un lavaplatos, dos microondas, un dispensador de bebidas y alimentos, y dos mesas largas con sillas. Para el cálculo del área necesaria para el comedor, se tomaron en cuenta las recomendaciones de OSHA de $1.58 \mathrm{~m} 2$ por personas, los operarios están divididos en dos turnos y la hora del refrigerio se dará en 2 momentos en cada turno. Se contará con un comedor con mesas, sillas y microondas para las personas que llevan sus propios alimentos, y con una máquina dispensadora de bebidas y una de alimentos. Esta área se encontrará dentro de la planta idealmente alejada de la zona de producción y de la zona administrativa. Se concluye que el área mínima requería para el comedor es de $17.38 \mathrm{~m} 2$.

$$
\text { Área del comedor }=\frac{1.58 \mathrm{~m}^{2}}{\text { persona }} \times \frac{44 \text { personas }}{2 \text { turnos }} \times \frac{\text { turno }}{2 \text { refrigerios }}=17.38
$$

d) Iluminación y ventilación: Dentro de las indicaciones para la correctamente iluminación de la planta se encuentran:

- La planta contará con paredes de tonalidades claras.

- Se utilizarán luminarias ahorradoras LED. En el área de producción se colocarán 8 y en cada almacén 4.

- Las oficinas administrativas contarán con ventanas con un ancho mínimo de $1 \mathrm{~m}$ para promover el ingreso de la luz solar y evitar gastos innecesarios de electricidad. Por ello, cada oficina solo contará con una luminaria.

Dentro de las indicaciones para la correcta ventilación de aire de la planta se encuentran: 
- Las oficinas contarán con ventanas con una altura suficiente para proporcionar iluminación y para que en la parte superior puedan abrirse para permitir el flujo de aire.

- Se contará con la instalación de un sistema de ventilación que permitirá mitigar olores y partículas, y promoverá un aire más limpio dentro de las instalaciones, en especial en el área de producción.

\subsubsection{Determinación de las zonas físicas requeridas}

La fábrica deberá contar con un patio de maniobras, el área de producción, el almacén, servicios higiénicos, comedor, área de mantenimiento, área de desechos residuales, área de oficinas administrativas y un showroom.

\subsubsection{Cálculo de áreas para cada zona}

Cálculo de áreas requeridas

\section{a) Área de producción}

Para determinar el área mínima requerida para la zona de producción se utilizará el Método Guerchet. Para ello, se utilizarán los puntos de espera mencionados anteriormente y las dimensiones de las máquinas y equipos.

En primer lugar, se determinará si los puntos de espera son parte de la superficie gravitacional $(\mathrm{Sg})$ del elemento estático al que pertenecen o si constituyen un área separada adicional. Para ello se realiza el "análisis del 30\%" el cual indica que si el punto de espera representa más que ese porcentaje con respecto al área gravitacional de la máquina debe considerar como un elemento independiente.

Con ayuda de las siguientes formulas se realizará en análisis correspondiente donde Ss es la superficie estática, $\mathrm{Sg}$ es la superficie gravitacional y $\mathrm{N}$ es el número de lados a utilizar en cada máquina

$$
\text { Ss }=\text { Largo } \times \text { Ancho } \quad S g=S s \times N
$$

- Punto de espera en la cortadora:

Con la cortadora se obtienen las partes que conformaran las prendas. Como su nombre lo indica, en este proceso se corta la tela que llega del almacén y se obtiene 
las partes o la forma de la bata y de los scrubs. Una vez obtenidas las partes, se colocan en unos depósitos a la espera de ser llevadas al siguiente proceso o al almacén. Debido a que los puntos de espera representan más del 30\% de la superficie gravitacional de la máquina, se considerará como un elemento independiente. Es decir que no se encuentran dentro de la superficie gravitacional de la máquina. A continuación, se muestra el resumen de los cálculos.

\section{Tabla 5.23}

Ingreso de fibras y salida de tela

\begin{tabular}{ll}
\hline Ingreso de Tela & Salida de Partes \\
\hline Superficie de la máquina: & Superficie de la máquina: \\
$S S=3 m \times 1 m=3 m^{2}$ & $S s=3 m \times 1 m=3 m^{2}$ \\
$S g=3 m^{2} \times 1=3 m^{2}$ & $S g=3 m^{2} \times 1=3 m^{2}$ \\
Superficie del punto de espera: & Superficie del punto de espera: \\
$S S=1 m \times 1 m=1 m^{2}$ & $S S=1 m \times 1 m=1 m^{2}$ \\
$P E 1$ Linea $S M S=\frac{1 m^{2}}{3 m^{2}}=33.33 \%$ & $P E 1$ Linea $S M S=\frac{1 m^{2}}{3 m^{2}}=33.33 \%$ \\
\hline
\end{tabular}

Nota: $\mathrm{Ss}=$ superficie estatica, $\mathrm{Sg}=$ Superficie gravitacional.

Elaboración propia

- Punto de espera en las selladoras ultrasónicas:

Las selladoras son las máquinas que unen las partes de la prenda que llegan del proceso anterior, las cuales se mantienen en espera hasta ser utilizadas. De las selladoras salen las batas o scrubs que se mantienen a la espera de ser llevadas al almacén o al siguiente proceso. Debido a que los puntos de espera representan más del $30 \%$ de la superficie gravitacional de la máquina, se considerará como un elemento independiente. Es decir que no se encuentran dentro de la superficie gravitacional de la máquina. A continuación, se muestra el resumen de los cálculos. 
Tabla 5.24

Ingreso de fibras y salida de tela

\begin{tabular}{ll}
\hline Ingreso de Partes & Salida de Batas/Scrubs \\
\hline Superficie de la máquina: & Superficie de la máquina: \\
$S s=1.27 \mathrm{~m} \times 0.6 \mathrm{~m}=0.76 \mathrm{~m}^{2}$ & $S S=1.27 \mathrm{~m} \times 0.6 \mathrm{~m}=0.76 \mathrm{~m}^{2}$ \\
$S g=0.76 \times 2=1.52 \mathrm{~m}^{2}$ & $S g=0.76 \times 2=1.52 \mathrm{~m}^{2}$ \\
Superficie del punto de espera: & Superficie del punto de espera: \\
$S S=1 \mathrm{~m} \times 1 \mathrm{~m}=1 \mathrm{~m}^{2}$ & $S S=1 \mathrm{~m} \times 1 \mathrm{~m}=1 \mathrm{~m}^{2}$ \\
$P E 1$ Linea $S M S=\frac{1 \mathrm{~m}^{2}}{1.52 \mathrm{~m}^{2}}=65.62 \%$ & $P E 1$ Linea $S M S=\frac{1 \mathrm{~m}^{2}}{1.52 \mathrm{~m}^{2}}=65.62 \%$ \\
\hline
\end{tabular}

Nota: $\mathrm{Ss}=$ superficie estatica, $\mathrm{Sg}=$ Superficie gravitacional.

Elaboración propia

- Punto de espera en las empaquetadoras

En las empaquetadoras se dan los procesos de acabado, empaquetado y etiquetado.

A la espera de ingresar al proceso se encuentran las batas o scrubs, las etiquetas y los paquetes de plástico. Finalmente salen las prendas empaquetadas a la espera de ser llevadas al almacén. Debido a que los puntos de espera no representan más del 30\% de la superficie gravitacional de la máquina, no se considerará como un elemento independiente. Es decir, que se encuentran dentro de la superficie gravitacional de la máquina. A continuación, se muestra el resumen de los cálculos.

Tabla 5.25

Ingreso de fibras y salida de tela

\begin{tabular}{ll}
\hline Ingreso de prendas & Salida de prendas \\
\hline Superficie de la máquina: & Superficie de la máquina: \\
$S s=2.5 \mathrm{~m} \times 1.1 \mathrm{~m}=2.75 \mathrm{~m}^{2}$ & $S s=2.5 \mathrm{~m} \times 1.1 \mathrm{~m}=2.75 \mathrm{~m}^{2}$ \\
$S g=2.75 \mathrm{~m}^{2} \times 2=5.5 \mathrm{~m}^{2}$ & $S g=2.75 \mathrm{~m}^{2} \times 2=5.5 \mathrm{~m}^{2}$ \\
Superficie del punto de espera: & Superficie del punto de espera: \\
$S S=1.5 \mathrm{~m} \times 1 \mathrm{~m}=1.5 \mathrm{~m}^{2}$ & $S S=1.5 \mathrm{~m} \times 1 \mathrm{~m}=1.5 \mathrm{~m}^{2}$ \\
$P E 1$ Linea $S M S=\frac{1.5 \mathrm{~m}^{2}}{5.5 \mathrm{~m}^{2}}=27.27 \%$ & $P E 1$ Linea $S M S=\frac{1.5 \mathrm{~m}^{2}}{5.5 \mathrm{~m}^{2}}=27.27 \%$ \\
\hline
\end{tabular}

Nota: $\mathrm{Ss}=$ superficie estática, $\mathrm{Sg}=$ Superficie gravitacional.

Elaboración propia

Luego se determinó la superficie evolutiva (Se) de las máquinas y puntos de espera a considerar en el cálculo del área requerida, mediante el cálculo de la constante $\mathrm{K}$ como se muestra a continuación. 


$$
\begin{aligned}
& S e=K \times(S s+S g) \\
& h_{e e}=\frac{\sum(S S \times h \times n)}{\sum(S s \times n)}=\frac{57.41}{35.52}=10.62 \\
& h_{e m}=\frac{\sum(S s \times h \times n)}{\sum(S s \times n)}=\frac{22.34}{14.41}=1.54 \\
& K=\frac{\sum h_{e m}}{2 \times \sum h_{e e}}=\frac{1.54}{2 \times 10.22}=0.0758
\end{aligned}
$$

Finalmente se calcula la Superficie total (St) de cada uno los elementos y posteriormente se suman todos los totales para encontrar el área mínima requería para la zona de producción, en donde $\mathrm{n}$ es el número de máquinas.

$$
S t=n \times(S s+S g+S)
$$

A continuación, se muestra el cuadro resumen del Método Guerchet. 
Tabla 5.26

Método Guerchet

\begin{tabular}{|c|c|c|c|c|c|c|c|c|c|c|c|}
\hline \multirow{2}{*}{ Elementos } & \multicolumn{3}{|c|}{ Dimensiones } & \multirow{2}{*}{$\mathbf{N}$} & \multirow{2}{*}{$\mathbf{n}$} & \multirow{2}{*}{ Ss } & \multirow{2}{*}{ Sg } & \multirow{2}{*}{ Se } & \multicolumn{2}{|c|}{ Cálculo de K } & \multirow{2}{*}{ St } \\
\hline & $\mathbf{L}$ & $\mathbf{A}$ & $\mathbf{h}$ & & & & & & SS*h*n & SS*n & \\
\hline \multicolumn{12}{|l|}{ Elementos Estáticos } \\
\hline$(*)$ PE 1 Cortadora & 1,00 & 1,00 & 0,50 & & 1 & 1,00 & & 0,48 & 0,50 & 1,00 & 1,48 \\
\hline Cortadora & 3,00 & 1,00 & 0,80 & 2 & 2 & 3,00 & 6,00 & 4,28 & 5 & 6,00 & 26,57 \\
\hline$(*)$ PE 2 Cortadora & 1,00 & 1,00 & 0,50 & & 1 & 1,00 & & 0,48 & 0,50 & 1,00 & 1,48 \\
\hline (*) PE 1 Selladora Ultrasónica & 1,00 & 1,00 & 0,50 & & 1 & 1,00 & & 0,48 & 0,50 & 1,00 & 1,48 \\
\hline Selladora Ultrasónica & 1,27 & 0,60 & 1,27 & 1 & 2 & 0,76 & 0,76 & 0,73 & 1,94 & 1,52 & 4,50 \\
\hline (*) PE 2 Selladora Ultrasónica & 1,00 & 1,00 & 0,50 & & 1 & 1,00 & & 0,48 & 0,50 & 1,00 & 1,48 \\
\hline (*) PE 1 Mesa de cocide & 1,00 & 1,00 & $\theta, 50$ & & + & 1,00 & & $\theta, 48$ & 0,50 & 1,00 & \\
\hline (*)PE 2 Mesa de cocide & 1,00 & $\theta, 50$ & $\theta, 50$ & & 4 & 0,50 & & $\theta, 24$ & 0,25 & 0,50 & \\
\hline Mesa de cocido & 2,50 & 1,10 & 2,65 & 2 & 2 & 2,75 & 5,50 & 3,93 & 14,58 & 5,50 & 24,35 \\
\hline (*) PE 3 Mesa de cocide & 1,00 & 1,00 & $\theta, 8 \theta$ & & 4 & 1,00 & & $\theta, 48$ & $\theta, 8 \theta$ & 1,00 & \\
\hline (*) PE 1 Mesa de aeabade & 2,00 & 1,50 & $\theta, 8 \theta$ & & 4 & 3,00 & & 1,43 & 2,40 & 3,00 & \\
\hline Mesa de acabado & 2,50 & 1,10 & 2,65 & 2 & 2 & 2,75 & 5,50 & 3,93 & 14,58 & 5,50 & 24,35 \\
\hline (*) PE 2 Mesa de aeabade & 1,00 & $\theta, 50$ & $\theta, 50$ & & 4 & $\theta, 50$ & & 0,24 & 0,25 & $\theta, 50$ & \\
\hline (*) PE 1 Empaquetadora & 1,00 & 0,50 & 0,50 & & 1 & 0,50 & & 0,24 & 0,25 & 0,50 & 0,74 \\
\hline (*) PE 2 Empaquetadora & 1,00 & 0,50 & 0,50 & & 1 & 0,50 & & 0,24 & 0,25 & 0,50 & 0,74 \\
\hline Empaquetadora & 2,50 & 1,10 & 2,65 & 2 & 2 & 2,75 & 5,50 & 3,93 & 14,58 & 5,50 & 24,35 \\
\hline (*) PE 3 Empaquetadora & 1,00 & 0,50 & 0,50 & & 1 & 0,50 & & 0,24 & 0,25 & 0,50 & 0,74 \\
\hline \multicolumn{12}{|l|}{ Elementos Móviles } \\
\hline Operarios & & & 1,65 & & 14 & 0,50 & & & 11,55 & 7,00 & \\
\hline Montacargas & 2,26 & 1,07 & 0,80 & & 2 & 2,41 & & & 3,85 & 4,81 & \\
\hline Carretilla hidráulica & 1,00 & 0,55 & 4,06 & & 2 & 0,55 & & & 4,46 & 1,10 & \\
\hline
\end{tabular}

Elaboración propia

Se concluye que el área mínima requerida para la zona de producción es de $111 \mathrm{~m} 2$. 


\section{b) Otras áreas}

\section{- Almacén de Materias Primas}

El almacén constará de estanterías de 4 niveles donde se almacenarán todas las materias primas necesarias para la producción de prendas médicas desechables: rollos de tela de polipropileno SMS, hilos, bolsas, elásticos, cajas y etiquetas.

$$
\begin{aligned}
& \text { Cantidad a almacenar }(\text { tela })=\frac{Q}{2}+S S=\frac{8385}{2}+(5 \% \times 8385)=4612 \mathrm{~kg} \text { de tela } \\
& \text { Cantidad a almacenar }(\text { hilo })=\frac{Q}{2}+S S=\frac{40}{2}+(5 \% \times 40)=22 \mathrm{~kg} \text { de hilo } \\
& \text { Cantidad a almacenar (elásticos) }=\frac{Q}{2}+S S=\frac{46099}{2}+(5 \% \times 46099)=25355 \text { m. de elástico } \\
& \text { Cantidad a almacenar (bolsas) }=\frac{Q}{2}+S S=\frac{18980}{2}+(5 \% \times 18980)=10439 \text { bolsas } \\
& \text { Cantidad a almacenar (etiquetas })=\frac{Q}{2}+S S=\frac{18980}{2}+(5 \% \times 18980)=10439 \text { etiquetas } \\
& \text { Cantidad a almacenar (cajas) }=\frac{Q}{2}+S S=\frac{1600}{2}+(5 \% \times 1600)=880 \text { cajas }
\end{aligned}
$$

Para determinar el área mínima requerida se tomó en cuenta 4 estanterías: 2 para apilar los rollos de tela de polipropilenos SMS y 2 para aplicar los demás insumos. Las recomendaciones de los manuales del equipo de acarreo que indican un pasillo principal deben tener un ancho mínimo de $5 \mathrm{~m}$. y los pasillos secundarios un ancho mínimo de $2.8 \mathrm{~m}$.

$$
\begin{aligned}
& \text { Ancho }=4 \text { estanterías }+ \text { holgura }+2 \text { pasillos secundrios } \\
& \text { Ancho }=(4 \times 1.2)+(4 \times 0.15)+(2.8 \times 2)=11 \mathrm{~m} \\
& \text { Largo }=\text { estantería }+ \text { holgura }+ \text { pasillos prncipal } \\
& \text { Largo }=4+(2 \times 0.15)+(3 \times 0.1)+5=9.6 \mathrm{~m} \\
& \text { Área mínima }=11 \mathrm{~m} \times 9.6 \mathrm{~m}=105.60 \mathrm{~m}^{2}
\end{aligned}
$$

\section{- Almacén de Producto en Proceso}

El almacén constará de estanterías de 4 niveles donde se almacenarán las bajas embolsadas antes de su esterilización. Para el cálculo del área del almacén primero se determinó el inventario promedio mensual.

Cantidad a almacenar $=\frac{Q}{2}+S S=\frac{18980}{2}+(5 \% \times 18980)=10439$ prendas

Luego se determinó el número de prendas por nivel considerando que las dimensiones de las plataformas son de $1 \mathrm{~m}$ x $1.2 \mathrm{~m}$ x $0.145 \mathrm{~m}$ y los prendas miden $0.25 \mathrm{~m} \times 0.3 \mathrm{~m} \times 0.025 \mathrm{~m}$. 
Para determinar el máximo número de niveles a apilar se tomaron en cuenta las siguientes restricciones considerando que cada prenda soporta $50 \mathrm{~kg}$., la altura de los casilleros de las estanterías es $1.5 \mathrm{~m}$, se debe consideran una holgura de $0.1 \mathrm{~m}$ en todos los lados y las plataformas soportan hasta $1080 \mathrm{~kg}$.

$$
\begin{aligned}
& \text { Resistencia de la prenda }=\frac{50 \mathrm{~kg}}{0.109 \mathrm{~kg}}+1=459.72 \cong 460 \text { niveles } \\
& \text { Altura máxima }=\frac{(1.5-0.145-0.1) \mathrm{m}}{0.025 \mathrm{~m}}=50.2 \cong 50 \text { niveles } \\
& \text { Resistencia de plataforma }=\frac{1080 \mathrm{~kg}}{16 \times 0.109 \mathrm{~kg}}=619.27 \cong 620 \text { niveles }
\end{aligned}
$$

El número de niveles apilables es 50 debido a la restricción de la altura máxima de los casilleros. Con esta información se determinó el número de prendas por plataforma y el número de plataformas necesarias

$$
\begin{aligned}
& \frac{16 \text { prendas }}{\text { nivel }} \times \frac{50 \text { niveles }}{\text { plataforma }}=\frac{800 \text { prendas }}{\text { plataforma }} \\
& 10439 \text { prendas } \times \frac{\text { plataformas }}{800 \text { prendas }}=13.049 \cong 14 \text { plataformas }
\end{aligned}
$$

Finalmente, para determinar el área mínima requerida se tomó en cuenta 2 estanterías para apilar las prendas, y las recomendaciones de los manuales del equipo de acarreo que indican un pasillo principal con un ancho mínimo de $5 \mathrm{~m}$. y pasillos secundarias con un ancho mínimo de $2.8 \mathrm{~m}$.

$$
\begin{aligned}
& \text { Ancho }=2 \text { estanterías }+ \text { holgura }+1 \text { pasillos secundrios } \\
& \text { Ancho }=(2 \times 1.2)+(2 \times 0.15)+(2.8 \times 1)=5.5 \mathrm{~m} \\
& \text { Largo }=\text { estantería }+ \text { holgura }+ \text { pasillos prncipal } \\
& \text { Largo }=4+(2 \times 0.15)+(3 \times 0.1)+5=9.6 \mathrm{~m} \\
& \text { Área mínima }=5.5 \mathrm{~m} \times 9.6 \mathrm{~m}=52.80 \mathrm{~m}^{2}
\end{aligned}
$$

\section{- Almacén de Producto Terminado}

El almacén constará de estanterías de 4 niveles donde únicamente se almacenarán las cajas con prendas esterilizadas. Para el cálculo del área del almacén primero se determinó el inventario promedio mensual.

$$
\text { Cantidad a almacenar }=\frac{Q}{2}+S S=\frac{400}{2}+(5 \% \times 400)=220 \text { cajas }
$$

Luego se determinó el número de cajas por nivel considerando que las dimensiones de las plataformas son de $1 \mathrm{~m}$ x $1.2 \mathrm{~m}$ x $0.145 \mathrm{~m}$ y las cajas miden 0.5 $\mathrm{m} \times 0.6 \mathrm{~m} \times 0.6 \mathrm{~m}$. 
Para determinar el máximo número de niveles a apilar se tomaron en cuenta las siguientes restricciones considerando que cada prenda soporta $20 \mathrm{~kg}$., la altura de los casilleros de las estanterías es $1.5 \mathrm{~m}$, se debe consideran una holgura de $0.1 \mathrm{~m}$ en todos los lados y las plataformas soportan hasta $1080 \mathrm{~kg}$.

$$
\begin{aligned}
& \text { Resistencia de la caja }=\frac{20 \mathrm{~kg}}{(48 \times 0.109 \mathrm{~kg})+0.545 \mathrm{~kg}}+1=4.46 \cong 4 \text { niveles } \\
& \text { Altura máxima }=\frac{(1.5-0.145-0.1) \mathrm{m}}{0.6 \mathrm{~m}}=2.09 \cong 2 \text { niveles } \\
& \text { Resistencia de plataforma }=\frac{1080 \mathrm{~kg}}{(48 \times 0.109 \mathrm{~kg})+0.545 \mathrm{~kg}}=186.95 \cong 187 \text { niveles }
\end{aligned}
$$

El número de niveles apilables es 2 debido a la restricción de la altura máxima de los casilleros. Con esta información se determinó el número de prendas por plataforma y el número de plataformas necesarias

$$
\begin{aligned}
& \frac{4 \text { cajas }}{\text { nivel }} \times \frac{2 \text { niveles }}{\text { plataforma }}=\frac{8 \text { cajas }}{\text { plataforma }} \\
& 220 \text { cajas } \times \frac{\text { plataforma }}{8 \text { cajas }}=27.5 \cong 28 \text { plataformas }
\end{aligned}
$$

Finalmente, para determinar el área mínima requerida se tomó en cuenta 2 estanterías para apilar las prendas, y las recomendaciones de los manuales del equipo de acarreo que indican un pasillo principal con un ancho mínimo de $5 \mathrm{~m}$. y pasillos secundarias con un ancho mínimo de $2.8 \mathrm{~m}$.

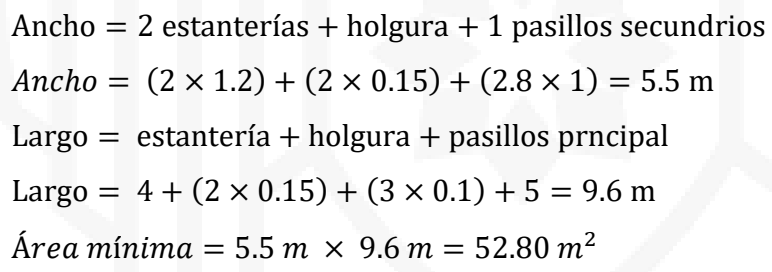

- Servicios Higiénicos:

Como se calculó en el punto anterior se definió $21 \mathrm{~m}^{2}$ por baño. 


\section{Plano tentativo y final del proyecto}

Figura 5.11

Plano tentativo del proyecto
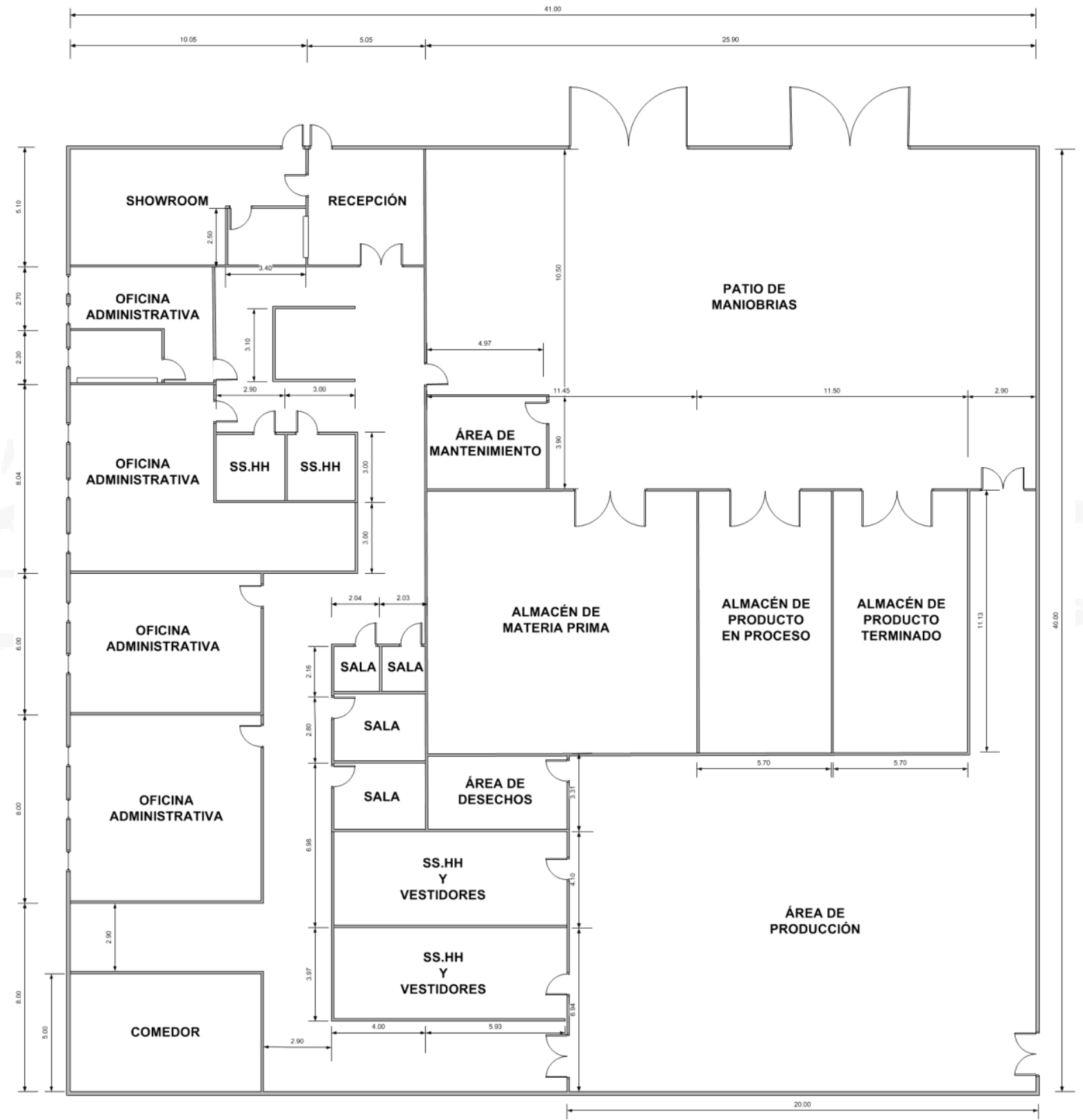

Elaboración propia 


\subsubsection{Dispositivos de seguridad industrial y señalización}

Como se mencionó anteriormente, las salidas de emergencia requerirán un mínimo de $0.8 \mathrm{~m}$ de ancho por cada $1000 \mathrm{~m} 2$ construidos. Los pasadizos tendrán un ancho mínimo de $1.2 \mathrm{~m}$. Además, se contará con una zona de estacionamientos de uso del personal y de las actividades de transporte de la empresa.

Figura 5.12

Señalización

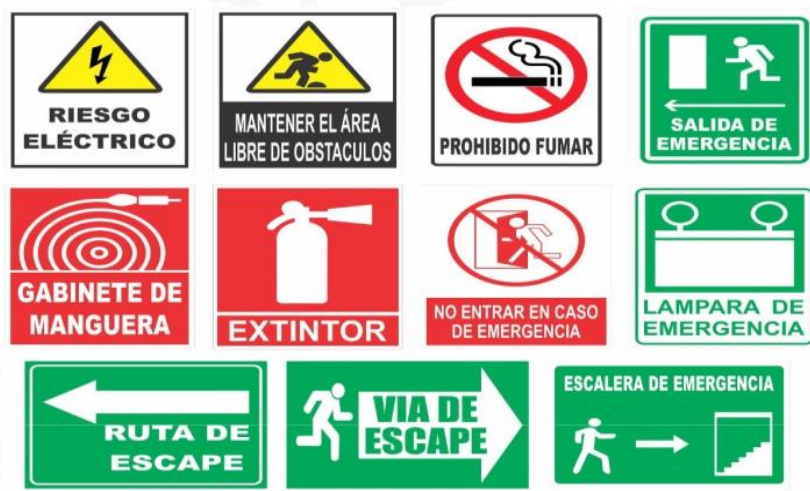

Fuente: Estampaciones Casado (2016)

\subsubsection{Disposición de detalle de la zona productiva}

Para disponer la distribución de todas las áreas dentro de un terreno de $450 \mathrm{~m} 2$, se realizará un análisis relacional. Para ellos se elabora una forma de semi-matriz donde se registran las relaciones que guarda cada actividad con todas las demás actividades. Luego de que se ha calculado con el método de Guerchet todos los espacios físicos necesarios para la planta, se procede a analizar la disposición de estos espacios con la ayuda de la tabla relacional. 


\section{Análisis de relaciones de las áreas de la empresa}

Tabla 5.27

\section{Tabla relacional de actividades}

\begin{tabular}{|c|c|}
\hline Código & Razón \\
\hline 1 & Recepción y despacho \\
2 & Flujo de materiales \\
3 & Servicio \\
4 & Conveniencias \\
5 & Comunicación \\
6 & Sonidos y olores Fuertes \\
7 & Atención a clientes \\
\hline
\end{tabular}

\begin{tabular}{|c|c|}
\hline Código & Proximidad \\
\hline $\mathrm{A}$ & Absolutamente necesario \\
$\mathrm{E}$ & Especialmente necesario \\
$\mathrm{I}$ & Importante \\
$\mathrm{O}$ & Normal u ordinario \\
$\mathrm{U}$ & Sin importancia \\
$\mathrm{X}$ & No recomendble \\
$\mathrm{XX}$ & Extremadamente no recomendable \\
\hline
\end{tabular}

Elaboración propia

Figura 5.13

Análisis relacional

\begin{tabular}{|l|l|l|l|l}
\hline 1 & Patio de Maniobras \\
\hline 2 & Almacén de MP & Área de Producción \\
\hline 3 & Almacén de PP & Almacén de PT \\
\hline 5 & Manitarios & Comedor & Almacén de Desechos \\
\hline 10 & Oficinas Administrativas \\
\hline 11 & Showroom
\end{tabular}

Elaboración propia

a) Relacional de actividades

$$
\begin{aligned}
\mathrm{A} & :(1,2)(1,3)(1,4)(1,5)(1,9)(2,3)(3,4)(3,5)(4,5)(10,11) \\
\mathrm{E} & :(3,8) \\
\mathrm{I} & :(2,10)(3,9)(4,10)(5,10)(6,7) \\
\mathrm{O} & :(1,6)(1,8)(2,6)(3,6)(3,10)(4,6)(5,6)(5,11) \\
\mathrm{U} & :(1,7)(1,10)(1,11)(2,4)(2,5)(2,7)(2,8)(2,9)(2,11)(3,7)(3,11)(4,7) \\
& (4,8)(4,9)(4,11)(5,7)(5,8)(5,9)(6,8)(6,9)(6,11)(7,11)(8,9) \\
\mathrm{X} & :(6,10),(7,8)(7,9)(7,10)(8,10)(8,11)(9,10)(9,11)
\end{aligned}
$$


b) Diagrama relacional de espacio

\section{Figura 5.14}

Análisis relacional

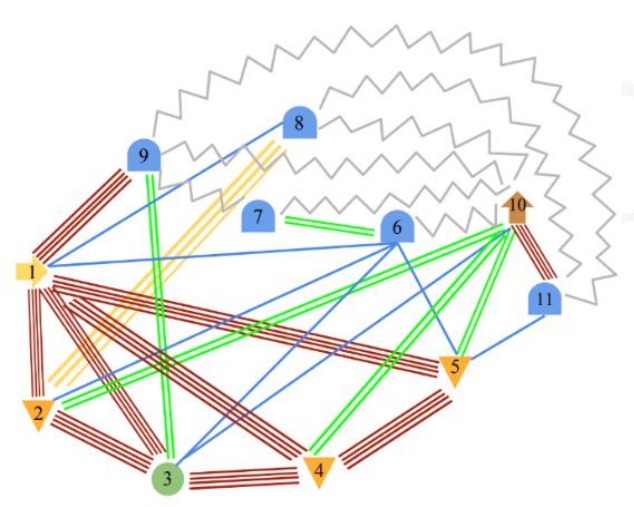

Elaboración propia

\subsubsection{Disposición general}


Figura 5.15

Plano tentativo del proyecto

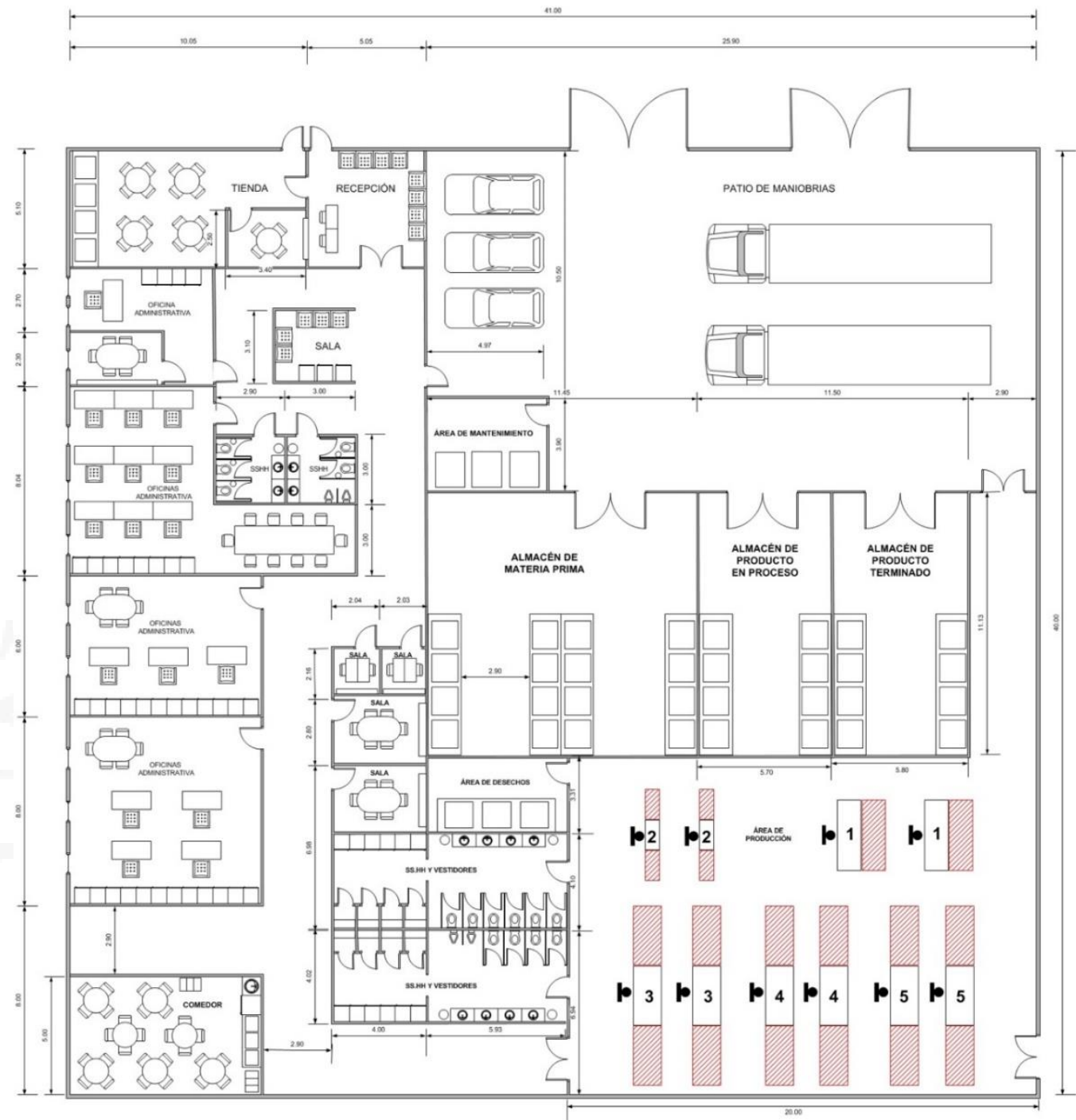

Elaboración propia

Figura 5.16

Membrete del Plano tentativo del proyecto

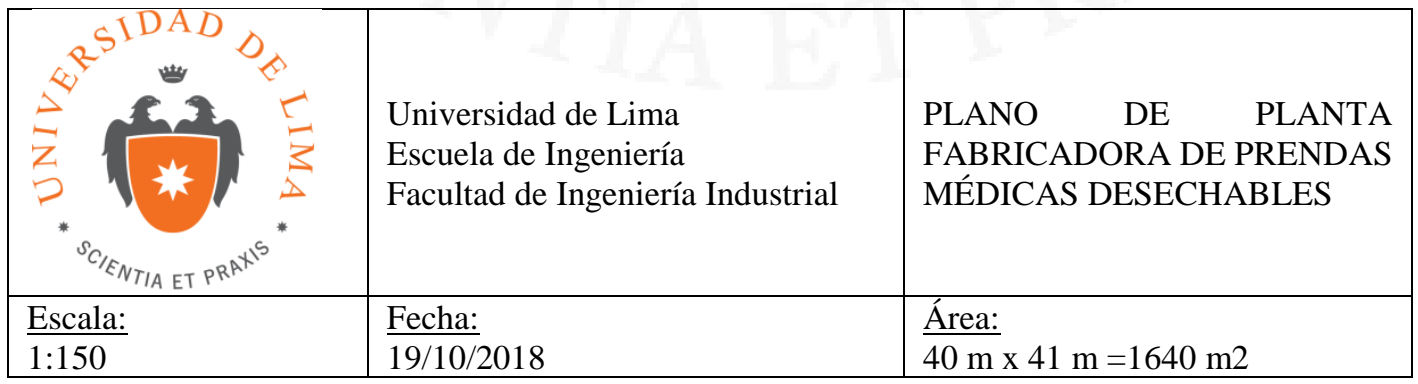

Elaboración propia 


\title{
5.14 Cronograma de implementación del proyecto
}

\author{
Tabla 5.28
}

Nombre de tareas puesta en marcha

\begin{tabular}{ll}
\hline Nombre de la Tarea & Duración (semanas) \\
\hline 1. Estudio de Pre-Factibilidad & 6 \\
2. Estudio de Factibilidad & 6 \\
3. Constitución de la empresa & 4 \\
4. Obtención del financiamiento & 4 \\
5. Trámites legales & 3 \\
6. Alquilar local y equiparlo & 10 \\
7. Adquisición de maquinaria y equipos & 6 \\
8. Instalación y prueba de maquinaria & 5 \\
9. Capacitación del personal & 4 \\
10. Puesta en marcha & 2 \\
\hline
\end{tabular}

Elaboración propia

Tabla 5.29

Diagrama de Gantt

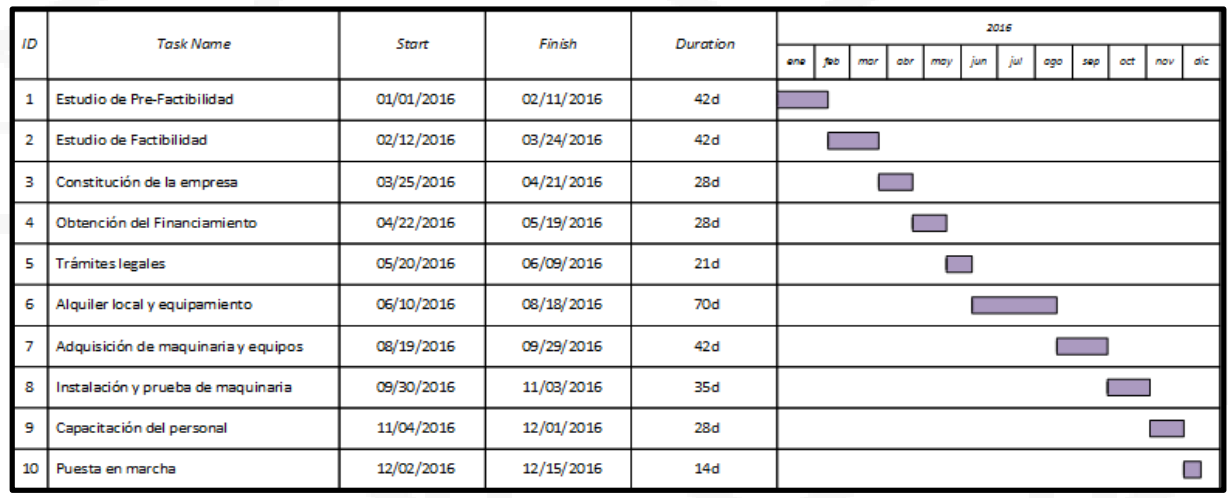

Elaboración propia 


\section{CAPÍTULO VI: ORGANIZACIÓN Y ADMINISTRACIÓN}

\subsection{Formación de la organización empresarial}

Para la puesta en marcha de una organización empresarial es necesario formalizar los trámites legales en caso se quiera acceder a capitales de terceros y elaborar un organigrama.

Como primer paso, se acordó con los socios iniciales que la empresa a constituir será de tipo sociedad anónima cerrada, debido a que la compañía no contará con más de 20 accionistas o socios, los cuales participaran de forma directa y activa en la administración, representación social y gestión.

Con este tipo de sociedad, se espera integrar los aportes de los accionistas, pero con una responsabilidad limitada, que sustenta en caso se generen deudas, los accionistas responden con el capital social aportado, más no con sus bienes personales.

Por otro lado, se cuenta con una junta de accionistas, que se encargan de asignar a los respectivos jefes y al gerente. Es importante mencionar que el número de votos de los accionistas están limitados por el número de sus acciones.

Esta sociedad puede funcionar sin un directorio y es la más recomendad para empresas familiares, chicas o medianas.

Pasos para constituir una Sociedad Anónima Cerrada:

1. Nombre de la sociedad: es necesario validar que nombre esté disponible en registros públicos, así mismo realizar la reserva del nombre.

2. Capital social: este capital puede estar expresado en bienes o efectivo.

3. Contar con un mínimo de 2 socios y no más de 20.

4. Definir un gerente general, sus funciones y facultades.

5. Establecer si funcionara con o sin directorio.

6. Domicilio y duración, basta con colocar "ciudad de Lima" e "indefinida". Luego de realizar lo mencionado anteriormente, se realizará los trámites administrativos y legales. Se debe solicitar el contrato privado de constitución de Persona Jurídica. 
Este contrato lleva por nombre Minuta de Constitución, que contiene los datos personales de los socios, lugar de la empresa, persona que representa la sociedad, entre otros. Al finalizar este documento se remite a un notario público cuya función es elevarla a la Escritura Pública, con la firma y sello del notario.

Luego de la inscripción, se procede a la obtención del Registro Único de Contribuyentes (RUC) que permite el pago de impuestos. Estos trámites se realizan en las oficinas de la SUNAT, se llena un formulario de justificación y se espera que llegue la notificación a la empresa. Del mismo modo se debe elegir el Régimen Tributario, el cual será Régimen Especial de Impuesto a la Renta (RER), que funciona para sociedades anónimas cerradas.

Finalmente, la empresa recibe el RUC y está en capacidad de generar facturas, registrar en libros contables, que al final de cada mes debe ser llevado a una notaría para su legalización. Respecto a los trabajadores se deben registrar en el Seguro Social de Salud y solicitar la licencia municipal en la municipalidad el distrito del Cercado de Lima. Luego de obtener la licencia, la empresa puede esta apta para iniciar sus operaciones.

\subsection{Requerimientos de personal directivo, administrativo y de servicios}

La organización estará compuesta por lo siguiente:

- Gerente general: es la máxima autoridad de la empresa.

- Jefe comercial: se encarga de manejar el plan de ventas y estrategias comerciales de la compañía.

- Jefe de operaciones: es el responsable del manejo de materiales, producción, calidad y buen estado del producto final, así mismo debe llevar un buen control de los inventarios y logística.

- Jefe de administración y finanzas: es el responsable de administrar los recursos financieros de manera óptima, así como elaborar estados financieros.

- Asistente de marketing: brindara apoyo directo al Jefe Comercial, plasmando estrategias de marketing para el negocio y analizando indicadores de la empresa y sector. 
- Asistente de ventas: brindara apoyo directo al Jefe Comercial, plasmando estrategias para incrementar las ventas y analizando indicadores de la empresa y sector.

- Representantes de ventas: son la fuerza de ventas, los cuales deben ir en busca de los clientes principales y ofrecer el producto.

- Supervisor: es aquel que estará pendiente de la producción y tiene a su cargo a los operarios.

- Analista financiero: reporta directamente al Jefe de Administración y Finanzas, realiza el análisis de costos de producción, estados financieros y ventas.

- Analista logístico: reporta directamente al Jefe de Administración y Finanzas, realiza el análisis de la logística.

- Operarios: pieza fundamental en el proceso productivo, realizan la transformación de la materia prima en el producto final.

Tabla 6.1

Manual de Funciones Gerente General

\begin{tabular}{lll}
\hline & Código & TP-2015:01 \\
MANUAL DE FUNCIONES & Emisión & $22-11-2015$ \\
ANCIN MEDICSOLUTIONS S.A.C & Vigencia & $22-11-2015$ \\
& Cargo & Gerente General \\
\hline
\end{tabular}

DESCRIPCIÓN DEL CARGO

HABILIDADES: liderazgo, buena comunicación y gestión de proyectos y mejoras. ESFUERZO FISICO: realiza esfuerzo físico de estar sentado y parado. CONDICIONES DEL CARGO: sitio cerrado de ambiente agradable. SUPERVISIÓN: recibe supervisión de la Junta de Accionistas. AUTORIDAD: ejerce decisiones sobre las políticas y acciones estratégicas de la empresa. RESPONSABILIDAD: es responsable del rendimiento y funcionamiento de las actividades. RELACIONES:

Internas: con los accionistas y demás gerentes.

Externas: SUNAT y Ministerio del Trabajo.

\begin{tabular}{lll} 
Realizado por: & Revisado por: & Aprobado por: \\
Andrea Talavera & Cinthia Cabrera & Cinthia Cabrera \\
\hline Elaboración propia & &
\end{tabular}


Tabla 6.2

Manual de Funciones de Jefes

\begin{tabular}{lll}
\hline & Código & TP-2015:03 \\
MANUAL DE FUNCIONES & Emisión & $22-11-2015$ \\
ANCIN MEDSOLUTIONS S.A.C & Vigencia & $22-11-2016$ \\
& Cargo & Jefes \\
\hline
\end{tabular}

DESCRIPCIÓN DEL CARGO

HABILIDADES: buena comunicación, ESFUERZO FISICO: realiza esfuerzo físico de estar sentado y parado.

CONDICIONES DEL CARGO: sitio cerrado de ambiente agradable

SUPERVISIÓN: revise supervisión de cada gerente de su área.

AUTORIDAD: ejerce decisiones

RESPONSABILIDAD: es responsable del rendimiento y funcionamiento de las actividades.

RELACIONES:

Internas: con los gerentes y demás analistas y jefes.

Externas: SUNAT y Ministerio del Trabajo.

Realizado por:

Revisado por:

Aprobado por:

Andrea Talavera

Cinthia Cabrera

Cinthia Cabrera

Elaboración propia

Tabla 6.3

Manual de Funciones de Supervisor

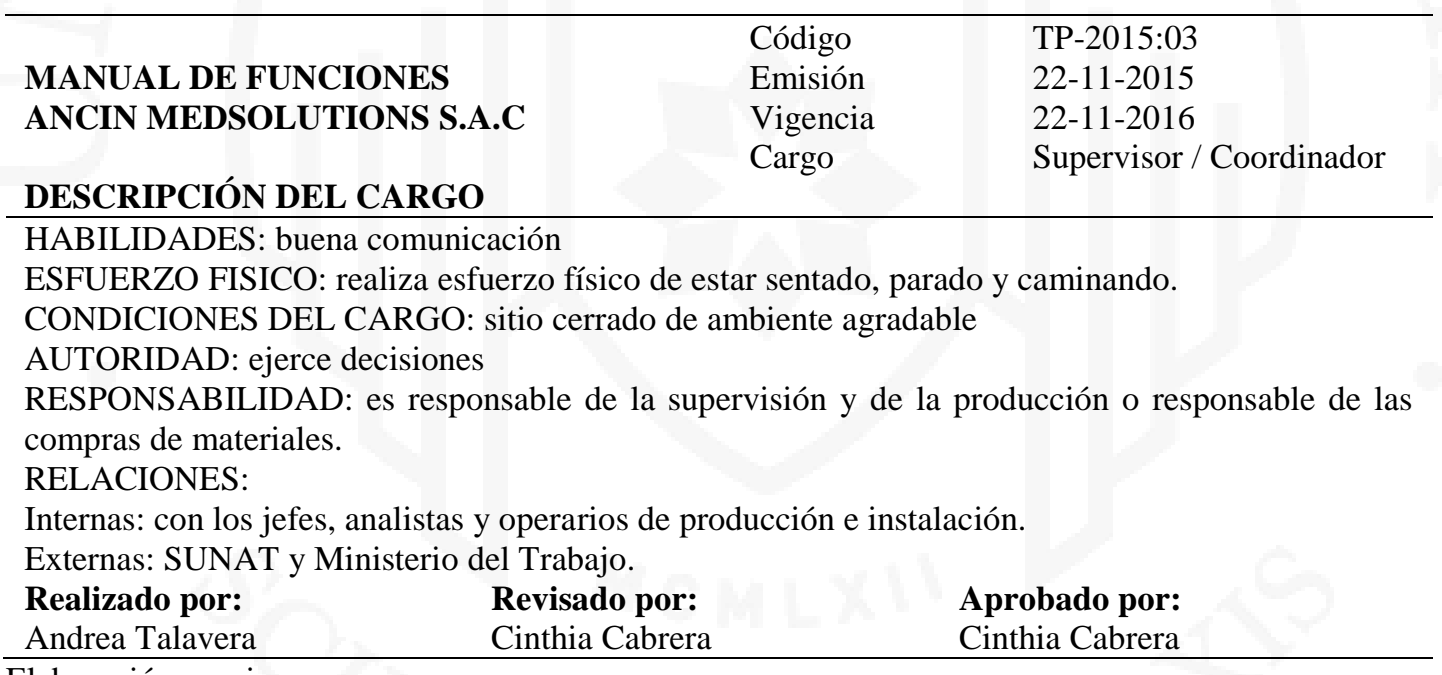

Elaboración propia 
Tabla 6.4

Manual de Funciones de Operarios

\begin{tabular}{lll}
\hline & Código & TP-2015:03 \\
MANUAL DE FUNCIONES & Emisión & $22-11-2015$ \\
ANCIN MEDSOLUTIONS S.A.C & Vigencia & $22-11-2016$ \\
& Cargo & Operarios \\
\hline
\end{tabular}

\section{DESCRIPCIÓN DEL CARGO}

HABILIDADES: compromiso, habilidades interpersonales y buena comunicación.

ESFUERZO FISICO: realiza esfuerzo físico de estar parado.

CONDICIONES DEL CARGO: sitio cerrado de ambiente agradable.

SUPERVISIÓN: revise supervisión del Jefe de Producción.

AUTORIDAD: ejerce decisiones

RESPONSABILIDAD: es responsable del rendimiento y funcionamiento de las actividades.

RELACIONES:

Internas: con los gerentes y demás analistas y jefes.

Externas: SUNAT y Ministerio del Trabajo.

Realizado por:

Andrea Talavera

Elaboración propia
Revisado por:

Cinthia Cabrera
Aprobado por:

Cinthia Cabrera

\subsection{Esquema de la estructura organizacional}

Figura 6.1

Organigrama

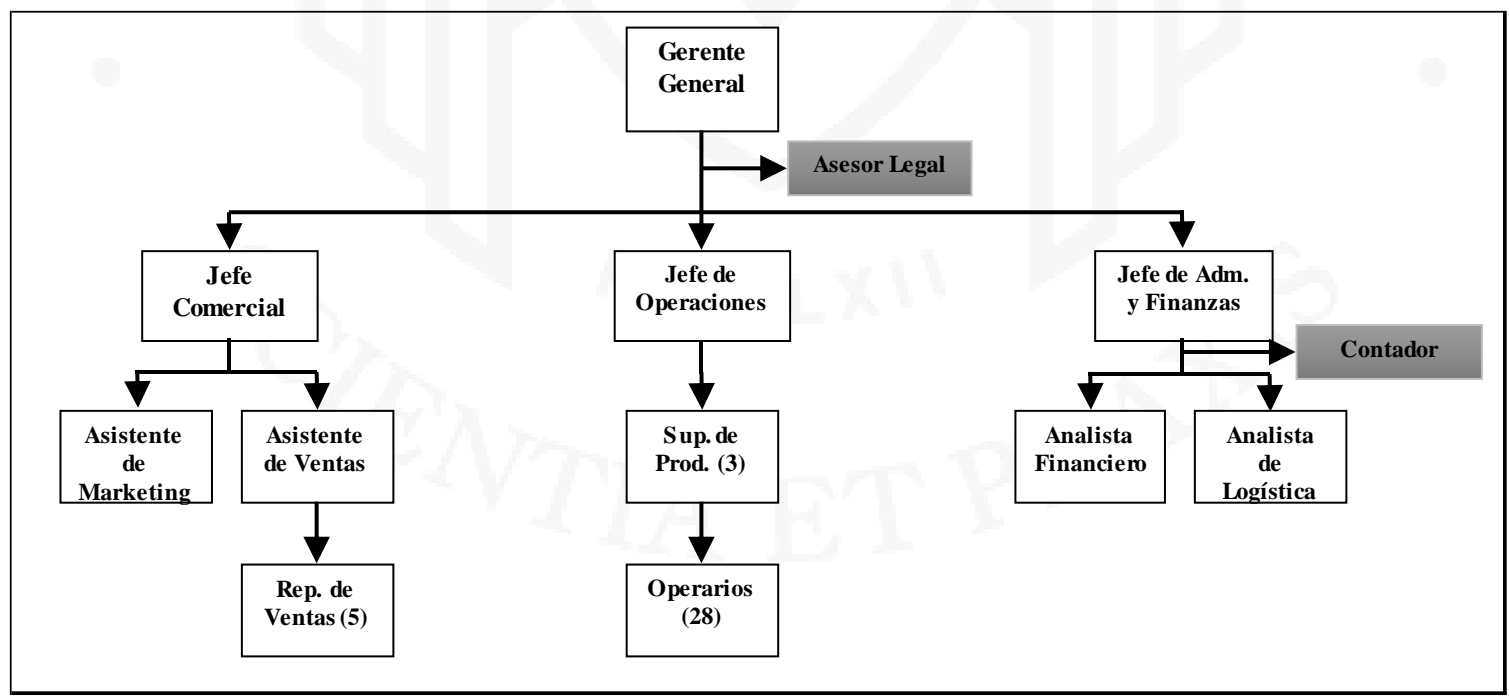

Elaboración propia 


\section{CAPÍTULO VII: PRESUPUESTOS Y EVALUACIÓN DEL PROYECTO}

\subsection{Inversiones}

Tabla 7.1

Activos Tangibles

\begin{tabular}{llll}
\hline Maquinaria & Cantidad & Valor USD & Monto USD \\
\hline Sellado ultrasónico & 1 & 900 & 900 \\
Empaquetadora & 2 & 3,000 & 6,000 \\
Cosedora & 2 & 1,000 & 4,000 \\
Cortadora & 2 & 600 & 1,200 \\
Total & 7 & 5,500 & 12,100 \\
\hline
\end{tabular}

Nota: Cálculo de la Activos Tangibles.

Elaboración propia

Tabla 7.2

Importación de Activos

\begin{tabular}{|c|c|c|c|}
\hline \multicolumn{2}{|l|}{ Rubro } & Monto USD & Monto S/. \\
\hline \multicolumn{2}{|l|}{ FOB } & 12,100 & 39,204 \\
\hline \multicolumn{2}{|c|}{ Flete marítimo China - Perú } & 1,747 & 5,661 \\
\hline \multicolumn{2}{|c|}{ Seguro de travesía } & 182 & 588 \\
\hline \multicolumn{2}{|l|}{ CIF } & 14,029 & 45,453 \\
\hline \multirow[t]{3}{*}{ Costo de aduanas } & Ad Valorem & $2,244.60$ & 7,272 \\
\hline & Impuesto & 2,929 & 9,491 \\
\hline & Percepción & $1,402.87$ & 4,545 \\
\hline \multicolumn{2}{|c|}{ Gastos de aduana Lima } & 70 & 227 \\
\hline \multicolumn{2}{|c|}{ Flete interno (Callao - Chilca) } & 772 & 2,500 \\
\hline \multicolumn{2}{|c|}{ Inspección de embarque en destino } & 429 & 1,390 \\
\hline \multicolumn{2}{|c|}{ Desestiba muelle local } & 400 & 1,296 \\
\hline \multicolumn{2}{|c|}{ Manipuleo local Callao } & 400 & 1,296 \\
\hline \multicolumn{2}{|c|}{ DDP } & 22,676 & 73,471 \\
\hline
\end{tabular}

Elaboración propia 
Tabla 7.3

Inversión en Equipos de planta

\begin{tabular}{lllc}
\hline Rubro & Cantidad & Costo unit (S/.) & Costo total (S/.) \\
\hline Carretilla hidráulica & 2 & 312 & 624 \\
Mesa de espera & 2 & 250 & 500 \\
Mesa de corte & 2 & 300 & 600 \\
Mesa de sellado & 1 & 160 & 160 \\
Extintor & 3 & 60 & 180 \\
Total & & & 2,064 \\
Elaboración propia & & &
\end{tabular}

Tabla 7.4

Inversión en Muebles y enseres de oficina

\begin{tabular}{llrr}
\hline Rubro & Cantidad & $\begin{array}{l}\text { Costo } \\
\text { unit }(\text { S/.) }\end{array}$ & \multicolumn{2}{l}{$\begin{array}{l}\text { Costo total } \\
(\text { S/.) }\end{array}$} \\
\hline Escritorios & 16 & 350 & 5,600 \\
Sillas de escritorio & 16 & 120 & 1,920 \\
Computadora & 16 & 1,000 & 16,000 \\
Impresora & 2 & 300 & 600 \\
Teléfono & 16 & 100 & 1,600 \\
Otros & & & 1,000 \\
Total & & & $\mathbf{2 6 , 7 2 0}$ \\
\hline
\end{tabular}

Elaboración propia

Tabla 7.5

Otras instalaciones

\begin{tabular}{lr}
\hline Rubro & $\begin{array}{l}\text { Costo } \\
(\mathbf{S} / .)\end{array}$ \\
\hline Servicios higiénicos & 2,976 \\
Microondas & 600 \\
Comedor & 2,800 \\
Lockers & 2,313 \\
Otros & 500 \\
Total & $\mathbf{9 , 1 8 9}$ \\
\hline Elaboración propia &
\end{tabular}

Tabla 7.6

Vehículo

\begin{tabular}{lccc}
\hline Rubro & Cantidad & $\begin{array}{l}\text { Costo } \\
\text { unit }(\mathrm{S} / .)\end{array}$ & $\begin{array}{l}\text { Costo total } \\
(\mathrm{S} / .)\end{array}$ \\
\hline $\begin{array}{l}\text { Camioneta } \\
\text { Total }\end{array}$ & 3 & 57,928 & 173,783 \\
& & & $\mathbf{1 7 3 , 7 8 3}$ \\
\hline
\end{tabular}

Elaboración propia 


\subsubsection{Estimación de las inversiones de largo plazo (tangibles e intangibles)}

Tabla 7.7

Resumen de activos tangibles

\begin{tabular}{lc}
\hline Rubro & Costo total (S/.) \\
\hline Maquinaria & 73,471 \\
Equipo de planta & 2,064 \\
Muebles y enseres para oficina & 26,720 \\
Remodelación & 42,869 \\
Vehículo & 173,783 \\
Imprevistos Fabriles & 30,000 \\
Imprevistos No Fabriles & 15,000 \\
Total activos tangibles & 363,907 \\
\hline Elaboración propia &
\end{tabular}

Tabla 7.8

Resumen de activos Intangibles

\begin{tabular}{lc}
\hline Rubro & Costo total (S/.) \\
\hline Estudios & 15,000 \\
Gastos de organización & 10,000 \\
Gastos de puesta en marcha & 15,000 \\
Contingencias & 20,000 \\
Total & 60,000 \\
\hline Elaboración propia
\end{tabular}

Elaboración propia

\subsubsection{Estimación de las inversiones de corto plazo (Capital de trabajo)}

Tabla 7.9

Inversión según el uso y según dónde proviene

\begin{tabular}{lr}
\hline Rubro & $\begin{array}{l}\text { Costo } \\
(\mathbf{S} / .)\end{array}$ \\
\hline Activos tangibles & 363,907 \\
Activos intangibles & 60,000 \\
Inversión Fija total & 423,907 \\
Capital de trabajo - KW (15\%) & 63,586 \\
Inversión Total Económica & 487,493 \\
\hline Elaboración propia &
\end{tabular}


Tabla 7.10

Inversión total según de donde proviene

\begin{tabular}{lr}
\hline Rubro & $\begin{array}{l}\text { Costo } \\
(\text { S/.) }\end{array}$ \\
\hline Deuda (60\%) & 292,496 \\
Aporte propio (40\%) & 194,997 \\
Inversión Total Financiera & 487,493 \\
\hline Elaboración propia &
\end{tabular}

7.2 Costos de producción

\subsubsection{Costos de las materias primas}

Tabla 7.11

Costo unitario de la tela SMS

\begin{tabular}{llll}
\hline Materiales directos & $\begin{array}{r}\text { Costo Unit } \\
\text { (SOLES/kg) }\end{array}$ & kg/Bata & $\begin{array}{r}\text { Costo Unit } \\
\text { (Soles/Bata) }\end{array}$ \\
\hline $\begin{array}{c}\text { Tela de polipropileno } \\
\text { SMS }\end{array}$ & 12.01 & 0.109 & 1.31 \\
\hline Elaboración propia & &
\end{tabular}


Tabla 7.12

Costo de importar la materia prima

\begin{tabular}{llll}
\hline Rubro & & Monto USD & Monto S/. \\
\hline FOB (1000kg) & 272,290 & 882,219 \\
Flete marítimo China - Perú & 1,747 & 5,661 \\
Seguro de travesía & & 4,084 & 13,233 \\
CIF & Ad & 278,121 & 901,113 \\
& Valorem & 144,178 & 29,530 \\
Costo de aduanas & Impuesto & 188,152 & 38,536 \\
& Percepción & 90,111 & 18,456 \\
Gastos de aduana Lima & & 1,391 & 4,506 \\
Flete interno (Callao - Chilca) & & 772 & 2,500 \\
Inspección de embarque en destino & & 429 & 1,390 \\
Desestiba muelle local & & 400 & 1,296 \\
Manipuleo local Callao & & 400 & 1,296 \\
DDP & & 411,896 & $1,334,542$ \\
DDP (Kilogramo) & 3.71 & 12 \\
DDP (Bata) & & 0.4045 & 1.3104 \\
\hline Elaboracion & & & \\
\hline
\end{tabular}

Elaboración propia

Tabla 7.13

Costo unitario del hilo

\begin{tabular}{lclc}
\hline Materiales directos & $\begin{array}{c}\text { Costo Unit } \\
\text { (SOLES/kg) }\end{array}$ & kg/Bata & $\begin{array}{r}\text { Costo Unit } \\
\text { (Soles/Bata) }\end{array}$ \\
\hline Hilo & 14.60 & 0.001 & 0.01 \\
\hline
\end{tabular}

Elaboración propia 
Tabla 7.14

Costo de importar la materia prima

\begin{tabular}{llll}
\hline Rubro & & Monto USD & Monto S/. \\
FOB (5000kg) & 12,000 & 38,880 \\
Flete marítimo China - Perú & 1,747 & 5,661 \\
Seguro de travesía & 180 & 583 \\
CIF & Ad & 13,927 & 45,124 \\
& Valorem & $2,228.36$ & 29,530 \\
Costo de aduanas & Impuesto & 2,908 & 38,536 \\
& Percepción & $1,392.72$ & 18,456 \\
Gastos de aduana Lima & & 70 & 226 \\
Flete interno (Callao - Chilca) & & 772 & 2,500 \\
Inspección de embarque en destino & & 429 & 1,390 \\
Desestiba muelle local & & 400 & 1,296 \\
Manipuleo local Callao & & 400 & 1,296 \\
DDP & & 22,527 & 72,986 \\
DDP (Kilogramo) & 4.51 & 15 \\
DDP (Bata) & & 0.0023 & 0.0073 \\
\hline E & & & \\
\hline
\end{tabular}

Elaboración propia

Tabla 7.15

Costo unitario del elástico

\begin{tabular}{llll}
\hline Materiales directos & $\begin{array}{c}\text { Costo Unit } \\
\text { (SOLES/m) }\end{array}$ & m/Bata & $\begin{array}{r}\text { Costo Unit } \\
\text { (Soles/Bata) }\end{array}$ \\
\hline Elastico & 0.17 & 0.600 & 0.10 \\
\hline Elaboración propia & & &
\end{tabular}


Tabla 7.16

Costo de importar la materia prima

\begin{tabular}{llll}
\hline Rubro & & Monto USD & Monto S/. \\
FOB (3000m) & 17,450 & 56,539 \\
Flete marítimo China - Perú & 1,747 & 5,661 \\
Seguro de travesía & & 262 & 848 \\
CIF & Ad & 19,459 & 63,048 \\
& Valorem & 10,088 & 29,530 \\
Costo de aduanas & Impuesto & 13,164 & 38,536 \\
& Percepción & 6,305 & 18,456 \\
Gastos de aduana Lima & & 97 & 315 \\
Flete interno (Callao - Chilca) & & 772 & 2,500 \\
Inspección de embarque en destino & & 429 & 1,390 \\
Desestiba muelle local & & 400 & 1,296 \\
Manipuleo local Callao & & 400 & 1,296 \\
DDP & & 30,680 & 99,403 \\
DDP (Kilogramo) & 0.05 & 0 \\
DDP (Bata) & & 0.0316 & 0.1025 \\
\hline E & & & \\
\hline
\end{tabular}

Elaboración propia

Tabla 7.17

Costo unitario de bolsas

\begin{tabular}{llll}
\hline Materiales directos & $\begin{array}{c}\text { Costo } \\
\text { (SOLES/unidad) }\end{array}$ & $\begin{array}{c}\text { Unit } \\
\text { bolsa/bata }\end{array}$ & $\begin{array}{c}\text { Costo Unit } \\
\text { (Soles/Bata) }\end{array}$ \\
\hline Bolsas & 0.01 & 1.000 & 0.01 \\
\hline Elaboración propia & & &
\end{tabular}


Tabla 7.18

Costo unitario de cajas

\begin{tabular}{llll}
\hline Materiales directos & $\begin{array}{l}\text { Costo Unit } \\
\text { (SOLES/caja) }\end{array}$ & $\begin{array}{c}\mathbf{1} \text { bata } \\
\text { caja/ }\end{array}$ & $\begin{array}{c}\text { Costo Unit } \\
\text { (Soles/Bata) }\end{array}$ \\
\hline Cajas & 1.50 & 0.021 & 0.0313 \\
\hline
\end{tabular}

Elaboración propia

Tabla 7.19

Costo unitario de etiquetas

\begin{tabular}{llccc}
\hline Materiales directos & $\begin{array}{c}\text { Costo } \\
\text { (SOLES/etiqueta) }\end{array}$ & $\begin{array}{c}\text { Unit } \\
\text { bata }\end{array}$ & caja/ & $\begin{array}{c}\text { Costo Unit } \\
\text { (Soles/Bata) }\end{array}$ \\
\hline Etiqueta & 0.20 & 1.000 & 0.2000 \\
\hline
\end{tabular}

Elaboración propia

\subsubsection{Costos de la mano de obra directa}

Tabla 7.20

Costo de mano de obra directa

\begin{tabular}{ll}
\hline Mano de obra directa & Monto \\
\hline \# Operarios & 28 \\
Salario mensual & 1,000 \\
Salario anual & 12,000 \\
Subtotal & 336,000 \\
Gratificaciones (2) & 61,040 \\
CTS & 33,087 \\
Seguros & 30,240 \\
Total salarios anual (S/.) & 460,367 \\
\hline Elaboración propia &
\end{tabular}

7.2.3 Costo Indirecto de Fabricación (materiales indirectos, mano de obra indirecta y costos generales de planta) 


\section{Tabla 7.21}

Costo de mano de obra indirecta

\begin{tabular}{lr}
\hline Mano de obra indirecta & \multicolumn{1}{c}{ Monto } \\
\hline \# Supervisores & 3 \\
Salario anual & 24,000 \\
Subtotal & 72,000 \\
Gratificaciones (2) & 8,720 \\
CTS & 4,727 \\
Seguros & 4,320 \\
Total salarios anual (S/.) & 89,767 \\
\hline Elaboración propia &
\end{tabular}

Tabla 7.22

Costos indirectos de fabricación

\begin{tabular}{|c|c|c|}
\hline Rubro & $\begin{array}{l}\text { Costo } \\
\text { mensual (S/.) }\end{array}$ & $\begin{array}{l}\text { Costo } \\
(\mathrm{S} / .)\end{array}$ \\
\hline Supervisores & & 89,767 \\
\hline Electricidad & 2,000 & 24,000 \\
\hline Agua & 600 & 7,200 \\
\hline Grasas y aceites & 100 & 1,200 \\
\hline Mantenimiento maq & & 12,000 \\
\hline Depreciación & & 10,760 \\
\hline Total CIF & & 144,927 \\
\hline
\end{tabular}

Elaboración propia

Tabla 7.23

Gastos Administrativos y de Ventas

\begin{tabular}{lrr}
\hline Rubro & $\begin{array}{c}\text { Gasto } \\
\text { mensual (S/.) }\end{array}$ & $\begin{array}{c}\text { Gasto } \\
\text { (S/.) }\end{array}$ \\
& \multicolumn{2}{c}{ anual } \\
\hline Salarios administrativos & 800 & 526,133 \\
Servicio Contable & 800 & 9,600 \\
Servicio Asesoria Legal & & 9,600 \\
Combustible (vehículo & 2,800 & 33,600 \\
ventas) & 10,650 & 127,800 \\
Alquiler local & & \\
Depreciación vehículo (no fab) & 500 & 6,000 \\
Agua (oficinas) & 2,000 & 24,000 \\
Electricidad (oficinas) & 800 & 9,600 \\
Publicidad en revistas & 1,100 & 13,200 \\
Limpieza (oficinas) & & 776,912 \\
Total GAV & & \\
\hline
\end{tabular}

Nota: Cálculo de GAV= Gastos Administrativos y de Ventas.

Elaboración propia 
Tabla 7.24

Costos Variables Unitario

\begin{tabular}{lc}
\hline Rubro & C Variable (S/./bata) \\
\hline Materia prima & 1.70 \\
Total & 1.70 \\
\hline Elaboración propia &
\end{tabular}

Tabla 7.25

Costos y gastos fijos

\begin{tabular}{lr}
\hline Rubro & C Fijos (S/.) \\
\hline MOD (fabril) & 460,367 \\
CIF & 144,927 \\
Gastos adm y ventas & 776,912 \\
Total & $1,382,205$ \\
\hline
\end{tabular}

Nota: $\mathrm{MOD}=$ Mano de obra directa, $\mathrm{CIF}=$ Costos indirectos de fabricación.

Elaboración propia

\subsection{Presupuestos Operativos}

\subsubsection{Presupuesto de ingreso por ventas}

Tabla 7.26

Presupuesto de ingreso por ventas

\begin{tabular}{|c|c|c|c|c|c|c|}
\hline Año & 2018 & 2019 & 2020 & 2021 & 2022 & 2023 \\
\hline Ventas (batas) & 865,631 & 895,963 & 926,295 & 956,627 & 986,959 & $1,017,291$ \\
\hline Precio (S/./batas) & 3.89 & 4.03 & 4.17 & 4.32 & 4.47 & 4.62 \\
\hline Ventas $(\mathrm{S} /)$. & $3,370,768$ & $3,610,991$ & $3,863,901$ & $4,130,090$ & $4,410,180$ & $4,704,817$ \\
\hline
\end{tabular}

Nota: Cálculo de los ingresos con un precio de venta incrementando en $3.5 \%$ anualmente. Elaboración propia 


\subsubsection{Presupuesto operativo de costos}

Tabla 7.27

Cálculo de la amortización y depreciación

\begin{tabular}{|c|c|c|c|c|c|c|c|c|c|}
\hline Rubro & Monto (S/.) & $\begin{array}{c}\text { Dep. y Am. } \\
\text { (años) }\end{array}$ & 2019 & 2020 & 2021 & 2022 & 2023 & VL & VM \\
\hline Maquinaria & 73,471 & 10 & 7,347 & 7,347 & 7,347 & 7,347 & 7,347 & 36,735 & 18,368 \\
\hline Equipo de planta & 2,064 & 5 & 413 & 413 & 413 & 413 & 413 & - & - \\
\hline Muebles y enseres para oficina & 26,720 & 10 & 2,672 & 2,672 & 2,672 & 2,672 & 2,672 & 13,360 & 6,680 \\
\hline Vehículo & 173,783 & 5 & 34,757 & 34,757 & 34,757 & 34,757 & 34,757 & - & - \\
\hline Imprevistos Fabriles & 30,000 & 10 & 3,000 & 3,000 & 3,000 & 3,000 & 3,000 & 15,000 & 7,500 \\
\hline Imprevistos No Fabriles & 15,000 & 10 & 1,500 & 1,500 & 1,500 & 1,500 & 1,500 & 7,500 & 3,750 \\
\hline Estudios & 15,000 & 5 & 3,000 & 3,000 & 3,000 & 3,000 & 3,000 & - & - \\
\hline Gastos de organización & 10,000 & 5 & 2,000 & 2,000 & 2,000 & 2,000 & 2,000 & - & - \\
\hline Gastos de puesta en marcha & 15,000 & 5 & 3,000 & 3,000 & 3,000 & 3,000 & 3,000 & - & - \\
\hline Contingencias & 20,000 & 5 & 4,000 & 4,000 & 4,000 & 4,000 & 4,000 & - & - \\
\hline Total & 381,038 & & 61,689 & 61,689 & 61,689 & 61,689 & 61,689 & 72,595 & $36,297.7$ \\
\hline
\end{tabular}

Elaboración propia

\section{Tabla 7.28}

Cálculo de costo de producción y venta

\begin{tabular}{|c|c|c|c|c|c|c|}
\hline Año & 2018 & 2019 & 2020 & 2021 & 2022 & 2023 \\
\hline Costo de producción variable & & $1,577,583$ & $1,688,076$ & $1,804,370$ & $1,926,736$ & $2,055,458$ \\
\hline Costo de producción fijo (mod +cif) & & 605,293 & 605,293 & 605,293 & 605,293 & 605,293 \\
\hline Depreciación fabril & & 10,760 & 10,760 & 10,760 & 10,760 & 10,760 \\
\hline Costo Total de Producción & & $2,182,877$ & $2,293,369$ & $2,409,663$ & $2,532,029$ & $2,660,751$ \\
\hline Costo unitario de Producción & & 2.44 & 2.48 & 2.52 & 2.57 & 2.62 \\
\hline Unidades vendidas & & 895,963 & 926,295 & 956,627 & 986,959 & $1,017,291$ \\
\hline Costo Total de Ventas & & $\mathbf{2 , 1 8 2 , 8 7 7}$ & $2,293,369$ & $2,409,663$ & $2,532,029$ & $2,660,751$ \\
\hline
\end{tabular}

Elaboración propia

\subsubsection{Presupuesto operativo de gastos}

Tabla 7.29

Presupuesto de gastos

\begin{tabular}{|c|c|c|c|c|c|}
\hline Año & 2019 & 2020 & 2021 & 2022 & 2023 \\
\hline GAV & 776,912 & 776,912 & 776,912 & 776,912 & 776,912 \\
\hline Depreciación no fabril & 38,929 & 38,929 & 38,929 & 38,929 & 38,929 \\
\hline Amortización intangibles & 12,000 & 12,000 & 12,000 & 12,000 & 12,000 \\
\hline GAVT & 827,840 & 827,840 & 827,840 & 827,840 & 827,840 \\
\hline
\end{tabular}

Elaboración propia 


\subsection{Presupuestos Financieros}

\subsubsection{Presupuesto de Servicio de Deuda}

Tabla 7.30

Presupuesto de Servicios de Deuda

\begin{tabular}{|c|c|c|c|c|c|}
\hline Año & Deuda & Factor & Interés & Amortizacion & Cuota \\
\hline $2018(0)$ & 292,496 & & & & \\
\hline 2019 (1) & 292,496 & 0.067 & 61,424 & 19,500 & 80,924 \\
\hline $2020(2)$ & 272,996 & 0.133 & 57,329 & 38,999 & 96,329 \\
\hline $2021(3)$ & 233,997 & 0.200 & 49,139 & 58,499 & 107,638 \\
\hline $2022(4)$ & 175,498 & 0.267 & 36,854 & 77,999 & 114,853 \\
\hline $2023(5)$ & 97,499 & 0.333 & 20,475 & 97,499 & 117,973 \\
\hline
\end{tabular}

TCEA

$21 \%$

Factor

15

Nota: Cálculo del Servicio de la Deuda, con una TCEA de $21 \%$.

Elaboración propia

\subsubsection{Presupuesto de Estado de Resultados}

Tabla 7.31

Presupuesto de Estado de Resultados

\begin{tabular}{|c|c|c|c|c|c|}
\hline Año & 2019 & 2020 & 2021 & 2022 & 2023 \\
\hline Ventas (sin igv) & $3,060,162$ & $3,274,492$ & $3,500,077$ & $3,737,441$ & $3,987,133$ \\
\hline (-) Costo de venta & $-2,182,877$ & $-2,293,369$ & $-2,409,663$ & $-2,532,029$ & $-2,660,751$ \\
\hline Utilidad bruta & 877,285 & 981,123 & $1,090,414$ & $1,205,411$ & $1,326,382$ \\
\hline (-) GAVT & $-827,840$ & $-827,840$ & $-827,840$ & $-827,840$ & $-827,840$ \\
\hline (-) Comisiones & 30,602 & 32,745 & 35,001 & 37,374 & 39,871 \\
\hline Utilidad ope rativa & 18,843 & 120,538 & 227,573 & 340,197 & 458,670 \\
\hline (-) Gasto financiero & $-61,424$ & $-57,329$ & $-49,139$ & $-36,854$ & $-20,475$ \\
\hline Ingresos excepcionales & & & & & 36,298 \\
\hline (-) Gastos excepcionales & & & & & $-72,595$ \\
\hline UAPI & $-42,581$ & 63,209 & 178,433 & 303,342 & 401,898 \\
\hline (-) Participaciones & & $-6,321$ & $-17,843$ & $-30,334$ & $-40,190$ \\
\hline UAIR & $-42,581$ & 56,888 & 160,590 & 273,008 & 361,708 \\
\hline (-) Impuesto a la renta & & $-15,929$ & $-44,965$ & $-76,442$ & $-101,278$ \\
\hline UARL & $-42,581$ & 40,959 & 115,625 & 196,566 & 260,430 \\
\hline (-) Reserva legal & & $-4,096$ & $-11,562$ & $-19,657$ & $-3,684$ \\
\hline Utilidad neta & $-42,581$ & 36,863 & 104,062 & 176,909 & 256,745 \\
\hline
\end{tabular}

Nota: Cálculo del Estado de Resultados del primer año del proyecto. 
Elaboración propia

\subsubsection{Presupuesto de Estado de Situación Financiera (apertura)}

Tabla 7.32

Presupuesto de Balance de Apertura

\begin{tabular}{|l|r|l|r|}
\hline \multicolumn{2}{|c|}{ ACTIVO } & \multicolumn{2}{c|}{ PASIVO Y PATRIMONIO } \\
\hline CAJA & 63,586 & DEUDA & 292,496 \\
\hline ACTIVO FIJO & 423,907 & CAP SOCIAL & 194,997 \\
\hline TOTAL & $\mathbf{4 8 7 , 4 9 3}$ & TOTAL & $\mathbf{4 8 7 , 4 9 3}$ \\
\hline
\end{tabular}

Nota: Cálculo del Balance de apertura para el primer año del proyecto.

Elaboración propia 


\subsubsection{Flujo de fondos económicos}

Tabla 7.33

Flujo de fondos económico

\begin{tabular}{|c|c|c|c|c|c|c|}
\hline Año & 2018 & 2019 & 2020 & 2021 & 2022 & 2023 \\
\hline UN & & $-42,581$ & 36,863 & 104,062 & 176,909 & 256,745 \\
\hline (-) Inversión & $-487,493$ & & & & & \\
\hline (+) Dep. fabril & & 10,760 & 10,760 & 10,760 & 10,760 & 10,760 \\
\hline (+) Dep. no fabril & & 38,929 & 38,929 & 38,929 & 38,929 & 38,929 \\
\hline (+) Amortizacion intangiles & & 12,000 & 12,000 & 12,000 & 12,000 & 12,000 \\
\hline (+) GF x 0.7 & & 42,997 & 40,130 & 34,398 & 25,798 & 14,332 \\
\hline$(+) \mathrm{VL}$ & & & & & & 72,595 \\
\hline$(+) \mathrm{KW}$ & & & & & & 63,586 \\
\hline FFE & $-487,493$ & 62,105 & 138,682 & 200,148 & 264,396 & 468,947 \\
\hline
\end{tabular}

Nota: Cálculo del flujo de fondos económico, considerando un impuesto a la renta de $28 \%$.

Elaboración propia

\subsubsection{Flujo de fondos financieros}

Tabla 7.34

Flujo de fondos financieros

\begin{tabular}{lcccccc}
\multicolumn{1}{c}{ Año } & $\mathbf{2 0 1 8}$ & $\mathbf{2 0 1 9}$ & $\mathbf{2 0 2 0}$ & $\mathbf{2 0 2 1}$ & $\mathbf{2 0 2 2}$ & $\mathbf{2 0 2 3}$ \\
\hline UN & & $-42,581$ & 36,863 & 104,062 & 176,909 & 256,745 \\
(-) Inversión & $-487,493$ & & & & & \\
(+) Deuda & 292,496 & & & & & \\
(+) Dep. fabril & & 10,760 & 10,760 & 10,760 & 10,760 & 10,760 \\
(+) Dep. no fabril & 38,929 & 38,929 & 38,929 & 38,929 & 38,929 \\
(+) Amortizacion intangiles & & 12,000 & 12,000 & 12,000 & 12,000 & 12,000 \\
(+) VL & & & & & 72,595 \\
(+) KW & & $-19,500$ & $-38,999$ & $-58,499$ & $-77,999$ & $-97,499$ \\
(-) Amortizacion de deuda & & -392 & $\mathbf{5 9 , 5 5 3}$ & $\mathbf{1 0 7 , 2 5 2}$ & $\mathbf{1 6 0 , 5 9 9}$ & $\mathbf{3 5 7 , 1 1 7}$
\end{tabular}

Nota: Cálculo del flujo de fondos financieros, considerando un financiamiento por parte del banco. Elaboración propia 


\section{CAPÍTULO VIII: EVALUACIÓN ECONÓMICA Y FINANCIERA}

\subsection{Evaluación Económica y Financiera}

Con la siguiente información se calcula el Beta, Rm y Cok

\begin{tabular}{|lr|}
\hline Accion nominal & 32.18 \\
Accion real & 36.54 \\
Beta & 1.14 \\
\hline
\end{tabular}

\begin{tabular}{|cc|}
\hline Utilidad Neta & 113 \\
Patrimonio & 755 \\
Rm & 0.15 \\
\hline
\end{tabular}

$\mathrm{Rm}=$ Utilidad Neta/ Patrimonio

\begin{tabular}{|c|c|}
\hline Rf & $3.70 \%$ \\
\hline $\mathrm{Rm}$ & $14.97 \%$ \\
\hline Beta & 1.14 \\
\hline Cok & $16.49 \%$ \\
\hline
\end{tabular}

\subsubsection{Evaluación económica: VAN, TIR, B/C, PR}

$\begin{array}{lr}\text { Cok } & 24 \% \\ \text { VNA } & 517,048 \\ \text { VAN } & 29,555 \\ \text { TIR } & 26.13 \% \\ \text { Relacion B/C } & 1.06 \\ \text { Periódo de recupero } & 3 \text { años, 3 meses y 29 días }\end{array}$

\subsubsection{Evaluación financiera: VAN, TIR, B/C, PR}

Cok

VNA

284,411

VAN

89,414

TIR

$36.59 \%$

Relacion B/C

1.46

Periódo de recupero

3 años, 2 meses y 5 días 


\subsubsection{Análisis de ratios (liquidez, solvencia, rentabilidad) e indicadores económicos y financieros del proyecto}

Tabla 8.1

Balance General del Primer Año

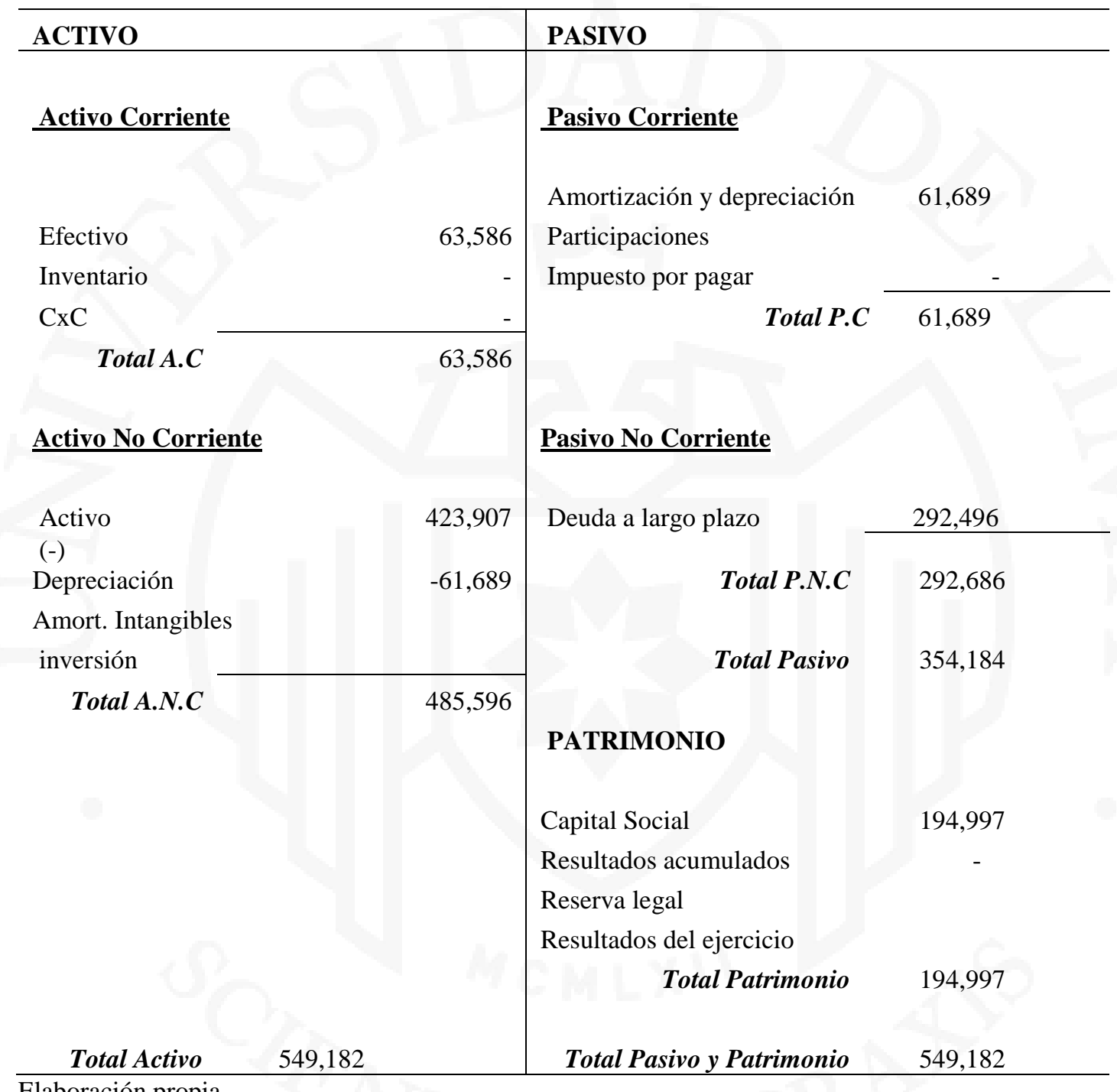

Elaboración propia

Para el desarrollo de las ratios es necesario la información del Balance de Situación Financiera mostrado anteriormente.

$$
\begin{aligned}
& \text { Razón corriente }=\frac{\text { Activo Corriente }}{\text { Pasivo Corriente }}=\frac{63586}{61689}=1.03 \text { veces } \\
& \text { Razón de efectivo }=\frac{\text { Efectivo y equivalentes }}{\text { Pasivo Corriente }}=\frac{63586}{61689}=1.03 \text { veces }
\end{aligned}
$$


Capital de Trabajo $=$ Activo Corriente - Pasivo Corriente

Capital de Trabajo $=63586-61689=1897.51$ nuevos soles

Solvencia Total $=\frac{\text { Pasivo } \text { Total }}{\text { Activo Total }}=\frac{354184}{549182}=64.49 \%$

Margen Bruto $=\frac{\text { Utilidad Bruta }}{\text { Ventas }}=\frac{877285}{3060161}=28.7 \%$

Margen Neto $=\frac{\text { Utilidad Neta }}{\text { Ventas }}=\frac{-42581}{3060162}=-1,39 \%$

Rentabilidad Neta sobre el Patrimonio $=\frac{\text { Utilidad Neta }}{\text { Patrimonio }}=\frac{-42581}{194997}=-21.84 \%$

\subsubsection{Análisis de sensibilidad del proyecto}

Tabla 8.2

Análisis Vertical

\begin{tabular}{|c|c|c|c|c|c|c|c|c|c|c|}
\hline Año & 2019 & \% VENTAS & 2020 & $\%$ VENTAS & 2021 & $\%$ VENTAS & 2022 & $\%$ VENTAS & 2023 & \% VENTAS \\
\hline Ventas & $3,060,162$ & $100 \%$ & $3,274,492$ & $100 \%$ & $3,500,077$ & $100 \%$ & $3,737,441$ & $100 \%$ & $3,987,133$ & $100 \%$ \\
\hline (-) Costo de venta & $-2,182,877$ & $-71.3 \%$ & $-2,293,369$ & $-70.0 \%$ & $-2,409,663$ & $-68.8 \%$ & $-2,532,029$ & $-67.7 \%$ & $-2,660,751$ & $-66.7 \%$ \\
\hline Utilidad bruta & 877,285 & $28.7 \%$ & 981,123 & $30.0 \%$ & $1,090,414$ & $31.2 \%$ & $1,205,411$ & $32.3 \%$ & $1,326,382$ & $33.3 \%$ \\
\hline$(-)$ GAVT & $-827,840$ & $-27.1 \%$ & $-827,840$ & $-25.3 \%$ & $-827,840$ & $-23.7 \%$ & $-827,840$ & $-22.1 \%$ & $-827,840$ & $-20.8 \%$ \\
\hline (-) Comisiones por venta & $-30,602$ & $-1.0 \%$ & $-32,745$ & $-1.0 \%$ & $-35,001$ & $-1.0 \%$ & $-37,374$ & $-1.0 \%$ & $-39,871$ & $-1.0 \%$ \\
\hline Utilidad operativa & 18,843 & $0.6 \%$ & 120,538 & $3.7 \%$ & 227,573 & $6.5 \%$ & 340,197 & $9.1 \%$ & 458,670 & $11.5 \%$ \\
\hline (-) Gasto financiero & $-61,424$ & $-2.0 \%$ & $-57,329$ & $-1.8 \%$ & $-49,139$ & $-1.4 \%$ & $-36,854$ & $-1.0 \%$ & $-20,475$ & $-0.5 \%$ \\
\hline Ingresos excepcionales & - & $0.0 \%$ & - & $0.0 \%$ & - & $0.0 \%$ & - & $0.0 \%$ & 36,298 & $0.9 \%$ \\
\hline (-) Gastos excepcionales & - & $0.0 \%$ & - & $0.0 \%$ & - & $0.0 \%$ & - & $0.0 \%$ & $-72,595$ & $-1.8 \%$ \\
\hline UAPI & $-42,581$ & $-1.4 \%$ & 63,209 & $1.9 \%$ & 178,433 & $5.1 \%$ & 303,342 & $8.1 \%$ & 401,898 & $10.1 \%$ \\
\hline (-) Participaciones & - & $0.0 \%$ & $-6,321$ & $-0.2 \%$ & $-17,843$ & $-0.5 \%$ & $-30,334$ & $-0.8 \%$ & $-40,190$ & $-1.0 \%$ \\
\hline UAIR & $-42,581$ & $-1.4 \%$ & 56,888 & $1.7 \%$ & 160,590 & $4.6 \%$ & 273,008 & $7.3 \%$ & 361,708 & $9.1 \%$ \\
\hline (-) Impuesto a la renta & - & $0.0 \%$ & $-15,929$ & $-0.5 \%$ & $-44,965$ & $-1.3 \%$ & $-76,442$ & $-2.0 \%$ & $-101,278$ & $-2.5 \%$ \\
\hline UARL & $-42,581$ & $-1.4 \%$ & 40,959 & $1.3 \%$ & 115,625 & $3.3 \%$ & 196,566 & $5.3 \%$ & 260,430 & $6.5 \%$ \\
\hline (-) Reserva legal & - & $0.0 \%$ & $-4,096$ & $-0.1 \%$ & $-11,562$ & $-0.3 \%$ & $-19,657$ & $-0.5 \%$ & $-3,684$ & $-0.1 \%$ \\
\hline Utilidad neta & $-42,581$ & $-1.4 \%$ & 36,863 & $1.1 \%$ & 104,062 & $3.0 \%$ & 176,909 & $4.7 \%$ & 256,745 & $6.4 \%$ \\
\hline
\end{tabular}

Elaboración propia

Tabla 8.3

Análisis Horizontal

\begin{tabular}{|c|c|c|c|c|c|c|c|c|c|}
\hline Año & 2019 & 2020 & $\operatorname{var} \%(1-2)$ & 2021 & $\operatorname{var} \%(2-3)$ & 2022 & $\operatorname{var} \%(3-4)$ & 2023 & $\operatorname{var} \%(4-5)$ \\
\hline Ventas & $3,060,162$ & $3,274,492$ & $7 \%$ & $3,500,077$ & $7 \%$ & $3,737,441$ & $7 \%$ & $3,987,133$ & $7 \%$ \\
\hline (-) Costo de venta & $-2,182,877$ & $-2,293,369$ & $5.1 \%$ & $-2,409,663$ & $5.1 \%$ & $-2,532,029$ & $5.1 \%$ & $-2,660,751$ & $5.1 \%$ \\
\hline Utilidad bruta & 877,285 & 981,123 & $11.8 \%$ & $1,090,414$ & $11.1 \%$ & $1,205,411$ & $10.5 \%$ & $1,326,382$ & $10.0 \%$ \\
\hline$(-) \mathrm{GAVT}$ & $-827,840$ & $-827,840$ & $0.0 \%$ & $-827,840$ & $0.0 \%$ & $-827,840$ & $0.0 \%$ & $-827,840$ & $0.0 \%$ \\
\hline Utilidad operativa & 18,843 & 120,538 & $539.7 \%$ & 227,573 & $88.8 \%$ & 340,197 & $49.5 \%$ & 458,670 & $34.8 \%$ \\
\hline (-) Gasto financiero & $-61,424$ & $-57,329$ & $-6.7 \%$ & $-49,139$ & $-14.3 \%$ & $-36,854$ & $-25.0 \%$ & $-20,475$ & $-44.4 \%$ \\
\hline Ingresos excepcionales & - & - & & - & & - & & 36,298 & \\
\hline (-) Gastos excepcionales & - & - & & - & & - & & $-72,595$ & \\
\hline UAPI & $-42,581$ & 63,209 & $-248.4 \%$ & 178,433 & $182.3 \%$ & 303,342 & $70.0 \%$ & 401,898 & $32.5 \%$ \\
\hline (-) Participaciones & - & $-6,321$ & $0.0 \%$ & $-17,843$ & $182.3 \%$ & $-30,334$ & $70.0 \%$ & $-40,190$ & $32.5 \%$ \\
\hline UAIR & $-42,581$ & 56,888 & $-233.6 \%$ & 160,590 & $182.3 \%$ & 273,008 & $70.0 \%$ & 361,708 & $32.5 \%$ \\
\hline (-) Impuesto a la renta & - & $-15,929$ & & $-44,965$ & $182.3 \%$ & $-76,442$ & $70.0 \%$ & $-101,278$ & $32.5 \%$ \\
\hline UARL & $-42,581$ & 40,959 & $-196.2 \%$ & 115,625 & $182.3 \%$ & 196,566 & $70.0 \%$ & 260,430 & $32.5 \%$ \\
\hline (-) Reserva legal & - & $-4,096$ & & $-11,562$ & $182.3 \%$ & $-19,657$ & $0.0 \%$ & $-3,684$ & \\
\hline Utilidad neta & $-42,581$ & 36,863 & $-186.6 \%$ & 104,062 & $182.3 \%$ & 176,909 & $70.0 \%$ & 256,745 & $45.1 \%$ \\
\hline
\end{tabular}

Elaboración propia 
Tabla 8.4

Análisis de Sensibilidad

\begin{tabular}{cccccc}
\hline Año & $\begin{array}{c}\text { Disponibilidad } \\
\text { Real }\end{array}$ & $\begin{array}{c}\text { Demanda } \\
\text { Teórica }\end{array}$ & Posición & Distancia & Escenario \\
\hline 2018 & $1,841,327.41$ & $1,790,865$ & arriba & 50,463 & optimista \\
2019 & $1,864,712.27$ & $1,985,835$ & abajo & 121,123 & pesimista \\
2020 & $1,888,394.12$ & $1,996,900$ & abajo & 108,506 & optimista \\
2021 & $1,912,376.72$ & $1,960,540$ & abajo & 48,163 & optimista \\
2022 & $1,936,663.90$ & $2,027,406$ & abajo & 90,742 & optimista \\
\hline
\end{tabular}

Elaboración propia

Tabla 8.5

Probabilidad escenarios

\begin{tabular}{lccc}
\hline & Escenarios & Probabilidad & Variación \\
\hline Optimista & 1 & $20.00 \%$ & $2.82 \%$ \\
Pesimista & 4 & $80.00 \%$ & $-6.10 \%$ \\
Total & 5 & $100.00 \%$ & \\
\hline Elaboración propia & &
\end{tabular}

Tabla 8.6

Escenario Optimista

\begin{tabular}{lrrrrr}
\multicolumn{1}{c}{ Año } & $\mathbf{2 0 1 9}$ & $\mathbf{2 0 2 0}$ & $\mathbf{2 0 2 1}$ & $\mathbf{2 0 2 2}$ & $\mathbf{2 0 2 3}$ \\
\hline Ventas & $3,146,390$ & $3,366,760$ & $3,598,701$ & $3,842,754$ & $4,099,482$ \\
(-) Costo de venta & $-2,244,385$ & $-2,357,991$ & $-2,477,562$ & $-2,603,376$ & $-2,735,726$ \\
\hline Utilidad bruta & 902,005 & $1,008,769$ & $1,121,139$ & $1,239,377$ & $1,363,756$ \\
(-) GAVT & $-827,840$ & $-827,840$ & $-827,840$ & $-827,840$ & $-827,840$ \\
\hline Utilidad operativa & 74,165 & 180,929 & 293,299 & 411,537 & 535,916 \\
(-) Gasto financiero & $-61,424$ & $-57,329$ & $-49,139$ & $-36,854$ & $-20,475$ \\
Ingresos excepcionales & & & & & 36,298 \\
(-) Gastos excepcionales & & & & $-72,595$ \\
\hline UAPI & 12,741 & 123,600 & 244,160 & 374,682 & 479,143 \\
(-) Participaciones & $-1,274$ & $-12,360$ & $-24,416$ & $-37,468$ & $-47,914$ \\
\hline UAIR & 11,467 & 111,240 & 219,744 & 337,214 & 431,229 \\
(-) Impuesto a la renta & $-3,211$ & $-31,147$ & $-61,528$ & $-94,420$ & $-120,744$ \\
\hline UARL & 8,256 & 80,093 & 158,215 & 242,794 & 310,485 \\
(-) Reserva legal & -826 & $-8,009$ & $-15,822$ & $-14,343$ & - \\
\hline Utilidad neta & $\mathbf{7 , 4 3 0}$ & $\mathbf{7 2 , 0 8 3}$ & $\mathbf{1 4 2 , 3 9 4}$ & $\mathbf{2 2 8 , 4 5 1}$ & $\mathbf{3 1 0 , 4 8 5}$
\end{tabular}

Elaboración propia 


\section{Tabla 8.7}

Flujo Financiero Optimista

\begin{tabular}{|c|c|c|c|c|c|c|}
\hline Año & 2018 & 2019 & 2020 & 2021 & 2022 & 2023 \\
\hline UN & & 7,430 & 72,083 & 142,394 & 228,451 & 310,485 \\
\hline (-) Inversión & $-487,493$ & & & & & \\
\hline (+) Deuda & 292,496 & & & & & \\
\hline (+) Dep. fabril & & 10,760 & 10,760 & 10,760 & 10,760 & 10,760 \\
\hline (+) Dep. no fabril & & 38,929 & 38,929 & 38,929 & 38,929 & 38,929 \\
\hline (+) Amortizacion intangiles & & 12,000 & 12,000 & 12,000 & 12,000 & 12,000 \\
\hline$(+) \mathrm{VL}$ & & & & & & 72,595 \\
\hline$(+) \mathrm{KW}$ & & & & & & 63,586 \\
\hline (-) Amortizacion de deuda & & $-19,500$ & $-38,999$ & $-58,499$ & $-77,999$ & $-97,499$ \\
\hline Flujos Fondos Financiero & $-194,997$ & 49,619 & 94,772 & $\mathbf{1 4 5 , 5 8 3}$ & 212,141 & 410,856 \\
\hline
\end{tabular}

Elaboración propia

\section{Tabla 8.8}

\section{Escenario Pesimista}

\begin{tabular}{lrrrrr}
\multicolumn{1}{c}{ Año } & $\mathbf{2 0 1 9}$ & $\mathbf{2 0 2 0}$ & $\mathbf{2 0 2 1}$ & \multicolumn{1}{c}{$\mathbf{2 0 2 2}$} & $\mathbf{2 0 2 3}$ \\
\hline Ventas & $2,873,512$ & $3,074,769$ & $3,286,595$ & $3,509,481$ & $3,743,944$ \\
(-) Costo de venta & $-2,049,735$ & $-2,153,488$ & $-2,262,689$ & $-2,377,592$ & $-2,498,463$ \\
\hline Utilidad bruta & 823,777 & 921,281 & $1,023,906$ & $1,131,889$ & $1,245,481$ \\
(-) GAVT & $-827,840$ & $-827,840$ & $-827,840$ & $-827,840$ & $-827,840$ \\
\hline Utilidad operativa & $-4,064$ & 93,441 & 196,065 & 304,049 & 417,641 \\
(-) Gasto financiero & $-61,424$ & $-57,329$ & $-49,139$ & $-36,854$ & $-20,475$ \\
Ingresos excepcionales & & & & & 36,298 \\
(-) Gastos excepcionales & & & & & $-72,595$ \\
\hline UAPI & $-65,488$ & 36,112 & 146,926 & 267,194 & 360,868 \\
(-) Participaciones & 6,549 & $-3,611$ & $-14,693$ & $-26,719$ & $-36,087$ \\
\hline UAIR & $-58,939$ & 32,500 & 132,233 & 240,475 & 324,781 \\
(-) Impuesto a la renta & 16,503 & $-9,100$ & $-37,025$ & $-67,333$ & $-90,939$ \\
\hline UARL & $-42,436$ & 23,400 & 95,208 & 173,142 & 233,843 \\
(-) Reserva legal & 4,244 & $-2,340$ & $-9,521$ & $-17,314$ & $-14,068$ \\
\hline Utilidad neta & $\mathbf{3 8 , 1 9 3}$ & $\mathbf{2 1 , 0 6 0}$ & $\mathbf{8 5 , 6 8 7}$ & $\mathbf{1 5 5 , 8 2 8}$ & $\mathbf{2 1 9 , 7 7 5}$
\end{tabular}

Elaboración propia 


\section{Tabla 8.9}

\section{Flujo Financiero Pesimista}

\begin{tabular}{|c|c|c|c|c|c|c|}
\hline Año & 2018 & 2019 & 2020 & 2021 & 2022 & 2023 \\
\hline UN & & $-38,193$ & 21,060 & 85,687 & 155,828 & 219,775 \\
\hline (-) Inversión & $-487,493$ & & & & & \\
\hline (+) Deuda & 292,496 & & & & & \\
\hline (+) Dep. fabril & & 10,760 & 10,760 & 10,760 & 10,760 & 10,760 \\
\hline (+) Dep. no fabril & & 38,929 & 38,929 & 38,929 & 38,929 & 38,929 \\
\hline (+) Amortizacion intangiles & & 12,000 & 12,000 & 12,000 & 12,000 & 12,000 \\
\hline$(+) \mathrm{VL}$ & & & & & & 72,595 \\
\hline$(+) \mathrm{KW}$ & & & & & & 63,586 \\
\hline (-) Amortizacion de deuda & & $-19,500$ & $-38,999$ & $-58,499$ & $-77,999$ & $-97,499$ \\
\hline Flujos Fondos Financierc & $-194,997$ & 3,996 & 43,749 & $\mathbf{8 8 , 8 7 7}$ & 139,517 & 320,146 \\
\hline
\end{tabular}

A continuación, se realiza la comparación con el VAN esperado de ambos escenarios.

\begin{tabular}{llcr}
\hline & VAN & Prob. & \multicolumn{1}{c}{ VAN esp. } \\
\hline Optimista & $316,219.04$ & $20.00 \%$ & $63,243.81$ \\
Pesimista & $121,872.30$ & $80.00 \%$ & $97,497.84$ \\
& & & $160,741.65$ \\
\hline
\end{tabular}




\section{CAPÍTULO IX. EVALUACIÓN SOCIAL DEL PROYECTO}

\subsection{Identificación de las zonas y comunidades de influencia del proyecto}

La ubicación de nuestra planta será en Chilca, específicamente en Panamericana Sur km 60, se alquilará un local industrial para poner en funcionamiento la empresa.

Figura 9.1

Ubicación de la planta

\section{Ubicación}

VM 60 Panamericana Sur, Chilca, San Vicente de Cañete

\section{Ubicación de}

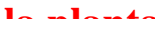
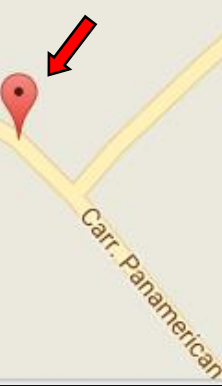

Fuente: Google Maps (2018)

Este proyecto contempla la contratación de 58 personas considerando al personal administrativo y al personal de operaciones. Para el reclutamiento del personal se dará prioridad a los habitantes del distrito y aledaños, esto con el objetivo de ofrecer una propuesta de desarrollo personal y profesional a la sociedad. Además, se brindarán todas las medidas ergonómicas y de seguridad necesarias para que los trabajadores puedan realizar sus actividades cotidianas sin perjudicar su salud y bienestar.

Por otro lado, todo el proyecto fue analizado en función a brindar una mejor propuesta amigable para el medio ambiente. En ese sentido, todas las etapas del proceso de producción, desde la llegada de materia prima hasta el desecho de sobrantes están creadas 
para no afectar la población de la sociedad, en especial la del distrito y zonas aledañas. Por ejemplo, se utilizarán procesos de producción eficientes y especiales, y los desechos serán enviados a tratamiento ambiental.

\subsection{Análisis de indicadores sociales}

A continuación, se realizará el análisis social y la evaluación de sus indicadores, para ello se utilizó la tasa de descuento equivalente a 16\%, misma que fue calculada en el análisis financiero.

Tabla 9.1

Análisis Social

\begin{tabular}{lccrrr}
\multicolumn{1}{c}{ Año } & $\mathbf{2 0 1 9}$ & $\mathbf{2 0 2 0}$ & $\mathbf{2 0 2 1}$ & $\mathbf{2 0 2 2}$ & $\mathbf{2 0 2 3}$ \\
\hline Ventas & $3,060,162$ & $3,274,492$ & $3,500,077$ & $3,737,441$ & $3,987,133$ \\
(-) MP & $-1,577,583$ & $-1,688,076$ & $-1,804,370$ & $-1,926,736$ & $-2,055,458$ \\
(-) CIF & $-134,167$ & $-134,167$ & $-134,167$ & $-134,167$ & $-134,167$ \\
(-) MOD & $-460,367$ & $-460,367$ & $-460,367$ & $-460,367$ & $-460,367$ \\
(-) Dep. fabril & $-10,760$ & $-10,760$ & $-10,760$ & $-10,760$ & $-10,760$ \\
\hline Utilidad bruta & 877,285 & 981,123 & $1,090,414$ & $1,205,411$ & $1,326,382$ \\
(-) GAV & $-776,912$ & $-776,912$ & $-776,912$ & $-776,912$ & $-776,912$ \\
(-) Dep. no Fabril & $-38,929$ & $-38,929$ & $-38,929$ & $-38,929$ & $-38,929$ \\
(-) Amor. Int & $-12,000$ & $-12,000$ & $-12,000$ & $-12,000$ & $-12,000$ \\
(-) Comisiones & $-30,602$ & $-32,745$ & $-35,001$ & $-37,374$ & $-39,871$ \\
\hline Utilidad operativa & 18,843 & 120,538 & 227,573 & 340,197 & 458,670 \\
(-) Gasto financiero & $-61,424$ & $-57,329$ & $-49,139$ & $-36,854$ & $-20,475$ \\
(+)Ingresos excepcionales & & & & & 36,298 \\
(-) Gastos excepcionales & & & & $-72,595$ \\
\hline UAPI & $-42,581$ & 63,209 & 178,433 & 303,342 & 401,898 \\
(-) Participaciones & - & $-6,321$ & $-17,843$ & $-30,334$ & $-40,190$ \\
\hline UAIR & $-42,581$ & 56,888 & 160,590 & 273,008 & 361,708 \\
(-) Impuesto a la renta & - & $-15,929$ & $-44,965$ & $-76,442$ & $-101,278$ \\
\hline UARL & $-42,581$ & 40,959 & 115,625 & 196,566 & 260,430 \\
(-) Reserva legal & - & $-4,096$ & $-11,562$ & $-19,657$ & $-3,648$ \\
\hline Utilidad neta & $-42,581$ & 36,863 & 104,062 & 176,909 & 256,781 \\
& & & & 801,668 & 956,439 \\
\hline Valor Agregado & 480,315 & 582,010 & 689,044 & & \\
& & & & & \\
\hline
\end{tabular}

VNA S/.2,158,150

Elaboración propia

Como se muestra en la tabla anterior, el valor agregado total que el presente trabajo genera a la sociedad durante los años de funcionamiento es de S/. 2 158,150. 


\subsubsection{Densidad de capital}

La densidad de capital es un ratio que resulta de dividir la inversión total entre el número de trabajadores del proyecto. El resultado significa que por cada trabajador al año se necesitará una inversión de S/. 11079.39. A continuación, se muestran los cálculos.

$$
\text { Densidad de Capital }=\frac{\text { Inversión Total }}{\text { Número de trabajadores }}=\frac{487493.08}{44}=11079.39 \frac{\mathrm{S} / \mathrm{.}}{\text { Trab }- \text { año }}
$$

\subsubsection{Intensidad de capital}

La intensidad de capital es un ratio que resulta de dividir la inversión total entre el capital social del proyecto. El resultado significa que por cada S/. 1 de sol aportado en la empresa se habrá invertido S/. 2.28. A continuación los cálculos realizados.

$$
\text { Intensidad de Capital }=\frac{\text { Inversión } \text { Total }}{\text { Capital Social }}=\frac{487493.08}{194997}=2.50 \frac{\mathrm{S} / . \text { invertido }}{\mathrm{S} / . \text { aportado }}
$$

\subsubsection{Relación producto - capital}

La relación producto - capital es un ratio que resulta de dividir el capital social entre la inversión total del proyecto; es decir el inverso de la intensidad de capital. El resultado significa que por cada S/. 1 invertido se aportaron S/. 0.44. A continuación los cálculos.

$$
\text { Producto }- \text { Capital }=\frac{\text { Capital Social }}{\text { Inversión Total }}=\frac{194997}{487493.08}=0.40 \frac{\text { S/. aportado }}{\text { S/. invertido }}
$$

\subsubsection{Productividad de la mano de obra}

La productividad de la mano de obra es un ratio que resulta de dividir la producción anual promedio entre el número total de trabajadores del proyecto. El resultado significa que por cada trabajador se producen S/. 21396.8 al año.

$$
\text { Productividad de } M O=\frac{\text { Producción anual promedio }}{\text { Número de trabajadores }}=\frac{941460.91}{44}=21396.8 \frac{S / .}{\text { Trab }-a \tilde{n} o}
$$




\section{CONCLUSIONES}

- Se cuenta con una alta demanda potencial en el sector salud privado, debido al gran cantidad de procesos en los cuáles pueden utilizarse las prendas médicas del presente estudio. Sin embargo, no se descarta expandir el mercado a fin de implementar economías de escala, comprobando que el proyecto genera liquidez y una rentabilidad elevada para los inversionistas.

- Existe una alta disponibilidad de importación de materias primas, se comprueba que existen múltiples proveedores que ofrecen las telas de polipropileno a costos diferenciados y facilidad de importación. Por otro lado, es factible obtener la maquinaria requerida para los procesos de confección, disponibles para importar a precios accesibles.

- Se concluye que es factible confeccionar prendas médicas que ofrezcan seguridad y protección a quienes las usen, gracias a la implementación de procedimientos y buenas prácticas locales e internacionales tales como la esterilización.

- Se concluye que la implementación de este proyecto es viable económica y financieramente debido a que existe un mercado potencial de instalaciones de salud privada dispuestas a comprar los productos. Los pronósticos de retorno de la inversión indican que a partir del segundo año es posible recuperar el dinero invertido y producir ganancias para los inversionistas.

- Se concluye que la implementación de este proyecto es viable tecnológicamente porque al finalizar el estudio se comprueba que es posible importar maquinaria especializada, implementar procesos de calidad y esterilización, y porque existe mano de obra disponible en el mercado.

- Se concluye que la implementación de este proyecto es viable socialmente porque contribuye al aumento de empleo; los indicadores sociales demuestran un impacto positivo de retorno por trabajador y ratios positivos de aporte de trabajador sobre inversión realizada. 
- Finalmente, se puede concluir que las prendas médicas desechables son una gran oportunidad de negocio, ya que en Perú no existe una planta que se dedique a su confección y porque después de este estudio se comprueba su viabilidad. 


\section{RECOMENDACIONES}

- Se recomienda expandir el mercado objetivo e incluir al sector público, debido a que se pueden implementar economías de mercado al aumentar la producción que permitirían ofrecer las prendas médicas a menores precios.

- Se recomienda tomar en cuenta para futuras expansiones de demanda, que, en diferentes áreas de los centros de salud, tales como Hematología, Oncología y Neonatología, el uso de batas y scrubs desechables es obligatorio para cualquier persona que ingrese, tanto trabajadores como familiares. Es una medida de bioseguridad que se ha venido implementando en los últimos años en áreas con pacientes en aislamiento. Esto debido a que existen muchos pacientes que podrían ver afectada su salud con la exposición a las bacterias del exterior, y porque existen muchos pacientes altamente infecciosos que podrían contagiar múltiples enfermedades a los trabajadores.

- Se recomienda implementar una estrategia de comercialización en la que se incluyan promociones para los compradores, dada la existencia de competidores que ofrecen el mismo producto a precios similares. Tales como descuentos por volumen a clientes que realicen pedidos muy grandes con el objetivo de fidelizarlos con la marca y fortalecer las relaciones, descuentos por pronto pago con el objetivo de mantener la liquidez en la empresa y así poder invertir en nuevas tecnologías y nuevos productos; y descuentos por temporada en épocas de operativos por embalse de cirugías, situación que se da cuando se acumulan de manera excesiva los procedimientos médico-quirúrgicos, lo cual puede suceder en cualquier época del año.

- Se recomienda seguir una buena estrategia la penetración de mercado, ya que con esta se garantiza captar gran número de clientes y reducir costos por el gran volumen de producción, que genera una economía de escala.

- Se recomienda alquilar el local para que de esta manera se ahorre en gastos de construcción, además el monto a invertir en el terreno significaría un préstamo muy elevado, que posiblemente no se pueda financiar junto con el resto de los activos. 
- Se recomienda aprovechar la capacidad de las máquinas no solo para la producción de la demanda, sino también para alquilar esta capacidad a otras empresas que la requieran de tal manera que se reciban ingresos excepcionales.

- Se recomienda tener un buen sistema deshumedecedor en los almacenas y la planta, de tal manera que se preserve la calidad de las materias primas y productos finales.

- Este proyecto no solo espera brindar un producto de buena calidad y bajo costo, sino también aspira a contribuir en la conservación del medio ambiente. Por ello se recomienda seguir un plan de manejo de residuos con los compradores a fin tratar los desechos adecuadamente. 


\section{REFERENCIAS}

Ambrocio, M. (s.f.). No Tejidos. Blogspot. Recuperado de http://notejidos.blogspot.com/

Costa, M. R. (Setiembre del 2012). Geovelos o no-tejidos Parte I. Mundo textil, 17-23.

Costa, M. R. (Noviembre del 2012). Geovelos o no-tejidos Parte II. Mundo textil, 16-23.

Enciclopedia de Clasificaciones (2017). Tipos de empresas. Recuperado de https://www.tiposde.org/empresas-y-negocios/4-tipos-de-empresas/

Grupo Camed S.A.C. (2018). Recuperado de http://www.grupocamed.com/productos.php

Gonzales, C., Espilco, L., \& Aragón, E. (Diciembre del 2003). Análisis de Estrategias Competitivas en Sectores Industriales del Perú. Notas Científicas, 6, 88-93. Recuperado de http://sisbib.unmsm.edu.pe/bibvirtualdata/publicaciones/indata/vol6_n2/pdf/estrateg ias.pdf

Instituto Nacional de Estadística e Informática (2013). Perú: Nacimientos, Defunciones, Matrimonios y Divorcios, 2012. Recuperado del sitio de Internet del INEI: https://www.inei.gob.pe/media/MenuRecursivo/publicaciones_digitales/Est/Lib110 0/libro.pdf

Islam Kiron, M. I. (s.f.). Bio Textile |Application of Biotechnology in Textiles | Importance of Bio-Technology in Textile Processing. Textile Learner. Recuperado de http://textilelearner.blogspot.com/2012/10/bio-textile-application-of.html

Laboratorio Cemedic S.A.C. (2018). Recuperado de http://laboratoriocemedic.com/ropadescartable/

Mosier, N. S., y Ladisch, M. R. (2009). Modern Biotechnology: Connecting Innovations in Microbiology and Biochemistry to Engineering Fundamentals, 165-242. New Jersey: Wiley.

NTP 231.242:1985. Fibras textiles y fibras sintéticas. Definiciones. (Revisado el 2010)

ONU (2018). Convention on Biological Diversity. Recuperado de https://www.cbd.int/

Polytex (2018). Recuperado de http://polytexdemaracay.com/productos/

Prendas desechable médicas (2018). Recuperado de http://www.prendasdesechablesmedicas.com.mx/

Portal SuSalud (2018). Superintendencia de Nacional de Salud. Recuperado de http://datos.susalud.gob.pe/

Schiffer, D., y Stopper, S. (2009.). Biodegradable breathable film and laminate. Recuperado de https://patents.google.com/patent/US20090191780A1/en 


\section{BIBLIOGRAFÍA}

APEIM (2 de Julio de 2015). Niveles Socioeconómicos Recuperado de http://apeim.com.pe/niveles.php

Asociación de Clínicas Particulares del Perú (2018). Lista de clínicas asociadas. Recuperado de http://www.acp.org.pe/asociados/

Instituto Nacional de Estadistica e Informatica (2018). Estadísticas de Seguridad Ciudadana. Recuperado de https://www.inei.gob.pe

Instituto Nacional de Estadistica e Informatica (2018). Censos Nacionales 2017: XII de Población, VII de Vivienda. Recuperado de https://www.inei.gob.pe

Instituto de Defensa Legal (2016). Informe Anual 2016 de Seguridad ciudadana. Recuperado de

https://seguridadidl.org.pe/sites/default/files/Informe\%20Anual\%20de\%20Segurida d\%20Ciudadana\%202016.pdf

Stericycle (2018). Hospital Integrated Waste Stream Solutions. Recuperado de https://www.stericycle.com/services/waste-services/integrated-waste-streamsolutions-for-hospitals 
ANEXOS 
ANEXO 1:

Listado de clínicas a nivel nacional

\begin{tabular}{|c|c|}
\hline Lima & Otros departamentos \\
\hline Clínica Ricardo palma & Clínica san pablo - Huaraz \\
\hline Clínica Stella Maris & Clínica Arequipa \\
\hline Clínica Tezza & Clínica san juan de dios \\
\hline Clínica Good Hope & Clínica san francisco de asís \\
\hline Clínica Anglo Americana & Laboratorio clínico el ingenio \\
\hline Cardiomedic & Clínica los fresnos \\
\hline Centro Médico San Judas Tadeo & Clínica del pacifico \\
\hline Clínica Internacional & Clínica san pedro \\
\hline Clínica Javier Prado & Clínica selva amazónica \\
\hline Clínica Cayetano Heredia & Clínica Cayetano Heredia - Huancayo \\
\hline Clínica Miraflores & Clínica Cayetano Heredia \\
\hline Clínica Montefiori & Clínica virgen del rosario \\
\hline Clínica San Felipe & Clínica adventista Ana Stahl \\
\hline Clínica Bellavista & Clínica santa Anita \\
\hline Clínica San Marcos & Clínica americana \\
\hline Clínica San Miguel & Clínica magol \\
\hline Clínica San Pablo - Sede Surco & Clínica san miguel \\
\hline Clínica San Gabriel & Clínica belén \\
\hline Clínica Jesús del Norte & Clínica Miraflores \\
\hline Clínica Santa María del Sur & Clínica tresa \\
\hline Clínica San Juan Bautista & Clínica san Martín \\
\hline Clínica San Pablo - Asia & Clínica de la mujer \\
\hline Clínica San Vicente & Clínica peruano americana \\
\hline Clínica Santa Isabel & Clínica Sánchez Ferrer \\
\hline Clínica de Especialidades Médicas & Clínica san juan \\
\hline Inppares & Hospital privado del Perú \\
\hline Clínica Virgen Milagrosa & Clínica Robles \\
\hline Clínica San Bernardo & \\
\hline Macula D\&T & \\
\hline Medavan & \\
\hline Medex & \\
\hline Medlab & \\
\hline Clínica San Camilo & \\
\hline Obgsac & \\
\hline Clínica Limatambo & \\
\hline Clínica Repromedic & \\
\hline Resomasa & \\
\hline Clínica Guadalupe & \\
\hline Clínica Maison de Sante & \\
\hline Clínica Vesalio & \\
\hline Hogar Clínica San Juan de Dios & \\
\hline Clínica Centenario Peruano Japonesa & \\
\hline Instituto de Imágenes Médicas & \\
\hline Centro Médico Jockey Salud & \\
\hline Clínica San Borja & \\
\hline Instituto Neuro Cardiovascular de las Américas (INCA) & \\
\hline Centro Médico Avendaño s.a.c. & \\
\hline Clínica Los Andes & \\
\hline Clínica San Pedro (Huacho) & \\
\hline
\end{tabular}

Nota: Datos de instituciones de Lima y Departamentos del Perú.

Fuente: Datos de la página web de la Asociación de Clínicas Particulares del Perú. (2017) 
ANEXO 2:

Porcentaje de participación de cada Nivel Socio Económico en Lima

\begin{tabular}{cccc}
\hline \multirow{2}{*}{ Años } & \multicolumn{3}{c}{$\%$ de cada NSE en Lima } \\
\cline { 2 - 4 } & A & B & C \\
\hline 2007 & $5.30 \%$ & $15.70 \%$ & $28.70 \%$ \\
\hline 2008 & $5.30 \%$ & $15.70 \%$ & $28.70 \%$ \\
\hline 2009 & $5.25 \%$ & $16.50 \%$ & $31.80 \%$ \\
\hline 2010 & $5.20 \%$ & $16.30 \%$ & $33.10 \%$ \\
\hline 2012 & $5.10 \%$ & $16.10 \%$ & $34.95 \%$ \\
\hline 2013 & $5.10 \%$ & $16.10 \%$ & $34.90 \%$ \\
\hline 2014 & $5.00 \%$ & $18.50 \%$ & $38.40 \%$ \\
\hline 2015 & $4.90 \%$ & $18.80 \%$ & $40.70 \%$ \\
\hline 2016 & $4.80 \%$ & $18.98 \%$ & $43 \%$ \\
\hline 2017 & $4.74 \%$ & $19.39 \%$ & $45 \%$ \\
\hline 2018 & $4.68 \%$ & $19.80 \%$ & $47 \%$ \\
\hline 2019 & $4.62 \%$ & $20.21 \%$ & $48 \%$ \\
\hline 2020 & $4.56 \%$ & $20.62 \%$ & $50 \%$ \\
\hline
\end{tabular}

NSE A

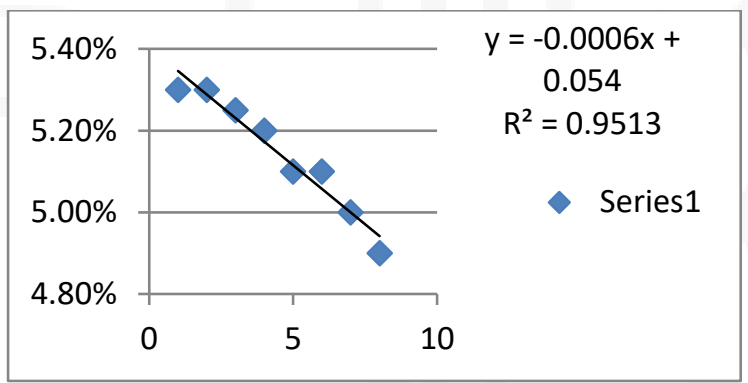

NSE B

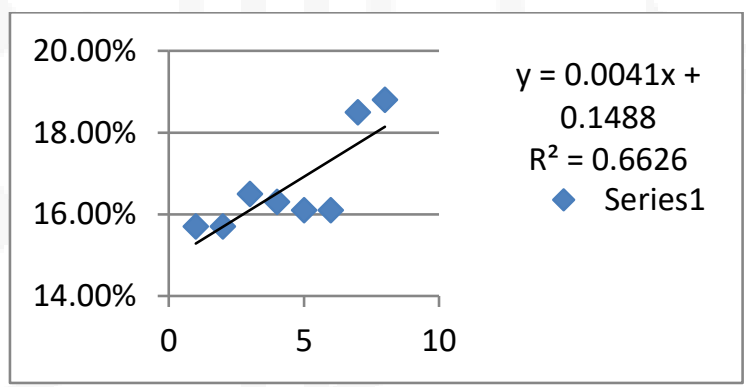

\section{NSE C}

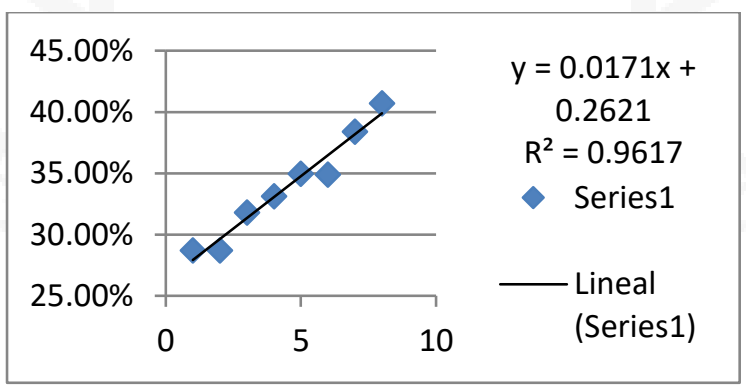

Fuente: Asociación Peruana de Empresas de Investigación de Mercados (2017) 


\section{ANEXO 3:}

Cuadro de población de 12 y más años de edad, por afiliación a algún tipo de seguro de salud, según departamento, provincia, área urbana y rural, sexo y estado civil

\begin{tabular}{|c|c|c|c|c|c|}
\hline $\begin{array}{c}\text { DEPARTAMENTO, } \\
\text { PROVINCIA, }\end{array}$ & \multirow{2}{*}{ TOTAL } & \multicolumn{4}{|c|}{ AFILIADO A ALGÚN SEGURO DE SALUD } \\
\hline $\begin{array}{c}\text { SEXO Y ESTADO } \\
\text { CIVIL }\end{array}$ & & $\begin{array}{l}\text { SIS (SEGURO } \\
\text { INTEGRAL } \\
\text { DE SALUD) }\end{array}$ & ESSALUD & PRIVADO & NINGUNO \\
\hline Dpto. de LIMA (000) & $6,751,252$ & 333,532 & $1,650,339$ & 808,73 & $\overline{4,043,994}$ \\
\hline Conviviente (001) & $1,478,235$ & 79,802 & 263,914 & 95,737 & $1,045,938$ \\
\hline Separado(a) (002) & 257,837 & 12,006 & 47,612 & 20,894 & 179,188 \\
\hline Casado(a) (003) & $1,966,374$ & 71,204 & 734,673 & 326,004 & 881,353 \\
\hline Viudo(a) (004) & 234,323 & 9,073 & 83,886 & 29,257 & 114,96 \\
\hline Divorciado(a) (005) & 52,766 & 1,639 & 17,688 & 10,85 & 24,344 \\
\hline Soltero(a) (006) & $2,761,717$ & 159,808 & 502,566 & 325,988 & $1,798,211$ \\
\hline Hombres (008) & $3,274,898$ & 144,333 & 791,889 & 427,967 & $1,954,286$ \\
\hline Conviviente (009) & 726,996 & 28,229 & 141,367 & 58,879 & 502,779 \\
\hline Separado(a) (010) & 82,371 & 2,569 & 16,394 & 8,57 & 55,519 \\
\hline Casado(a) (011) & 959,812 & 31,75 & 365,146 & 174,86 & 413,871 \\
\hline Viudo(a) (012) & 55,3 & 2,21 & 19,802 & 6,618 & 27,166 \\
\hline Divorciado(a) (013) & 20,882 & 638 & 6,413 & 4,089 & 10,287 \\
\hline Soltero(a) (014) & $1,429,537$ & 78,937 & 242,767 & 174,951 & 944,664 \\
\hline Mujeres (016) & $3,476,354$ & 189,199 & 858,45 & 380,763 & $2,089,708$ \\
\hline Conviviente (017) & 751,239 & 51,573 & 122,547 & 36,858 & 543,159 \\
\hline Separado(a) (018) & 175,466 & 9,437 & 31,218 & 12,324 & 123,669 \\
\hline Casado(a) (019) & $1,006,562$ & 39,454 & 369,527 & 151,144 & 467,482 \\
\hline Viudo(a) (020) & 179,023 & 6,863 & 64,084 & 22,639 & 87,794 \\
\hline Divorciado(a) (021) & 31,884 & 1,001 & 11,275 & 6,761 & 14,057 \\
\hline Soltero(a) (022) & $1,332,180$ & 80,871 & 259,799 & 151,037 & 853,547 \\
\hline & & & & & \\
\hline URBANA (024) & $6,620,568$ & 320,732 & $1,629,402$ & $\mathbf{8 0 4 , 8 2 4}$ & $3,950,646$ \\
\hline Conviviente (025) & $1,438,083$ & 76,558 & 257,834 & 94,736 & $1,016,009$ \\
\hline Separado(a) (026) & 253,638 & 11,715 & 47,113 & 20,761 & 175,905 \\
\hline Casado(a) (027) & $1,931,126$ & 69,311 & 725,939 & 324,507 & 858,103 \\
\hline Viudo(a) (028) & 229,099 & 8,819 & 82,99 & 29,085 & 111,056 \\
\hline Divorciado(a) (029) & 52,402 & 1,628 & 17,62 & 10,833 & 24,075 \\
\hline Soltero(a) (030) & $2,716,220$ & 152,701 & 497,906 & 324,902 & $1,765,498$ \\
\hline Hombres (032) & $3,202,460$ & 138,581 & 777,657 & 425,293 & $1,904,243$ \\
\hline Conviviente (033) & 705,392 & 27,104 & 136,927 & 58,147 & 487,379 \\
\hline Separado(a) (034) & 80,661 & 2,519 & 16,089 & 8,482 & 54,245 \\
\hline Casado(a) (035) & 940,471 & 30,957 & 359,297 & 173,851 & 402,074 \\
\hline Viudo(a) (036) & 53,611 & 2,153 & 19,47 & 6,551 & 25,932 \\
\hline Divorciado(a) (037) & 20,66 & 633 & 6,364 & 4,078 & 10,13 \\
\hline
\end{tabular}




\begin{tabular}{|c|c|c|c|c|c|}
\hline Soltero(a) (038) & $1,401,665$ & 75,215 & 239,51 & 174,184 & 924,483 \\
\hline Mujeres (040) & $3,418,108$ & 182,151 & 851,745 & 379,531 & $2,046,403$ \\
\hline Conviviente (041) & 732,691 & 49,454 & 120,907 & 36,589 & 528,63 \\
\hline Separado(a) (042) & 172,977 & 9,196 & 31,024 & 12,279 & 121,66 \\
\hline Casado(a) (043) & 990,655 & 38,354 & 366,642 & 150,656 & 456,029 \\
\hline Viudo(a) (044) & 175,488 & 6,666 & 63,52 & 22,534 & 85,124 \\
\hline Divorciado(a) (045) & 31,742 & 995 & 11,256 & 6,755 & 13,945 \\
\hline Soltero(a) (046) & $1,314,555$ & 77,486 & 258,396 & 150,718 & 841,015 \\
\hline RURAL (048) & 130,684 & 12,8 & 20,937 & 3,906 & 93,348 \\
\hline Conviviente (049) & 40,152 & 3,244 & 6,08 & 1,001 & 29,929 \\
\hline Separado(a) (050) & 4,199 & 291 & 499 & 133 & 3,283 \\
\hline Casado(a) (051) & 35,248 & 1,893 & 8,734 & 1,497 & 23,25 \\
\hline Viudo(a) (052) & 5,224 & 254 & 896 & 172 & 3,904 \\
\hline Divorciado(a) (053) & 364 & 11 & 68 & 17 & 269 \\
\hline Soltero(a) (054) & 45,497 & 7,107 & 4,66 & 1,086 & 32,713 \\
\hline Hombres (056) & 72,438 & 5,752 & 14,232 & 2,674 & 50,043 \\
\hline Conviviente (057) & 21,604 & 1,125 & 4,44 & 732 & 15,4 \\
\hline Separado(a) (058) & 1,71 & 50 & 305 & 88 & 1,274 \\
\hline Casado(a) (059) & 19,341 & 793 & 5,849 & 1,009 & 11,797 \\
\hline Viudo(a) (060) & 1,689 & 57 & 332 & 67 & 1,234 \\
\hline Divorciado(a) (061) & 222 & 5 & 49 & 11 & 157 \\
\hline Soltero(a) (062) & 27,872 & 3,722 & 3,257 & 767 & 20,181 \\
\hline Mujeres (064) & 58,246 & 7,048 & 6,705 & 1,232 & 43,305 \\
\hline Conviviente (065) & 18,548 & 2,119 & 1,64 & 269 & 14,529 \\
\hline Separado(a) (066) & 2,489 & 241 & 194 & 45 & 2,009 \\
\hline Casado(a) (067) & 15,907 & 1,1 & 2,885 & 488 & 11,453 \\
\hline Viudo(a) (068) & 3,535 & 197 & 564 & 105 & 2,67 \\
\hline Divorciado(a) (069) & 142 & 6 & 19 & 6 & 112 \\
\hline Soltero(a) (070) & 17,625 & 3,385 & 1,403 & 319 & 12,532 \\
\hline
\end{tabular}

Fuente: INEI (2016) 
ANEXO 4:

Información aduanera de las telas no tejidas de polipropileno

\begin{tabular}{|c|c|}
\hline Gravámenes Vigentes & Valor \\
\hline Ad / Valorem & $11 \%$ \\
\hline Impuesto Selectivo al Consumo & $0 \%$ \\
\hline Impuesto General a las Ventas & $16 \%$ \\
\hline Impuesto de Promoción Municipal & $2 \%$ \\
\hline Derecho Especificos & N.A. \\
\hline Derecho Antidumping & N.A. \\
\hline Seguro & $2 \%$ \\
\hline Sobretasa & $0 \%$ \\
\hline Unidad de Medida: & $(*)$ \\
\hline
\end{tabular}

Nota: Partida 6305.33.20.00

Fuente: Operatividad Aduanera SUNAT (2016) 